Andrews University

Digital Commons @ Andrews University

\title{
A Case Study Describing the Experiences of the Sexually Abused Children and Non-Offending Parents who Attended the Multi- Disciplinary Investigation Team After Care Clinic
}

Danielle DiMauro Williams

Andrews University

Follow this and additional works at: https://digitalcommons.andrews.edu/dissertations

Part of the Counseling Psychology Commons

\section{Recommended Citation}

Williams, Danielle DiMauro, "A Case Study Describing the Experiences of the Sexually Abused Children and Non-Offending Parents who Attended the Multi-Disciplinary Investigation Team After Care Clinic" (2009). Dissertations. 1549.

https://digitalcommons.andrews.edu/dissertations/1549

https://dx.doi.org/10.32597/dissertations/1549

This Dissertation is brought to you for free and open access by the Graduate Research at Digital Commons @ Andrews University. It has been accepted for inclusion in Dissertations by an authorized administrator of Digital Commons@ Andrews University. For more information, please contact repository@andrews.edu. 


\section{Andrews \$university}

Seek Knowledge. Affirm Faith. Change the World.

Thank you for your interest in the

\section{Andrews University Digital Library of Dissertations and Theses.}

Please honor the copyright of this document by not duplicating or distributing additional copies in any form without the author's express written permission. Thanks for your cooperation. 


\section{ABSTRACT}

A CASE STUDY DESCRIBING THE EXPERIENCES OF THE SEXUALLY ABUSED CHILDREN AND NON-OFFENDING PARENTS WHO ATTENDED THE MULTI-DISCIPLINARY INVESTIGATION TEAM AFTER CARE CLINIC

by

Danielle DiMauro Williams

Chair: James A. Tucker 


\title{
ABSTRACT OF GRADUATE STUDENT RESEARCH
}

\author{
Dissertation
}

\author{
Andrews University \\ School of Education
}

\section{Title: A CASE STUDY DESCRIBING THE EXPERIENCES OF THE SEXUALLY ABUSED CHILDREN AND NON-OFFENDING PARENTS WHO ATTENDED THE MULTI-DISCIPLINARY INVESTIGATION TEAM AFTER CARE CLINIC}

Name of researcher: Danielle DiMauro Williams

Name and degree of faculty chair: James A. Tucker, Ph.D.

Date of completion: October 2009

\section{Purpose}

This study examines the experiences of children and their non-offending parents who attended the Multi-disciplinary Investigation Team's (MIT) After Care Clinic. The study seeks to understand the ways in which the care provided at the After Care Clinic helped stabilize the child and the non-offending parent. Additionally, this study explores what strategies were effective in stabilizing the families and resulted in their cooperation with prosecution of the perpetrator. 


\section{Method}

Seven children and their non-offending parents simultaneously attended 12 weeks of trauma treatment with two trauma therapists. The case studies used for this study were based on clinical notes and observations that were documented in the case notes. All data used were secondary. Each child in the study attended the MIT After Care Clinic and was forensically interviewed by the Danbury Multi-disciplinary Investigation Team after a sexual abuse disclosure. Following the forensic interview, the child and the nonoffending parent were referred to the After Care Clinic for therapy.

\section{Results and Conclusion}

The findings from the study identified strategies from the trauma therapy that were effective in stabilizing both the child and the non-offending parent. The findings also identified that having the clinicians be trained forensic interviewers assisted in ascertaining additional disclosures and court-worthy information. Overall, the families that engaged in treatment at the MIT After Care Clinic had outcomes that resulted in convictions.

\section{Recommendations for Further Study}

Further study is needed. Many victims and their families are devastated by the disclosure of sexual abuse and are in need of support. There have been multiple studies conducted on trauma therapy, child abuse disclosure, and the necessity for support by the non-offending parent. The following is a list of recommendations that would continue to support this area of study: (a) compare the conviction rates of sexual offenders with conviction rates of sexual offenders when families are not engaged in therapy connected 
with a Multi-disciplinary Investigation Team, (b) perform a study with a larger number of families, (c) perform a study for children and families in group therapy and look at the success rates of trauma symptom reduction and court corporation, and (d) perform a study in which there is only one clinician, who is not forensically trained, connected to a Multi-disciplinary Investigation Team that is providing services to the victim. 
Andrews University

School of Education

A CASE STUDY DESCRIBING THE EXPERIENCES OF THE SEXUALLY ABUSED CHILDREN AND NON-OFFENDING PARENTS WHO ATTENDED THE MULTI-DISCIPLINARY INVESTIGATION TEAM AFTER CARE CLINIC

\author{
A Dissertation \\ Presented in Partial Fulfillment \\ of the Requirements for the Degree \\ Doctor of Philosophy
}

by

Danielle DiMauro Williams

October 2009 
CCopyright by Danielle DiMauro Williams 2009 All Rights Reserved 
A CASE STUDY DESCRIBING THE EXPERIENCES OF THE SEXUALLY ABUSED CHILDREN AND NON-OFFENDING PARENTS WHO ATTENDED THE MULTI-DISCIPLINARY INVESTIGATION TEAM AFTER CARE CLINIC

\author{
A dissertation \\ presented in partial fulfillment \\ of the requirements for the degree \\ Doctor of Philosophy
}

by

Danielle DiMauro Williams

APPROVAL BY THE COMMITTEE:

Chair: James A. Tucker

Member: Shirley A. Freed

Member: Elvin Gabriel

External: Ann-Marie Jones
Dean, School of Education James Jeffery 


\section{TABLE OF CONTENTS}

LIST OF TABLES $\quad \ldots \ldots \ldots \ldots \ldots \ldots \ldots$ vi

ACKNOWLEDGMENTS .................... . vii

\section{Chapter}

1. BACKGROUND ...................... 1

Introduction to the Problem . . . . . . . . . . . . . 1

Context of the Study . . . . . . . . . . . . . . . . . 7

Problem Statement . . . . . . . . . . . . . . . . . . 12

Purpose of the Study . . . . . . . . . . . . . . . . . . . 12

Research Questions . . . . . . . . . . . . . . . . . . . 12

General Methods . . . . . . . . . . . . . . . . . . . 13

Conceptual Framework . . . . . . . . . . . . . . . . . . . 13

Significance of the Study . . . . . . . . . . . . . . . . 16

Definition of Terms . . . . . . . . . . . . . . . . . . 17

Delimitations . . . . . . . . . . . . . . . . . . . 19

Assumptions. . . . . . . . . . . . . . . . . 20

Organization of the Study . . . . . . . . . . . . 20

2. REVIEW OF THE LITERATURE . . . . . . . . . . . . . . . . 22

Introduction . . . . . . . . . . . . . . . . 22

Traumagenic Dynamics of Sexual Abuse. . . . . . . . . . . . . . . 24

The Child Sexual Abuse Accommodation Syndrome . . . . . . . . . . 26

Trauma-Focused Cognitive Behavioral Therapy . . . . . . . . . . . . 29

Non-offending Parent . . . . . . . . . . . . . . . . . 32

Disclosure . . . . . . . . . . . . . . . . . 36

Identification of Sexual Abuse . . . . . . . . . . . . . . . 37

Prosecution of Offenders . . . . . . . . . . . 38

3. GENERAL METHODS. . . . . . . . . . . . . . . . . . . 41

Introduction . . . . . . . . . . . . . . . . 41

Self as the Researcher. . . . . . . . . . . . . . . . . . . . . . . 42

Population, Sample, and Research Setting . . . . . . . . . . . . . 43

Data Collection . . . . . . . . . . . . . . . . . . . 44

Procedure . . . . . . . . . . . . . . . . . . 47 
Methods for Summarizing, Interpreting, and Discussing Data . . . . . 50

Reliability and Validity . . . . . . . . . . . . . 50

Generalizability .................. 53

Ethical Considerations . . . . . . . . . . . . . . 54

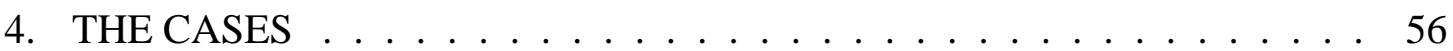

Introduction . . . . . . . . . . . . . . . 56

Samantha's Story . . . . . . . . . . . . . . . . 56

Lisa's Story . . . . . . . . . . . . . . . . . . . . . . . . . . . . . . . . . . . . . . . 89

Paige's Story . . . . . . . . . . . . . . . . . 82

Kate's Story . . . . . . . . . . . . . . . . . . . . . . 91

Brian's Story . . . . . . . . . . . . . . . . . 100

Peggy's Story . . . . . . . . . . . . . . . . . . . . . . . . . . . . . . . . . . . . . . . . . . . . . . .

Peter's Story. . . . . . . . . . . . . . . . . . . 117

5. CROSS-CASE ANALYSIS . . . . . . . . . . . . 125

Introduction . . . . . . . . . . . . . . . . . . . . 125

Research Question 1: How Did the Children Experience the MIT6

After Care Clinic?. . . . . . . . . . . . . . . . . . . . . . . . 130

A Place to Let Go . . . . . . . . . . . . . . . . . . . . . . . 130

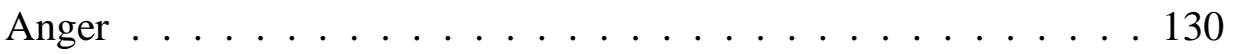

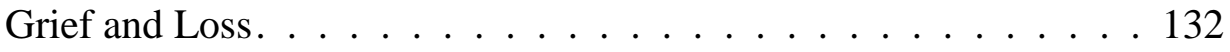

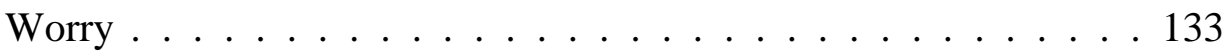

Feeling Better . . . . . . . . . . . . . . . . . . . . . . . 134

Research Question 2: In What Ways Did the Non-Offending Parent

Describe Their Experience After the Sexual Abuse Disclosure? . . . 134

Initial Feelings of Disbelief or Denying the Significance of

the Abuse . . . . . . . . . . . . . . . . 135

Isolation . . . . . . . . . . . . . . . . . . . 136

Feelings of Guilt . . . . . . . . . . . . . . . . . . . . . . . 138

Overwhelmed . . . . . . . . . . . . . . . . 139

Bringing up Past Issues . . . . . . . . . . . . . . . . . . . . 141

Legal System . . . . . . . . . . . . . . . . . . . . . . . . 141

Research Question 3: How Did the MIT After Care Clinic's

Interventions Help Stabilize the Families? . . . . . . . . . . . . . . 142

Establishing Positive Relationships . . . . . . . . . . . . . . . . . . 142

Role Modeling . . . . . . . . . . . . . . . . . . . . . 144

Empowerment. . . . . . . . . . . . . . . 146

Discussion. . . . . . . . . . . . . . . . . . 147

Recommendations for Practice . . . . . . . . . . . . . . . . . . . 149

Recommendations for Further Study . . . . . . . . . . . . . . 150

REFERENCE LIST . . . . . . . . . . . . . . . . . . . . . . . . . . . . 152 


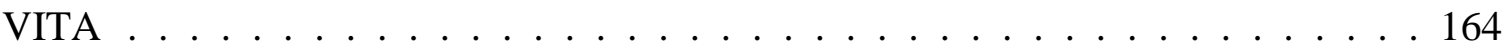




\section{LIST OF TABLES}

1. The Children of the After Care Clinic ...................................................................53

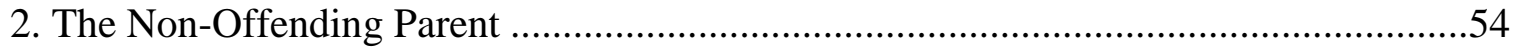




\section{ACKNOWLEDGMENTS}

This signifies the end of a long and rewarding journey for me. I have been blessed with the support of many family and friends during this time. I dedicate this to my beloved boys, Justin and Alexander. I am so lucky to be your mother and to have you both in my life! Some day when you are old enough to read this, you will have a better understanding of why I have protected you as I have. Both of you are so special, with your own uniqueness and strengths that will help you each do great things in your lives. I love you both eternally and I am always proud to be your Mom.

To my parents, Jacqueline and Paul DiMauro, without your love and support I never would have believed I could accomplish this. There were so many days that your love gave me strength and your words inspiration. Mom, you are so strong and wise. You have always been there for me, and have sacrificed so much to help me succeed. I only hope to be half the mother that you have been to me. Dad, you always believed I could do anything and have taught me so much. I know you would have been proud. To my sister Vanessa, you always reached out to me at the perfect time. You have helped me so much over the years. I love you all very much; how lucky I have been to have such a wonderful family.

To my husband, Mark, you have helped so many children in your career. I am blessed that you are my partner and my best friend. I could not imagine being without you and I look forward to spending the rest of my life with you. Thank you for 
everything you do each day. I never would have finished this without you! Your skillfulness in citing references is appreciated!

I would like to thank Drs. Jim Tucker and Shirley Freed for your continuous support, knowledge, and belief in the importance of this study. I am grateful for the opportunity you gave me as a participant at Andrews University. 


\section{CHAPTER 1}

\section{BACKGROUND}

\section{Introduction to the Problem}

Child sexual abuse (CSA) is a significant problem in the United States and throughout the world. It is estimated that one out of three females and one out of five males have been victims of sexual abuse before the age of 18 (Dominquez, Nelke, \& Perry, 2002). The number of sexual abuse victims has declined throughout the years. One explanation is due to prevention, treatment, and the aggressiveness of the criminal justice system prosecuting these crimes. Another explanation of the decline in victims could be explained by a decrease in the number of cases identified and reported or by the changes in practices by the child protection agencies (Finkelhor \& Jones, 2004). What has remained consistent is that sexual abuse occurs across all ethnic/racial, socioeconomic, and religious groups. Unfortunately, sexual abuse is considered a relatively common experience in the lives of many children. Although there is no universal definition of child sexual abuse, it is most commonly described as the use of force or coercion from a dominant individual, such as an adult or a person in a position of authority, who engages in sexual activity. Child sexual abuse may include fondling a child's genitals, masturbation, oral-genital contact, digital penetration, and vaginal and anal intercourse. CSA is not limited only to physical contact, as abuse could include non- 
contact such as viewing pornography, exposure, or voyeurism (National Clearinghouse on Child Abuse and Neglect Information, 2001).

Many victims will question why they were abused; they may become haunted by the memories and feel damaged or at fault. In this study, the parent or caregiver who has not abused the child will be referred to as the non-offending parent (NOP). It is acknowledged that the non-offending parent will generally be the mother; thus, in this study, the NOP will be referred to with pronouns such as she or her (Keeble, 1993). The non-offending parent will often question, "Why did this happen to my son/daughter?" "What did I do wrong?" "How did I not notice?" They may experience feelings of guilt or this may bring up their own issues of abuse, which may be an inhibiting factor in their emotional ability to be present for their child's recovery. The disclosure of abuse affects the entire family.

According to the Child Welfare League of America's 2009 Fact Sheet (2009), in 2006 there were an estimated 3.3 million reports of child abuse and neglect. In 2006, an estimated 905,000 children were determined to be victims of child abuse as reported by 50 states. Of these children, $64.1 \%$ were neglected, $16 \%$ were physically abused, and $8.8 \%$ were sexually abused. The victimization rate was 12.1 per 1,000 children $-\mathrm{a} 3.2 \%$ decrease from 2001. Of the children substantiated as abused and neglected, only $58.9 \%$ received follow-up services. In 2006, 1,530 children died as a result of abuse or neglect. These statistics identify the number of children who have been subject to both abuse and neglect as well as the percentage of children who were tracked as having received followup treatment. 
In 2008, the following substantiations were made in the Danbury Connecticut Department of Children and Families Office: 21 cases of educational neglect, 18 cases of emotional abuse/maltreatment, 125 cases of emotional neglect, 15 cases of medical neglect, 38 cases of physical neglect, and 21 cases of sexual abuse/exploitation, for a total of 693 cases (State of Connecticut Department of Children and Families, 2008).

The total number of children removed from homes in Danbury, Connecticut, in 2007 was 47; 25 were placed in foster care. The total number of children removed from homes in 2008 was 70; 25 were placed in foster care (State of Connecticut Department of Children and Families, 2008).

In 2000, the U.S. Department of Justice estimated that only one-third of sexual assaults are reported to law enforcement.

Of the respondents who reported ever being raped, $21.6 \%$ of the women and $48.0 \%$ of the men were younger than age 12 when they experienced their first rape, and 32.4\% of the women and $23.0 \%$ of the men were ages $12-17$. Thus, more than half (54\%) of the female rape victims and nearly three-quarters $(71 \%)$ of the male victims identified by the survey were younger than age 18 when they experienced their first attempted or completed rape. Results from the National Violence Against Women (NVAW) Survey show that most children and adolescents are raped by someone they know. Only $14.3 \%$ of the women and $19.5 \%$ of the men raped before age 18 were raped by a stranger. (Tjaden \& Thoennes, 2000, pp. 35-36)

It is also estimated that between 30 and $40 \%$ of children are abused by a family member (Snyder, 2000). Another 50\% are abused by a person whom the family knows and trusts. Approximately $40 \%$ of children are abused by an older child whom they know; thus, only $10 \%$ of cases typically involved a sexual assault by a stranger. Many times a young child does not recognize that they have been victimized. It is not uncommon for a child to say, "I did not know what we were doing was wrong." Fabricated stories of abuse constitute only 1 to $4 \%$ of all reported cases. Of these reports, 
$75 \%$ are falsely reported by adults and $25 \%$ are reported by children. It is not uncommon for a child who falsely reports to also have psychiatric or behavioral issues. It is rare that during a divorce proceeding that a child falsely reports abuse. In a 1990 study of 9,000 divorces in 12 states, CSA allegations were made in less than $2 \%$ of contested divorces involving custody (Goldstein \& Tyler, 1998).

A study conducted by the United States Department of Health (2005, p. 27), published in the $16^{\text {th }}$ Annual Publication of Child Maltreatment, provided statistics on both physical and sexual abuse. The results of the study indicated that $47.3 \%$ of child victims were boys and $50.7 \%$ of the victims were girls. Young children had the highest rate of victimization; for the age group birth to 3 years the victimization rate was 16.5 per 1,000 children of the same age group. The victimization rate for children in the age group 4 to 7 years was 13.5 per 1,000 children in the same age group. Overall, the rate of victimization was inversely related to the age group of the child. For the victims in the age group 4 to 7 years, $15.6 \%$ were physically abused and $8.9 \%$ were sexually abused, compared with $21.3 \%$ and $17.3 \%$, respectively, for victims in the age group 12 to 15 years old.

Child sexual abuse occurs in any socioeconomic status; however, data from the Child Welfare Information Gateway from the U.S. Department of Health and Human Service Administration's (USDHS) Third National Incidence Study of Child Abuse and Neglect (NIS-3) (Sedlak \& Broadhurst, 1996) have indicated that the following factors are more indicative of homes in which children are more at risk of being abused. Children from lower economic status families were almost 18 times as likely to be sexually abused. U.S. Department of Health and Human Service Administration's (2005) statistics 
indicate that children in families with incomes under $\$ 15,000$ are 22 times more at risk of child sexual abuse than those in families with incomes over $\$ 30,000$ year. The U.S. Census Data for 2008 (DeNavas-Walt, Proctor, \& Smith, 2007) reports 38.5\% of 74 million children live in poverty. There are 88,582 children in Connecticut living in poverty; $11.4 \%$ of Danbury residents live below the Federal Poverty Level, and 37\% of Danbury students live in homes where English is not the primary language.

Children who have been victimized may experience trauma-related symptoms as a result of the abuse. It is not uncommon for a child who has experienced a traumatic event to have trauma-related symptoms, such as flashbacks, enuresis, encopresis, nightmares, or other emotional and psychological issues (Kendall-Tackett, Williams, \& Finkelhor, 1993; Mannarino, Cohen, \& Berman 1994; Morrow \& Sorrell, 1984). Treatment is essential immediately after the disclosure in order to reduce the trauma symptoms so they do not interfere with daily activities or cause emotional or psychological problems later in life. It is also important that the parent or caregiver be involved in the treatment. The non-offending parent often needs support in stabilizing the family, as well as assistance with understanding the current and future criminal proceedings resulting from the disclosure. (Everson, Hunter, Runyon, Edelsohn, \& Coulter, 1989; Hunter, Coulter, Runyan, \& Everson, 1990, Pellegrin \& Wagner, 1990).

The overall prognosis of a child who has been victimized has a strong correlation with the overall support and feeling that the non-offending parent believes their disclosure (Keeble, 1993); thus, not only does the support assist in the child's recovery, but it also reduces the recantation rate of the victim. Recantation refers to a situation in which a child has disclosed sexual abuse, and then the child withdraws their statement 
that any abuse occurred. Victims who recant their disclosure rarely have a prosecution in their case. Deblinger, Lippman, and Steer (1996) have found that when parents are included in treatment, and when parents are supportive of their sexually abused children, there is significantly greater improvement in the children's troubled behaviors (acting out and depression). In a 2-year follow-up study conducted by Deblinger, Lippman, and Steer (1999), they found the results of the 1996 study to be maintained.

The level of shame and secrecy that often goes along with being victimized may result in a child never disclosing. "Children may also minimize, delay disclosure or deny abuse when they are in a secrecy pact with the perpetrator, when they feel responsible for participating, or if they fear punishment by the perpetrator if they tell about their experiences" (Cederborg, Lamb, \& Orbach, 2007, p. 171). Thus it is difficult to obtain accurate data on child sexual abuse (Tang, Freyd, \& Wang, 2007). Each state has variations to the laws, which makes the studies on child sexual abuse additionally complex. Below is a summary of the Connecticut statutes regarding sexual abuse. Only statutes that are pertinent to the study have been included.

In Connecticut, an Aggravated Sexual Assault in the First Degree is a Class A or B felony contingent upon the age of the victim (Conn. Gen. Stat. § 53a-70a, 2009). An Aggravated Assault of a Minor is also a Class A Felony, and a first offense carries a 25year mandatory minimum; a second offense carries a 50-year mandatory minimum. This is when a victim is under 13 years of age. Sexual Assault in the Second Degree is a Class B Felony if the victim is under 16 years of age, and a Class C Felony for all other situations. A felony occurs when someone engages in sexual intercourse with any other person and the other person is over 13 years of age, but under 16 years of age, and the 
perpetrator is more than 3 years older than the victim (Conn. Gen. Stat. $53 a-71,2009$ ). Sexual Assault in the Third Degree is a Class C Felony if the victim is under 16 years of age and Class D Felony for other situations (Conn. Gen. Stat.§ 53a-72a, 2009). Sexual Assault in the Fourth Degree is a Class D Felony if the victim is under 16 years of age (Conn. Gen. Stat.§ 53a-73a, 2009).

Over the years, crimes against children have been investigated and taken more seriously by law enforcement. Consequently, the courts have begun to work more collaboratively with the police in obtaining search warrants in an effort to corroborate evidence. This effort, as well as those of other collaborating professionals such as forensic interviewers, medical professionals, and therapists, has assisted in the prosecution of child perpetrators. Accordingly, the number of prosecutions has increased over the years.

\section{Context of the Study}

Cases involving child sexual abuse can be complicated since there is rarely any physical evidence or witnesses, and thus may be difficult to prove. For many years, families, law enforcement, or the courts did not believe children. Over time, children's voices began to be heard and procedures were designed to minimize the trauma of having to share details of the abuse. In 1985, the first Child Advocacy Center was established in Alabama. Since that time, at least 500 Child Advocacy Centers have been developed to assist in coordinating the teams and have trained professionals to interview the children. "Legal and social responses to the problem of CSA required nearly a century of research on the psychological and trauma-related neuroses, and a more progressive legal and social environment" (Rix, 2002, p. 3). 
In 1999, the Danbury Connecticut Multi-disciplinary Investigation Team (MIT) was formed by the Danbury Regional Child Advocacy Center. The Danbury MIT began forensically interviewing children in an effort to minimize the number of interviews as well as to avoid having untrained persons question the child. It was also the hope that the videotape of the child's forensic interview would result in the child not having to testify in court as well as improve the overall conviction rate of the perpetrators. "The proper screening of cases to determine their potential for charges is crucial and should utilize a multi-disciplinary approach that will offer essential information and varied viewpoints on a case" (Sawicki, 2007, p. 1).

The Danbury MIT is a team comprised of trained individuals to investigate criminal-level crimes against children. Each region has its own MIT. In Danbury, the team's members include law enforcement, the State's Attorney's Office, a forensically trained pediatrician (Danbury Hospital), the Department of Children and Families (DCF), a forensic interviewer, the After Care Clinic's Clinical Director, and the Office of Victims Services.

One of the core factors related to improved handling of child sexual abuse (CSA) cases includes the creation of a collaboration of efforts from all of the primary disciplines involved. Different communities will have different disciplines represented depending on each community's unique characteristics. However, communities should strive to evolve so that eventually 5 specific disciplines are clearly represented at the core of MDT teams. The 5 core disciplines are: Child Protective Services, Law Enforcement, Therapy treatment providers, Medical/health care professionals and Prosecutors. (Conine et al., 2001, p. 1)

When a child makes a disclosure of sexual abuse, either DCF or law enforcement will contact the Danbury Regional Child Advocacy Center to set up a forensic interview. The interview is conducted no later than 72 hours post-disclosure. A child who has not made a verbal disclosure, even when there is suspicion of abuse, will not be interviewed. The 
necessary team members are present at the interview, which is conducted by the trained forensic interviewer and is videotaped in its entirety. That tape becomes evidence for law enforcement and later for the prosecutor. Law enforcement, the State's Attorney's office, the MIT After Care Clinic Director, and DCF may watch the interview through a oneway mirror and may ask clarifying questions through a wire that is worn by the interviewer.

Forensic interviews are conducted for disclosures of abuse, both sexual and physical, as well as for children who have witnessed a crime (i.e., shooting or murder). However, the majority of the interviews conducted are related to sexual abuse disclosures. After the interview is conducted, the team meets with the family; law enforcement is able to identify whether they will be applying for an arrest warrant, and DCF is able to identify safety measures that need to be taken for the child. At that time a medical exam is set up, as well as an appointment for the MIT After Care Clinic (MIT ACC). Each month the team meets to discuss cases and identify follow-through on services such as the MIT ACC and the forensic medical exam. "The goal of forensic interviewing is to gather information to use as evidence in a legal proceeding. In clinical interviewing, therapists also gather information, often with the same tools used by investigators, but they use the information in different ways" (Amecher, 2001, p. 1).

From 1999 to 2006, children forensically interviewed were referred to general therapists in the Danbury area; however, those therapists were not members of the MIT, nor did they specialize in trauma-related treatment. Having an independent therapist made it difficult to ascertain information regarding whether the non-offending parent had followed through with trauma therapy, whether the family had become stabilized, 
whether the non-offending parent continued to have contact with the perpetrator, and whether the child's symptoms had decreased. Additionally, in a follow-up survey conducted by the MIT, the non-offending parents had identified the need for a trauma therapist to provide treatment and support for their children. As a result, the needs of many families in need of support and specific trauma treatment were not being met. Lastly, due to financial constraints of many victims and their families they could not receive treatment.

The need to treat victims of sexual abuse is seldom questioned. Unlike the treatment of sexual abusers, the treatment of victims of sexual abuse is accepted as necessary for victim recovery. Unfortunately, although the sympathy of Americans is usually on the side of the victims, funding for treatment is often the responsibility of the victim/ or the victim's family. Lacking the ability to pay, many victims are placed on waiting lists for clinics and treatment programs that provide reduced-fee, free or very short-term emergency counseling. Many receive no help at all. (Freedman-Longo \& Blancard, 1998, pp. 163-164)

The State's Attorney's office, which is a member of the MIT, is responsible for prosecuting cases involving child sexual abuse or assault. Due to the lack of evidence or witnesses, these are difficult cases to prosecute, and it is important that the Prosecutor have the cooperation of the victim's families. Families may be reluctant to participate in the prosecution, because the perpetrator is often a family member or family friend. A family that has not dealt with the abuse and the aftermath of a disclosure is more likely to want to try to forget that the abuse ever happened, and therefore would be less cooperative with the prosecutor when the case is ready for trial, which may take at least a year. There are cases, however, in which the child may have to testify in court; thus, it is important that the child and the family be well prepared and stable to withstand trial. 
On March 5, 2003, a unanimous United States Supreme Court ruled that Connecticut and other states may post pictures of convicted sexual offenders on the Internet; this is informally called Megan's Law. At the Federal level, Megan's Law is known as the Sexual Offender Jacob Wettering Act of 1999 (Scholle, 2000, pp. 17-24). The U.S. Supreme Court ruled that this would not be a violation of their constitutional rights; thus, the Sex Offender Registry was developed. These laws are called "Megan's Laws" in a response to the death of Megan Kanka, a 7-year-old girl who was abducted, raped, and murdered in 1994 by a neighbor. The neighbor was a convicted sex offender, but no one in the community was made aware that he had been previously convicted of sexual offenses against young girls, nor was the community or neighborhood made aware that he was also living with two other men who had also been convicted of sexual offenses (Levenson \& Cotter, 2005).

As a result of Megan's Law funding, the MIT After Care Clinic was implemented in 2006 to provide support, assistance, and therapy to victims, including the secondary victim (i.e., the NOP), of sexual offenses or other criminal-level crimes against children. The After Care Clinic provides up to 12 weeks of trauma-focused cognitive behavioral therapy and is free of charge for the NOP and the child. Overall, the ACC's goal is to stabilize the family and provide support from the time of disclosure to the time of prosecution. The MIT After Care Clinic is the first and only one in the State of Connecticut. There is no research conducted on the MIT After Care Clinic, and thus is the rationale for this study. 


\section{Problem Statement}

Sexual abuse is prevalent, and, without interventions to stabilize the family, the perpetrators often go free to continue their abuse. The Multi-disciplinary Investigation Team (MIT) After Care Clinic was established to provide support for the child and the non-offending parent and to stabilize the family so they can proceed to prosecution. However, there has been no research conducted that describes the experiences of the children and non-offending parents who attended the MIT After Care Clinic. It is not clear how the program supports the child and NOP and what interventions are useful to stabilize the family.

\section{Purpose of the Study}

This study examines the experiences of children and their non-offending parents who attended the Multi-disciplinary Investigation Team's (MIT) After Care Clinic. The study seeks to understand the ways in which the care provided at the After Care Clinic helped stabilize the child and the non-offending parent. Additionally, this study explores what strategies were effective in stabilizing the families and resulted in their cooperation with prosecution of the perpetrator.

\section{Research Questions}

1. How did children describe their experience of trauma therapy at the MIT After Care Clinic?

2. In what ways did the non-offending parents describe their experience after the sexual abuse disclosure? 
3. How did the MIT After Care Clinic's program support and clinical interventions help stabilize the families, so they could proceed to prosecution?

\section{General Methods}

The primary purpose of this study is to describe the experiences of the child and non-offending parents who attended the MIT After Care Clinic. A secondary purpose is to explore whether the program support and clinical interventions provided at the MIT After Care Clinic have assisted in stabilizing the families and increased their participation in the prosecution, thus increasing the conviction rates of the perpetrators. This is a qualitative research study and includes narrative descriptions of therapy sessions, as well as observations that are documented in clinical case notes written after each therapy session. They are obtained at the Danbury Regional Child Advocacy Center MIT After Care Clinic. "Certain types of narratives, produced by a case study investigator upon completion of all data collection, also may be considered a formal part of the database and not part of the final case study report. The narrative reflects a special practice that should be used more frequently" (Yin, 2009, p. 121). Only cases involving child sexual abuse will be used, although both sexual abuse and physical abuse cases are often categorized together. While it is frequently categorized together with child physical abuse, child sexual abuse is more complicated and related to such areas as community perception, definition, reporting, and secrecy (Finkelhor, 1984).

\section{Conceptual Framework}

The framework for this study is based on two theories: The Traumagenic Dynamics of Sexual Abuse (Finkelhor \& Browne, 1985) and Trauma Focused Cognitive 
Behavioral Therapy (Cohen, Berlinger, \& Mannarino, 2000). The Traumagenic Dynamics of Sexual Abuse model utilizes four traumagenic dynamics as a way of understanding the effects from a victim of sexual abuse. It is necessary to understand as closely as possible the most commonly reported experiences pertaining to the trauma in order to effectively provide treatment for the victim. Finkelhor and Browne (1985) identify the four traumagenic dynamics of sexual abuse as "the core of the psychological injury inflicted by the abuse. Based on a review of the literature on the effects of sexual abuse, the paper suggests a conceptualization of the impact of sexual abuse that can be used in both research and treatment (Finkelhor \& Browne, 1985, p. 530).

The four Traumagenic Dynamics of Sexual Abuse are traumatic sexualization, betrayal, powerlessness, and stigmatization. When working with victims of sexual abuse, understanding these dynamics can assist the clinician in integrating the child's experiences and perceptions of the world with the trauma treatment to provide effective interventions.

Trauma-Focused Cognitive Behavioral Therapy (TF-CBT) is a psychotherapeutic intervention designed to effectively help children and their non-offending parents deal with the aftermath of a trauma (Cohen et al., 2000). Trauma-focused cognitive behavioral therapy was developed by SAMHSA (Substance Abuse and Mental Health Services Administration). It was developed and tested at the Allegheny General Hospital Center for Traumatic Stress in children and adults in Allegheny, Pennsylvania (Cohen et al., 2000). The treatment has been proven effective in helping victims deal with their trauma. One of the important components of the treatment is to involve the nonoffending parent. Through the work done with the non-offending parents, the clinician 
assists them in better understanding how their children are feeling and ultimately what is driving some of the behavioral or emotional changes resulting from the abuse.

These two theories are significant to this study because of the combination of the child's experiences of sexual abuse and the trauma therapy provided for the child who has been sexually abused. Without an understanding of the child's perception of the abuse, treatment may be ineffective. Each child's experience of being sexually abused differs; therefore, the trauma therapist must be able to establish a relationship that will create a sense of safety to allow the child to share their story without fear of judgment. The trauma therapist must be able to listen to the stories told and provide effective strategies that will be useful to the specific needs of the child. Some of the strategies may be effective for more than one child; however, having a set protocol that is without flexibility will not benefit a child who is not ready for the intensity of trauma therapy. Having a positive experience in treatment may provide children with other necessary skills so that when they are ready for the intense treatment, their perceptions are not filled with negative experiences of a clinician forcing them to talk (Gil, 2006).

The four Traumagenic Dynamics of Sexual Abuse (Finkelhor \& Browne, 1985) are important to understanding treatment at the MIT After Care Clinic. In addition to providing treatment, the trauma therapist may be gathering details of abuse in a courtworthy manner. The trauma therapist is responsible for putting the child's needs first. When a child is ready to provide details of the abuse (trauma narrative TF-CBT), then it is often pertinent to the child's well-being that the information be gathered in a nonthreatening manner, as well as non-leading or non-suggestive (Ceci \& Bruck, 1995). If this can also be done in a court-worthy manner, it may decrease the chance that the child 
will have to testify in court. Thus it is critical that the trauma therapist understands the dynamics of child sexual abuse in order to identify and understand as well as to effectively treat the trauma symptoms.

\section{Significance of the Study}

The benefits of this research for the subjects and the community are significant. The After Care Clinic is the only clinic in the state of Connecticut connected to a MIT to provide immediate and free follow-up care by forensically trained trauma therapists to children and their families who have been forensically interviewed. The results of this study can be used for the benefit of the Regional MITs in the state of Connecticut to demonstrate the importance of trauma therapy connected with their MIT and that immediate engagement in treatment can provide the child with a reduction of symptoms, which will assist in their ability to regain emotional stability. Overall, the study identifies which strategies the MIT After Care Clinic has provided that contributed to the emotional stability of the family and their ability to corporate with the prosecution of the perpetrator. The findings of this study add to the existing literature regarding the need for immediate engagement in trauma therapy (Everson et al., 1989; Hunter et al., 1990; Pellegrin \& Wagner, 1990), the importance of maternal support and the child's stability (Keeble, 1993), and therapy strategies that are useful in working with victims of sexual abuse (Gil, 2006). Additionally the themes from the children were consistent with literature on the Truamagenic Dynamics of Sexual Abuse (Finkelhor \& Browne, 1985) and The Child Sexual Abuse Accommodation Syndrome (Summit, 1983) and Trauma Focused Cognitive Behavioral Therapy (Cohen et al., 2000). 


\section{Definition of Terms}

Child Sexual Abuse (CSA): The use of force or coercion from a dominant individual, such as an adult or a person in a position of authority, who engages in sexual activity. Child sexual abuse may include fondling a child's genitals, masturbation, oralgenital contact, digital penetration, and vaginal and anal intercourse. CSA is limited not only to physical contact, as abuse could include non-contact such as viewing pornography, exposure, or voyeurism (National Clearinghouse on Child Abuse and Neglect Information, 2001).

Child Sexual Abuse Accommodation Syndrome: Helps explain how children experience sexual abuse as well as helping to explain behaviors and feelings associated with having been abused (Summit, 1983).

Department of Children and Families (DCF): Protects children who are being abused or neglected, strengthens families through support and advocacy, and builds on existing family and community strengths to help children who are facing emotional and behavioral challenges, including those committed to the Department by the juvenile justice system.

Disclosure: Either a purposeful or an accidental telling about the abuse (Sgroi, 1982).

Forensic interview: The primary goal is to gain "facts" for the child protection investigation. Forensic interviews are conducted for the judicial system and governed by rules of evidence. 
Forensic medical exam: An examination provided to a sexual assault victim by medical personnel trained to gather evidence of a sexual assault in a manner suitable for use in a court of law.

Grooming: A pre-meditated behavior intended to manipulate the potential victim into complying with the sexual abuse.

Mandated reporter: A professional who has been identified according the Connecticut Department of Children and Families, who in the ordinary course of employment or profession has reasonable cause to suspect or believe that any child under the age of 18 years has been abused or neglected, had non-accidental physical injury, or that a child is placed at imminent risk of serious harm, shall report or cause a report to be made to the Department of Children and Families.

Multi-disciplinary Investigation Team of Greater Danbury (MIT): The members of the MIT include DCF, state and local police, Danbury Hospital, Women's Center, Office of the State's Attorney, court-based victim's advocate, Danbury Regional Child Advocacy Center, including forensic interviewer, and the MIT After Care Clinic Director.

Non-offending parent (NOP): The parent who does not have abuse allegations pending. For the purpose of this dissertation and due to prior statistics, the non-offending parent will be referred to as the mother or with the use of the pronoun she or her.

Pediatric Emotional Distress Test (PEDS): This 21-item parent-report measure (Saylor, Swenson, Reynolds, \& Taylor, 1999) was designed to rapidly assess and screen for elevated symptomatology in children following exposure to a stressful and/or traumatic event. It is not intended to be a diagnostic instrument. It consists of behaviors 
that have been identified in the literature as associated with traumatic events and consists of 17 general behavior items and 4 trauma-specific items. The measure yields scores on the following scales: (a) Anxious/ Withdrawn, (b) Fearful, and (c) Acting Out.

Post-traumatic Stress Disorder (PTSD): An anxiety disorder that can occur after one has been through a traumatic event. A traumatic event is something horrible and/or scary that results in the person's response to the event with intense feelings of fear, helplessness, or horror.

Recantation: When the child retracts his or her statement about being sexually abused (Summit, 1983).

Re-victimization: An individual who experiences another unwanted sexual assault after he or she had been prior victimized.

Trauma Symptom Childhood Checklist (TSCC): An instrument used to evaluate the trauma-related symptomotology in children (Briere, 1996b).

Trauma: A sudden, unexpected, and non-normative event that overwhelms the person's perceived ability to cope, and at the same time causes physiological arousal. The most critical feature is that it produces a debilitating sense of helplessness and loss of control in the individual who experiences it (Monahon, 1993).

\section{Delimitations}

This study deals with children and families referred to the Danbury MIT and the MIT After Care Clinic. It is limited to referrals made to the police or Department of Children and Families after a disclosure of sexual abuse has been made. Only children between the ages of 3 and 17 and who speak English or Spanish can be interviewed. When the children do not speak English as their primary language, they are provided with 
an interpreter who works with the clinician to translate or they are referred to another Regional Multi-disciplinary Team. Due to the translation of the Spanish language, certain clinical themes may be lost in translation. This study is limited to children who reside in the greater Danbury area, have made a recent disclosure of sexual abuse, and have attended the MIT After Care Clinic. This study includes only children whose criminal-level case has had an arrest and has gone to the Danbury Connecticut Superior Court.

\section{Assumptions}

A major assumption is that any child who has been sexually abused is also traumatized. In many cases, the child does not exhibit any symptoms that are related to the experience of being sexually abused. It is also an assumption that when a child first discloses sexual abuse, they are providing all the details about what has happened (Summit, 1983). It is not uncommon for a child who has experienced multiple and repeated traumatic experiences not to recall all the information or to have a flat affect (no emotion) when they are being forensically interviewed or when they are in therapy. A final assumption is that the non-offending parent has colluded with the perpetrator and knew that the abuse was occurring and did not do anything (Schonberg, 1992).

\section{Organization of the Study}

The first chapter provides an overview of the background to the problem of the study. It also provides a context to the study that is important to the understanding of why this study is significant. Chapter 2 provides a comprehensive survey of child sexual abuse (CSA), and a brief history of the conceptual models associated with child sexual 
abuse is given. A literature review of the Traumagenic Dynamics of Sexual Abuse (Finekhor \& Browne, 1985) and Trauma Focused Cognitive Behavioral Therapy (Cohen et al., 2000) is presented, as well as the long-term effects of being sexually abused. Additionally, Summit's 1983 Child Sexual Abuse Accommodation Syndrome is examined as well as critiques of the theories explaining the child's experiences of abuse. Chapter 2 concludes with the importance of the non-offending parent during treatment, the process of disclosure, and the impact on prosecution. Chapter 3 describes the methods that are used in this qualitative study. Chapter 4 presents the stories of seven children and non-offending parents who attended the MIT After Care Clinic. Finally, chapter 5 consists of a summary of the study, demarcating the conclusions and recommendations for future study. 


\section{CHAPTER 2}

\section{REVIEW OF THE LITERATURE}

\section{Introduction}

A comprehensive survey of child sexual abuse (CSA) is described here as it pertains to this study, and a brief history of the conceptual models associated with child sexual abuse is given. A literature review of the dynamics of sexual abuse is addressed, including the Traumagenic Dynamics of Sexual Abuse (Finkelhor \& Browne, 1985), which includes the dynamics of sexual abuse and provides an explanation of each dynamic. The Child Sexual Abuse Accommodation Syndrome (Summit, 1983) provides an understanding of the reactions of children who have been sexually abused. The literature review will include the Child Sexual Abuse Accommodation Syndrome's (Summit, 1983) use in the court system as well as the criticisms of both theories. Included in the literature review are the long-term effects of being sexually abused as well as how this impacts the emotional and behavioral well-being of the child. The literature review also examines the reactions of the non-offending parent and their impact on the prognosis of their child.

Trauma-Focused Cognitive Behavioral Therapy (Cohen et al., 2000) is addressed as the treatment modality for trauma therapy. The use of Trauma-Focused Cognitive Behavioral Therapy (Cohen et al., 2000) is described as well as the identification of sexual abuse. Review of the literature found that children who have been sexually abused 
have more symptoms than non-abused children (Kendall-Tacket et al., 1993). Symptoms such as fears, nightmares, sexualized acting act, depression, and poor self-esteem have been associated with sexual abuse, "but no one symptom has categorized the majority of sexually abused children" (Kendall-Tacket et al., 1993, p. 164). Review of the literature reveals that once a child has been victimized, the child is more at risk for re-victimization (Scott, 2000). Lastly, the review of the literature discusses the difficulty in prosecuting child sexual abuse cases as well as sexual abuse disclosure.

Within the past 15 years, CSA has become recognized as a significant social problem in the United States (Chantler, Pelco, \& Mertin, 1993). Freeman and Morris (1999) assert that in the mid-1980s various conceptual models began to explain the variables associated with child sexual abuse as well as reactions to the abuse (Alexander, 1992; Burgess, Hartman, Wolbert, \& Grant, 1987; Cole \& Putnam, 1992; Hoier et al., 1992; Kiser et al., 1988; Polunsky \& Follette, 1995; Wolfe, Gentile, \& Wolfe, 1989). The shift has moved from documentation about the effects of child sexual abuse, to trying to explain the reactions to the abuse. Many of these explanations have derived from clinical experiences and clinical literature to provide a better understanding of sexual abuse. Consequently, many theoretical models have been published on the effects of child sexual abuse; thus the conceptual models have moved from explaining variables to Developmental Models (Alexander, 1992; Cole \& Putnam, 1992; Putnam, 1990; Spaccerelli, 1994), Behavioral Models (Freeman \& Morris, 2001; Hoier et al., 1992; Polunsky \& Follette, 1995), and PTSD (Briere, 1992; Kiser et al., 1988; Lindberg \& Distad, 1985, Wolfe et al., 1989). One of the conceptual models used to explain the 
dynamics of sexual abuse is the Traumagenic Dynamics of Sexual Abuse (Finkelhor \& Browne, 1985).

\section{Traumagenic Dynamics of Sexual Abuse}

Finkelhor and Browne (1985) describe the Traumagenic Dynamics of Sexual Abuse model and have identified a framework based on their clinical experiences to explain children's reactions to sexual abuse. Traumatic sexualization is the first dynamic explored. Traumatic sexualization refers to the process in which a child's sexuality (including both sexual feelings and attitudes) is shaped in a developmentally inappropriate and interpersonally dysfunctional fashion as a result of sexual abuse (Finkelhor \& Browne, 1985). This can occur when a child has been developmentally placed in a situation that is not age appropriate. For example, it is not uncommon for a perpetrator to manipulate a child into performing sexual acts and buying them gifts in exchange. Another way this is done is through attention and affection by the perpetrator, thus the child's sexual feelings and attitudes become distorted. Additionally, in the cases that involve threats or force, traumatic sexualization may result in the child associating sex with fear. As these experiences occur at ages that are not appropriate, the feelings and attitudes associated with sexualization become distorted. Due to these experiences, the child may become confused about sex, have misinformation, have learned to use sex as a form of manipulation, have a distorted self-image, and have emotionality associated with sexual encounters (Finkelhor \& Browne, 1985).

Betrayal refers to the dynamic that occurs when the child realizes that a person whom they trusted has hurt them. This may occur in more than one way: the abuser, who has lied to and manipulated the child, or the caregiver, who failed to protect the child 
from the abuser. The closer the offender was to the victim, the higher the likelihood of feeling betrayed. This often leads to increased amounts of hostility and anger (Freeman \& Morris, 2001). However, betrayal could also occur when a child discloses abuse to a caregiver who does not believe the abuse occurred.

Powerlessness refers to the child not having control of their personal space and body. The child is invaded by the offender and also by the form of manipulation. This can be further compounded by the offender's use of threat or force. Children who are victims are often told by the offender that no one will believe them; in many instances this is reinforced by a trusted person who does not believe their disclosure. When the child discloses and is believed, it often reinstates a sense of power or control (Finkelhor \& Browne, 1985). This dynamic is often linked with problems associated with fear and anxiety (Freeman \& Morris, 1999).

Stigmatization refers to the negative connotations that are associated with the sexual abuse. Many children express feeling bad, guilty, or shameful because of the experience, which directly connects to the child's self-image (Ackard, Kearney-Cook, \& Peterson, 2000). It is not uncommon for the offender to blame the child for the abuse"she wanted me; look how she dressed"- even when the victim was a child. Children who have been sexually abused often feel as if they are "damaged" or "their life is ruined." In some cases, the experience of keeping the secret of the abuse may reinforce the child's feelings that they are "different" (Finkelhor \& Browne, 1985).

Fiering, Taska, and Lewis (1996) expanded on the Truamagenic Dynamics of Sexual Abuse model (Finkelhor \& Browne, 1985) to say that child sexual abuse is likely to lead to a strong negative self-evaluative emotion of shame and that shame, not guilt, is 
the central emotion of stigmatization (Freeman \& Morris, 2001). Fiering et al. (1996) based their model on literature about the attributions and cognitive processing on behavior. It is their assertion that sexual abuse leads to shame via cognitive attributions about the abuse, and shame leads to poor adjustment, therefore, how the child perceives the abuse is a factor in their adjustment. This theory has been criticized because it is based solely on shame being the primary adverse reaction to child sexual abuse (Freeman \& Morris, 2001).

\section{The Child Sexual Abuse Accommodation Syndrome}

Another theory that has provided a framework to understanding child sexual abuse has been The Child Sexual Abuse Accommodation Syndrome (Summit, 1983). Children who have disclosed sexual abuse may be at risk for secondary trauma if the respondent does not react in an appropriate manner. Summit (1983) introduced the Child Sexual Abuse Accommodation Syndrome (CSAAS), which focused on the effects of female victims of incest. Summits explored the reaction of these children and identified five categories that had the most adverse impact on the child. The syndrome includes five categories: (a) secrecy, (b) helplessness, (c) entrapment and accommodation, (d) delayed, unconflicted, and unconvincing disclosure, and (e) retraction. These categories are described below.

Secrecy: The child is often told by their abuser to not tell. There are times that the perpetrator does not state those words, but the child is aware that they should not tell the secret. Telling is often filled with repressions; for example, if the child were to tell, the abuser may go to jail, mom may have to move (due to lack of resources), etc.

Additionally, there is the fear that the child may be blamed for the abuse. 
Helplessness: Victims are often victimized by persons who are in positions of authority. Many times the perpetrator is a trusted family member who has easy access to the child during bath or bedtime. Secrecy and helplessness often leads to the child feeling as though they were to blame and they did something "bad," or shameful.

Entrapment and accommodation: The child's perception of reality is altered by the abuser. The child fears the repercussions for telling the secret. The importance of not telling is often reiterated to the child, and the child is often unable to view the perpetrator as "bad" and thus begins to view themselves as bad or evil. Additionally the child learns to adapt to the abuse and develop skills such as parentification, self-mutilation or self punishment to allow the child to cope.

Delayed, conflicted, and unconvincing disclosure: It is not uncommon for a conflict in the family to trigger a disclosure or for a child to become older and feel more capable before she discloses. However, it is not uncommon for the disclosure to include limited details of the abuse.

Retraction: This often occurs after a child disclosed the abuse and several of the fears planted by the perpetrator have come true. The family is in turmoil, the child may not be believed, and the perpetrator was arrested. At that time, retraction may feel like the child's only option.

Historically the courts have struggled with entering the Child Sexual Abuse Accommodation Syndrome as testimony because of the criticism that it lacked scientific evidence (London, Bruck, Ceci, \& Shuman, 2005, p. 219). London et al. (2005) assert that the Child Sexual Abuse Accommodation Syndrome had no empirical basis of professional and lay opinions about disclosure patterns of child sexual abuse. However, 
their research found that there was much support for the silence/secrecy stage of the accommodation syndrome. Today, many courts allow the expert testimony regarding this theory.

Summit (1983) asserts that the accommodation syndrome is proposed as a simple and logical model for use by clinicians to improve understanding and acceptance of the child's position in the complex and controversial dynamics of sexual victimizations. Application of the syndrome tends to challenge entrenched myths and prejudice, providing credibility and advocacy for the child within the home, the courts, and throughout the treatment process. (p. 177)

The Child Sexual Abuse Accommodation Syndrome allows for the courts and the jury to have a better understanding of how children experience sexual abuse. "This study draws in part from statistically validated assumptions regarding prevalence, age relationships, and role characteristics of child sexual abuse and in part from correlations and observations that have emerged as self-evident within an extended network of child abuse treatment programs and self-help organizations" (Summit, 1983, p. 181). From experiences shared by survivors of sexual abuse, a better understanding has emerged. "The sexual abuse accommodation syndrome is derived from the collective experience of dozens of sexual abuse treatment centers in dealing with thousands of reports or complaints of adult victimization of young children" (Summit, 1983, p. 193). Ultimately, the Child Sexual Abuse Accommodation Syndrome provides a common language for the victims and has been useful as a tool in court to assist the jury in understanding the abuse from the victim's perspective. CSAAS is not a diagnostic tool used to determine whether a child has been sexually abused, and its validity has been tested for years. A criticism of both the Tramagenic Dynamic of Sexual Abuse and the Child Sexual Abuse Accommodation Syndrome has been that both models lack an empirical base and 
that both theorists used clinical experience rather than scientific data; consequently, the reliability and generality have been challenged (Freeman \& Morris, 2001).

In criminal trials, the proper use of the CSAAS is for the expert to explain to the jury the process of disclosure, that is, that a sexually abused child may not disclose immediately or even at all due to the feelings that are elicited in the child (shame, fear). In addition, if the abuser has threatened the child, he or she may fear repercussions. The child may be too young to understand the wrongfulness of the abuser's acts or she may suppress the whole experience. Thus it is imperative for the jury to understand the perspective and behaviors of a sexually abused child.

\section{Trauma-Focused Cognitive Behavioral Therapy}

Treatment of sexual abuse is essential, and many models of trauma therapy have been used: Brief Psychodynamic Psychotherapy (Horowitz, 1997; Horowitz et al., 1997; Krupnick, 2002); Cognitive Behavioral Therapy (Beck, 1995; Jaycox, Zoellner, \& Foa, 2002); Eye Movement Desensitization and Reprocessing (Shapiro, 1995); Self Trauma Model (Briere, 1996c); and Trauma-Focused Cognitive Behavioral Therapy (Cohen et al., 2000). Trauma-Focused Cognitive Behavioral Therapy (Cohen et al., 2000) is widely used today and is an evidence-based treatment for trauma. It can be used for various traumas, such as the loss of a loved one or exposure to violence or disasters, but was originally developed and tested to treat child victims of sexual abuse. Trauma-Focused Cognitive Behavioral Therapy (TF-CBT) was originally developed and tested as a clinicbased short-term treatment with children ages 3 to 14 and joint sessions with the nonoffending parent (Cohen et al., 2000). Many of these children had symptoms such as sexualized behaviors, behavioral issues, anxiety, and depression that required treatment. 
The treatment also addressed issues such as poor self-esteem, lack of trust, and selfinjurious behaviors, targeting symptoms of post-traumatic stress disorder. The children who participated in the study were from diverse socioeconomic backgrounds; however, most were from lower income or working-class families and were White or AfricanAmerican (Cohen et al., 2000).

TF-CBT is recognized as being one of the most effective interventions for children who have significant psychological symptoms related to trauma exposures. More than a dozen scientifically rigorous studies have demonstrated that TF-CBT helps children and families recover from the negative effects of traumatic experiences, including PTSD symptoms, depression, and related difficulties. Many of the studies compared TF-CBT to other treatments commonly provided to traumatized children, such as supportive therapy, child-centered therapy, play therapy, or usual community treatment, and showed that children receiving TF-CBT improved faster and more completely than the children who received other treatments. Studies that followed children for as long as one to two years after the end of treatment found that these improvements were sustained. This supports the promise of TF-CBT to potentially prevent the long-term problems associated with childhood trauma. (Child Sexual Abuse Task Force and Research \& Practice Core, National Child Traumatic Stress Network, 2004, p. 6)

The following is an overview of the components utilized in Trauma-Focused Cognitive Behavioral Therapy. It can be completed in approximately 12-16 weeks in the majority of cases. There are both individual and family sessions (joint session with childparent) for both the child and the non-offending parent.

The acronym PRACTICE is used to summarize the treatment. Psycho-education is provided to the child and non-offending parent. Parenting skills are provided to assist with teaching strategies. Relaxation and stress management skills are taught to both child and parent. Affective expression and modulation are taught to help children and parents identify and cope with a range of emotions. Cognitive coping assists the child and nonoffending parent with cognitive distortions regarding the abuse. Trauma narrative is used when the child shares the abuse with the non-offending parent. In-vivo mastery of trauma 
reminders is used to help children overcome situations that may be reminders of the original trauma. Conjoint child-parent sessions help the child and parent talk to each other about the child's abuse, and Enhancing future safety helps the child learn body safety (Windom, Czaja, \& Dutton, 2008; Child Sexual Abuse Task Force and Research \& Practice Core, National Child Traumatic Stress Network, 2004).

Four widely read studies were used to evaluate the efficacy of TF-CBT. The first included a sample size of 100 sexually abused children ages 8 to 14 years old and the non-offending parent. The study was randomized to TF-CBT for the child only, parent only, child plus parent, or only treatment. Children who had received TF-CBT experienced significantly greater improvement in PTSD symptoms. The non-offending parent who received TF-CBT experienced significantly greater improvement in depressive and behavioral symptoms; parents experienced significantly greater improvement in positive parenting practices. The differences were sustained at a 2-year follow-up (Deblinger et al., 1996).

In a study conducted by Cohen and Mannarino (1997), 86 sexually abused children ages 3 to 6 years old and their parents were randomized to TF-CBT or nondirective supportive therapy (NST) and were followed for 1-year post-treatment. This study had similar findings to the Deblinger et al. (1996) study, which also indicated that children receiving TF-CBT experienced significantly greater improvement in total behavior problems, internalizing, externalizing, and PTSD symptoms characteristic of young sexually abused children at a 1-year follow-up.

In a third study, conducted by Cohen, Mannarino, and Knudsen (2005), 82 sexually abused children ages 8 to 15 years old and their parents were randomized to TF- 
CBT or Non-Directive Supportive Therapy and followed for 1-year post-treatment. This study did not require minimum symptoms for entry, but rather only elevation on at least one of the study instruments (e.g., behavior or sexual behavior problems, depression, etc.). The findings indicated that the children receiving TF-CBT experienced significantly greater improvement in depression and social competence post-treatment; in anxiety, depression, sexual problems, and dissociation at 6 months post-treatment; and in PTSD and dissociation at 1-year post-treatment.

In a fourth study, by Cohen, Deblinger, Mannarino, and Steer (2004), 229 sexually abused children ages 8 to 14 years old and their parents were randomized to TFCBT or Child Centered Therapy (CCT) at two sites and followed for 1-year posttreatment. More than 90\% experienced multiple traumas. Children receiving TF-CBT experienced significantly greater improvement in PTSD, depression, behavior problems, shame, and abuse-related attributions. Parents in TF-CBT experienced significantly greater improvement in depression, abuse-specific distress, support of the child, and effective parenting practices. At the 1-year follow-up, children with multiple traumas and initially high levels of depression did worse in CCT group only, suggesting that TFCBT is more effective than CCT for these children.

\section{Non-Offending Parent}

The importance of family support has been established in the literature. Family dynamics and familial characteristics have been explored in relation to CSA symptoms. The most widely studied factor has been the maternal attitude (non-offending mother) and the support provided after a disclosure. "Maternal attitude influenced disclosure 
patterns greatly. Among those children whose parents were less supportive, $63 \%$ disclosed abuse during the initial interviews, whereas when caregivers expressed skepticism, only 17\% disclosed" (Olafson \& Lederman, 2006, p. 32).

The MIT After Care Clinic has a required component that provides support to the NOP, which includes but is not limited to areas pertaining to basic needs (i.e., food, clothing, and shelter), as well as behavioral issues that result from the abuse. If, for example, the perpetrator was the father, who had resided at home, then where the family lives may become jeopardized, especially if the perpetrator was the only working parent. Financially, the NOP may not have the resources to pay the rent or put food on the table, and his or her ability to provide appropriate emotional support becomes diminished. Although the non-offending parent is trying to provide support to their child, without having the basic needs met the stress level will become increased. Hobfoll et al. (1996) suggested that increasing stressors lead to more ineffectual coping mechanisms that can be buffered by greater access to resources (Bolen \& Lamb, 2002, p. 272).

The MIT After Care Clinic assists by providing information about finding housing or where to go to obtain a protective order if the perpetrator has been arrested and made bond. Additionally, the MIT After Care Clinic may provide food and clothing during the time immediately after a disclosure. The clinical literature suggests that the mother's support and belief that the child has been abused is monumental in the overall recovery of the child. However, the support becomes compromised if the mother continues in a relationship with the perpetrator (Everson et al., 1989; Heriot, 1996).

Everson et al. (1989) conducted a study to examine maternal support after a disclosure of incest. The results of the study confirmed that the support of the mother 
was essential in stabilizing the child. The children who did not receive maternal support demonstrated higher levels of psychopathology than the children who were provided with higher levels of support. It was found that the mothers who were not actively engaged in a relationship with the perpetrator were able to meet the children's needs. The child whose maternal parent was not able to provide support was linked to placement in foster care, thus significantly impacting the child's functioning.

Studies have also been conducted about the non-offending mother's reactions and support following a disclosure of sexual abuse. The findings from the study Psychosocial Characteristics of Non-Offending Mothers of Sexually Abused Girls: Findings From a Prospective, Multigenerational Study (Kim, Noll, Putnam, \& Trickett, 2007) were that abused children with supportive caretakers show fewer symptoms of distress (Conte \& Schuerman, 1987; Morrison \& Clavenna-Valleroy, 1998) and fewer psychological symptoms (Mannarino \& Cohen, 1996). Sexually abused children who have better relationships with their mothers exhibit fewer internalizing and externalizing symptoms (Hazzarel, Celeno, Could, Lawry, \& Webb, 1995), whereas sexually abused children with mothers who have a rejecting parenting style tend to have more emotional (Deblinger et al., 1999) and behavioral (Lovett, 1995) problems. However, the non-offending parent's initial response may be disbelief, but that does not always mean that they do not believe their child. "Viewing the response of a non-offending parent as a process may facilitate a non-offending parent moving from initial reactions such as denial and anger, to acceptance and positive action. This process may take time and may require therapeutic support" (Keeble, 1993, p. 27). Deblinger and Heflen (1996) assert that the NOP's 
ability to provide support to their child following their disclosure and in therapy could be the most critical factor influencing the child's post-abuse psychological adjustment.

It has been found that the long-term effects of child sexual abuse may be connected to adult adjustment issues, consequently affecting both the interpersonal and sexual relationships with males and females. Briere (1988) found that adults who were survivors of child sexual abuse had elevated rates of sexual dysfunction, suicidality, cutting, and drug and alcohol use. It is also not uncommon for a child to develop PostTraumatic Stress Disorder due to a single incident or multiple traumas. It is not uncommon for children to develop similar symptoms to depression and/or anxiety as a result of the abuse. Many trauma symptoms are identified by survivors, some of which include enuresis/encopresis, flashbacks, and nightmares. Thus it is important to reduce or minimize the symptoms that are interfering with daily interactions. For example, if a child is having nightmares, then he or she is not sleeping, and staying awake at school could be difficult. Grades begin to decrease and the child becomes more depressed and anxious, which often leads to an increase in other symptoms. It is imperative for the child's well-being that these symptoms are addressed as soon as possible. The need for the non-offending parent to provide support and apply healthy strategies to assist their child is often crucial to decreasing symptoms as they form rapidly. It is additionally important that the non-offending parent continue to provide support during the on-going process of disclosure. 


\section{Disclosure}

Research studies appear to be consistent in that most disclosures from victims are delayed until adulthood (London et al., 2005). Experts agree that disclosure is a process that takes time. There are two types of disclosure: accidental and purposeful (Sgroi, 1982). Accidental disclosure is more common among younger children. Approximately $75 \%$ of disclosures are accidental (Sorenson \& Snow, 1991). This may be because younger children have less linguistic ability and fewer social or emotional skills. Additionally, a younger child does not always understand what has happened to them, and they may say something such as, "It tickles when my dad touches my pee pee." A study conducted by Sorenson and Snow (1991) consisted of 630 children who had been abused for a period of time between ages 3 and 17. This was a quantitative analysis that identified certain characteristics of the disclosure process. Many of the subjects initially denied they were being abused. Through the study, Sorenson and Snow were able to identify the various stages of disclosure that the child who is disclosing may move through at various times. The five stages of disclosure include denial, tentative, active, recanting, and reaffirming. Overall, approximately $80 \%$ initially deny abuse or are in the tentative state of disclosure. More than $20 \%$ may recant for a variety of reasons.

"Disclosure of sexual abuse is best described by this research as a process, not an event" (Sorenson \& Snow, 1991, p. 126). Not all clinicians are in agreement with the stages of disclosure. "The evidence indicates that the majority of abused children do not reveal abuse during childhood. However, the evidence fails to support the notion that denials, tentative disclosures, and recantations characterize the disclosure patterns of children with validated histories of sexual abuse" (London et al., 2005, p. 124). 
The disclosure process is important to understand relating to this study, because it is often within 1 week of disclosure that the child begins trauma treatment at the MIT After Care Clinic; thus, the trauma therapist must be astutely aware of the stages and be able to assist the child in better understanding the abuse. Additionally, it is not uncommon for a child to have a minimal disclosure during the forensic interview but then be able to provide a very detailed account of the abuse during treatment.

Briere and Elliott's (1994) research on the immediate and long-term impacts of child sexual abuse has been monumental in raising awareness in linking the need for nonoffending parents (NOP) to be involved in the therapeutic process. Consequently, the treatment of child sexual abuse has fallen into one of two approaches: a victim advocacy/child welfare approach and a family-system model. Researchers and clinicians have determined that a comprehensive model that includes elements from both the child advocacy and family systems approach is the most effective and ethical way to address the problem.

\section{Identification of Sexual Abuse}

The emotional scars of a child being sexually abused is often seen through problematic behaviors. However, identification of sexual abuse can be difficult without evidence of physical trauma. Typically there is no eyewitness, and evidence is found in only $15 \%$ of the cases (Everson \& Boat, 1989). Thus, it is rare for a pediatrician to have evidence, which is why it is important to use a pediatrician trained in forensics. Many times a child is referred to his or her own pediatrician, who does not have the specialized training to confirm or deny abuse. Connecticut regional sexual abuse medical examiners are MDs or APRNs who have specialized training and equipment. Additionally, if the 
trauma has occurred more than 72 hours prior, then it is unlikely that evidence would be present, unless the child is pregnant or has contracted a sexually transmitted disease. However, even with a sexually transmitted disease, this does not prove abuse and will not deny or confirm abuse. If the sexual assault has occurred within the 72-hour window, there is a possibility of finding positive medical indicators, and the child would need to have a rape kit done at the Emergency Department. If the assault occurred after the 72 hours, the child is referred to a forensic pediatrician for the exam. Having the medical exam is critical for the child who has been abused. For many children, having an exam from head to toe assists in their feeling more certain that their body is healthy and that there is nothing wrong with them. "As a victim of sexual abuse, your body has been used without your permission. Regardless of the specific nature of the abuse, regardless of how recently or how long ago the abuse took place, many worry that their body has been permanently injured by the abuse" (Cooney, 1987, p. 74). For many years children have been disbelieved due to the lack of medical findings; however, professionals are becoming more aware that the lack of medical evidence is prevalent in sexual abuse cases.

\section{Prosecution of Offenders}

Of all the criminal cases that are in court, child sexual abuse cases are the most complicated and difficult to prove beyond a reasonable doubt (Goodman, Golding, \& Haith, 1984; Goodman, Golding, Helgeson, Heith, \& Michelli, 1987; Lieppe \& Romanczyk, 1989). Yozwiak, Golding, and Marsil (2004, p. 325) assert,

There has been a significant amount of research that has investigated the perception of child witnesses. Research has investigated how children are viewed when they are 
a bystander witness to a crime and have generally found that child eyewitnesses are perceived as less credible and less believable than adult eyewitnesses.

By the time a case reaches the courts it is often well over a year old. This could be extremely stressful for the families (Walsh, Lippert, Cross, Maurice, \& Davidson, 2008).

In 2004, Yozwiak et al. conducted a study on the impact of out-of-court child disclosure in sexual assault cases. Community participants read a fictional criminal trial summary of a 6-year-old child who disclosed being sexually assaulted. The disclosure was incomplete during the first interview, but the second disclosure was comprehensive. This study examined the effect the type of out-of-court disclosure of a sexual assault has on the believability of a child witness and verdict decisions. In summary, the results of this study demonstrated that the nature of out-of-court disclosure does affect the child's believability. Yozwiak et al. (2004) assert that studies investigating how children are perceived in cases in which they are alleged victims of sexual assault have typically shown that children younger than 10 years of age are generally viewed as more believable witnesses then either adolescents (i.e., 13- and 14-year-olds) or adults (Bottoms \& Goodman, 1994; Goodman, Bottoms, Herscovici, \& Shivor, 1989; Nightingale, 1993). There are various factors that are influential when a case is being prosecuted. Research on child sexual abuse cases has identified that child believability is important. "Child believability may be influenced by jurors' views about the likelihood that children fully disclosed abuse or were suggestively interviewed. However, case evidence can also play an important role in jurors' decision making” (Redlich, Myers, \& Goodman, 2002, p. 316).

The average time for a case at the Danbury MIT from start to finish (i.e., from the time of disclosure to the court proceedings) is approximately $11 / 2$ years. Many families 
that have been devastated by such abuse have moved on in their lives and often do not want to relive the trauma. However, for many children and families, the court process and finality of the case being presented in court may bring closure and healing. 


\section{CHAPTER 3}

\section{GENERAL METHODS}

\section{Introduction}

This case study examines the descriptions of the experiences from children and their non-offending parents who attended the Multi-disciplinary Investigation Team's (MIT) After Care Clinic. The study seeks to understand the ways in which the care provided at the After Care Clinic helped stabilize the child and the non-offending parent. Additionally, this study explores what strategies were effective in stabilizing the families and resulted in their cooperation with prosecution of the perpetrator.

This is a qualitative case research study and includes narrative descriptions of data that were collected through therapy sessions and observations that were recorded at MIT After Care Clinic's clinical case notes after each session. Each client attended approximately 12 therapy sessions. Demographic data obtained at the MIT as part of the forensic interview were used.

To sharpen the search for understanding, qualitative researchers perceive what is happening in key episodes or testimonies, represent happenings with their own direct interpretation and stories (i.e. narratives). Qualitative research uses these narratives to optimize the opportunity of the reader to gain an experiential understanding of the case. (Stake, 1995, p. 40)

Only cases involving child sexual abuse were used for this study, although sexual abuse and physical abuse cases are often categorized together. Although sexual abuse cases are frequently categorized together with child physical abuse, child sexual abuse is more 
complicated regarding areas such as community perception, definition, reporting, and secrecy (Finkelhor, 1984).

\section{Self as the Researcher}

I have had the privilege and pleasure of meeting with and conducting therapy with at least 500 children over the past $15+$ years. Early on, I knew I wanted to be a child therapist and had earned my Master's degree in Counseling by 24 years of age. I was fortunate to have gained experience in working with trauma survivors during my graduate internship. Shortly after graduating, I began providing trauma therapy for children who had been sexually abused and later began working with children identified and placed in special education, due to severe emotional disturbances. Many of those children had been sexually abused. Retrospectively, although I had the heart and book knowledge, I knew very little about the world. As I listened to stories that involved heinous acts, I very quickly learned about a world that was foreign to me.

Now, with many life lessons learned and as a seasoned therapist, I am skeptical that I will ever again be shocked by an experience that is shared with me by a victim. That said, the stories shared by the children continue to resonate in me, and my desire and commitment to help children move forward in their lives has not changed. It is not uncommon for a child to detach from their experience and to become unemotional. This does not mean that the child was not a victim; usually it means that the child was seriously traumatized.

The level of dedication and commitment demonstrated by professionals working with victims is immeasurable. It truly takes a team approach, and the team members must have the ability to respect each other's disciplines to work together for the best 
interest of the child and for the community. For many victims, the outcome of the court decision often provides the families with a sense of peace and validation. My hope is that for the many children who have lost their innocence, this study will help professionals who are in this field, along with the families and victims, to learn the skills to find peace and to move forward.

\section{Population, Sample, and Research Setting}

The sample used in this study was purposefully selected. The Danbury Regional Child Advocacy MIT forensically interviews approximately 50 children, ages 3 to 17, per year after disclosure of sexual abuse, physical abuse, or witnessing a crime. These interviews are conducted at 1 Terrace Place in Danbury, Connecticut. After the forensic interview, each family is offered the opportunity to attend the MIT After Care Clinic, which is free of charge. The MIT ACC is also located at 1 Terrace Place, Danbury, Connecticut, and provides up to 12 weeks of Trauma-Focused Cognitive Behavioral Therapy (Cohen et al., 2000) for the child and support (with a different clinician) for the non-offending parent. During the 12 weeks of trauma therapy, an assessment is

conducted of the trauma-related symptoms. The purpose of the assessment is to identify the primary trauma symptoms and, during the next 11 weeks, to reduce the acuity of the symptoms, thus meeting the overall goal of the client — to stabilize the family.

This study consists of a total of 7 clients who met the following criteria: (a) the child disclosed sexual abuse, (b) the child was forensically interviewed by the Danbury, Connecticut, MIT, (c) the child attended the MIT After Care Clinic, (d) law enforcement applied for an arrest warrant of the perpetrator, (e) the court accepted the warrant application, (f) the perpetrator was arrested, and (g) the case was heard by the Danbury 
Superior Court. The cases selected for this study pertained to children who were sexually abused; however, other cases that did not meet these specific criteria have been excluded. Since the time the ACC opened in September 2006 the clinic has seen a total of 37 children. Of those 37 cases, 7 cases were selected for this study; 2 cases did not result in an arrest, 13 cases were either prosecuted in the adult or juvenile court, and 15 are pending trial at the time of this writing, leaving 7 cases in this study.

\section{Data Collection}

The primary source of study was the existing clinical files of children who have attended the MIT After Care Clinic. These included clinical case notes taken after a therapy session, intake data, and information ascertained by a clinician during therapy sessions with the non-offending parent. The results of the Trauma Symptom Childhood Checklist (TSCC) (Briere, 1996b) or the Pediatric Emotional Distress Test (Saylor et al., 1999) were used as appropriate. Additionally, the MIT cases who attended the MIT After Care Clinic from September 2006 onward were explored regarding the prosecutory outcome of the case.

The Trauma Symptom Childhood Checklist (TSCC) is a 54-item self-report test that was created by John Briere in 1996. This is used with children ages 8 and up who have been traumatized. The TSCC has six subscales that enable the clinician to assess for anxiety, PTSD, sexual concerns, dissociation, depression, and anger. The TSCC's reliability analysis shows a relatively high internal consistency for the total scale of .96 . The instrument was normed on more than 3,000 individuals under age 18, and consists of two validity scores (under-response and hyper-response) (Briere \& Scott, 2006). Research has been conducted on the TSCC, and it has been highly regarded as a valid 
instrument for assessing trauma. The trauma assessment results were pertinent to this study because the symptoms that were contributing to familial disruption needed to be identified so the family could begin stabilization. The TSCC was only one component used in the assessment and treatment at the After Care Clinic. Children under the age of 8 were assessed using the PEDS (Pediatric Emotional Distress Test) (Saylor et al., 1999).

The PEDS is a 21-item parent-report measure that was designed to rapidly assess and screen for elevated symptomotology in children following exposure to a stressful and/or traumatic event. It is not intended to be a diagnostic instrument. It consists of behaviors that have been identified in the literature as associated with the experience of traumatic events and consists of 17 general-behavior items and 4 trauma-specific items. The measure yields scores on the following scales: (a) Anxious/Withdrawn, (b) Fearful, and (c) Acting Out (Saylor et al., 1999).

The intake conducted at the MIT After Care Clinic consists of three parts. Part One asks for demographic data such as psychosocial history by the non-offending parent. Part Two asks about the initial response to the child's disclosure of abuse. Part Three consists of symptoms that the non-offending parent has noticed prior to the disclosure of abuse and after the disclosure of abuse. A basic needs assessment is done to identify whether the family has food, shelter, and support. After the initial intake is completed, the non-offending parent meets with the same clinician to assist in addressing issues pertaining to behavioral or emotional changes in the child, court preparation and understanding of the court process, and any other information or issues that the nonoffending parent needs weekly support for. 
During the treatment, a child over the age of 7 is given the Trauma Symptom Childhood Checklist to complete. The symptoms that the child has reported that are elevated on the six subscales are cross-referenced with the symptoms that the nonoffending parent has identified on the intake questionnaire. The next subsequent sessions involve identification of healthy coping strategies as well as identification of feelings. During these sessions, additional information regarding the abuse is often ascertained (i.e., more details of the abuse).

It is important to note that any additional information that is provided by the child may increase the criminal charges against the perpetrator. This additional information is reported to law enforcement and the State's Attorney's office. For example, the initial disclosure may have been about inappropriate touching; however, during the course of treatment the child may disclose that there was penetration; consequently, the criminal charges may be increased. Both of the trauma therapists at the MIT After Care Clinic are forensically trained and are able to ascertain additional information in a child-friendly, court-worthy manner. The family is made aware that, should any additional information be ascertained during the course of therapy, this information would be given to both the prosecutor and law enforcement.

In addition, during the course of trauma therapy the child may choose to participate in a trauma narrative (Cohen et al., 2000) with the non-offending parent. A trauma narrative may include the child sharing with the non-offending parent the details of the abuse. For most non-offending parents, this is often the first time they hear the full disclosure. A component of the MIT After Care Clinic is working with the non- 
offending parent to prepare them for hearing this information, as well as being able to respond appropriately to their child.

Qualitative research is often used to seek understanding about experiences or to gain alternative perspectives. Phenomenological studies explore the meaning of the experiences that people have lived specific to a certain phenomenon (Hancock \& Algozzine, 2006). This study used the clinical case files of the children and nonoffending parents to examine their experiences at the MIT After Care Clinic, thus exploring their lived experiences during a traumatic event. Only children and families that have been forensically interviewed and received trauma treatment would be able to describe this experience. The three primary sources of data collection include observation, interviews, and documents. In this study, the information was collected primarily through individual and family therapy sessions with the victim and the nonoffending parent. After the therapy sessions, clinical notes are recorded with information about the session as well as observations; these were used as narrative descriptions of the families. Additionally, data collected through the intake at the MIT After Care Clinic regarding case outcomes was used.

Like therapy, clinical qualitative research requires that clinicians/researchers make a number of choices. On a daily basis, therapists must decide who will participate in therapy, which questions to ask, and what techniques and interventions to use, among others. Similarly, clinical researchers are faced with a number of decisions when creating qualitative studies. These decisions or 'choice points' are important because they help shape and guide the research endeavor. (Maione, 1997)

In summary, the data used in this study was the existing clinical files in the MIT After Care Clinic, of which, the clinical interviews comprised the most valuable pieces of information. 


\section{Procedure}

All data used in this study were secondary. The following is the existing procedure for the MIT and the MIT After Care Clinic. Written consent was given from the legal guardian, allowing the child to participate in the forensic interview. The consent form was explained to the non-offending parent; it was also explained that the data collected may be used for educational purposes. To ensure confidentiality, each case was coded by town and number. By means of example only, Jane Doe may be coded as 0308-D, which would indicate that the case occurred in March (03) and was the eighth forensic interview conducted that month (08). The D stands for the town Danbury (Connecticut), where the crime occurred. Only the forensic interviewer, clinician, law enforcement, and the prosecutor are privy to the name of the victim. The forensic interview was recorded to a DVD in its entirety and coded; the DVD and the anatomically correct drawings were signed over to law enforcement by the interviewer immediately after the conclusion of the interview. This is one piece of the evidence that was collected.

When the child begins trauma therapy at the MIT After Care Clinic, the same coding is used to continue to protect his or her identity. Another release of information is signed, again denoting that the information may be used for educational purposes. The non-offending parent fills out an intake form, which has several questions pertaining to the trauma symptoms they are observing, how they found out about the abuse, what would be helpful to the family, etc. During the time the non-offending parent is meeting with the trauma therapist (the individual who conducted the forensic interview), a 
different trauma therapist is meeting with the child, conducting an assessment, and beginning trauma therapy. Clinical notes are written after every child session and secured in a file that is coded and locked. "Original records such as contact information sheets, informed consent forms, and audiotapes, must be kept in a secure place to guard against the names of participants being accidentally revealed" (Seidman, 2006, p. 70). Themes pertaining to the child and non-offending parent's experience of the care provided at the ACC as well as clinical interventions resulting in stabilization of the families were compiled from the data. The themes reflect the purpose of the research and use of all data collected (Hancock \& Algozzine, 2006).

The primary method of gaining client perspective was through the therapy sessions with the child and the non-offending parent. Therapeutic or clinical interviews are another special kind of professional interview in which the purpose is to increase understanding and produce change in the person being interviewed. While interviews for research or evaluation purposes may also promote understanding and change, the emphasis is on intellectual understanding rather than on producing personal change (Kvale, 1996).

M.Q. Patton (2002) has written that good questions in qualitative interviews should be open-ended, neutral, sensitive, and clear to the interviewee. In clinical interviews, the questions are typically open-ended, neutral, and sensitive to the needs of the client. It is important for the person engaged in the trauma therapy to feel a sense of safety and support, with the ultimate goal of trauma treatment being to diminish the symptoms that are interfering with their lives and to stabilize the family. For many children, this includes being taught skills to prevent them from being re-victimized as 
well as understanding that the abuse was not their fault.

In this study it was important to determine whether the MIT After Care Clinic was able to reduce the primary symptoms reported at intake. This would have assisted in stabilizing the child and consequently the family. It was also important to gather the themes that the non-offending parents were reporting to the trauma therapist. "Thus, it is the intimacy of the inquirer and the patient that is the key term for Coles: learners and teachers coming together over their texts—not only the patient's text but, emphasizes Coles, the psychiatrist's texts as well" (Clandinin \& Connelly, 2002, p. 14). In summary, the secondary data were derived from multiple data sources that followed the existing procedures at the MIT After Care Clinic.

\section{Methods for Summarizing, Interpreting, and Discussing Data}

This study examined, through a case study, the components of care provided by the MIT After Care Clinic that assist in stabilizing the child and the family, as well as whether those interventions were a contributing factor in the family supporting the prosecution of the offender. The trauma assessment instruments were scored using the appropriate procedures. The purpose of the trauma assessment was to evaluate and interpret for clinical significance. In some of the cases, the results of the trauma instruments were invalid and not used.

\section{Reliability and Validity}

M. Q. Patton (2002) states that reliability and validity are two factors, which any qualitative researcher should be concerned about while designing a study, analyzing the results, and judging the quality of the study. Credibility, transferability, and 
trustworthiness are often used interchangeably in qualitative research to refer to validity and reliability (Golafshani, 2003). Triangulation was first introduced by an unobtrusive method proposed by Webb, Campbell, Schwartz, and Sechrest (1966). Triangulation is a strategy using multiple methods to establish validity. The goal of triangulation is not "to corroborate study findings, but to analyze them in different ways" (Padgett, 1998, p. 97). Eisner (1986) asserts that another criterion for assessing qualitative research and evaluation is structural corroboration. Structural corroboration is the use of multiple sources of evidences or recurrence of instances that support a conclusion (Eisner, 1998). Therefore, the purpose of corroboration is not to confirm that the perspectives portrayed in the results are accurate, rather corroboration is to present the findings and to verify that the perspectives have been accurately portrayed. Table 1 provides examples of the seven children studied and the themes extrapolated from the multiple data sources collected for this study (i.e., observation, intake, clinical notes). Table 2 also provides examples of themes collected from the data.

Merriam suggests another method that demonstrates validity is the use of peer review or peer evaluation. This method adds to the reliability of the study by having another individual, who is familiar with the information being studied that can objectively review the data. The results of the study were peer evaluated thoroughly by the Danbury Regional Child Advocacy Center MIT Coordinator. This individual is familiar with the MIT process as well as therapeutic interventions, policies and procedures at the MIT ACC.

Although there is disparity regarding how to establish trustworthiness in qualitative research (Golafshani, 2003), triangulation is an acceptable method used in 
demonstrating trustworthiness in qualitative research (Creswell \& Miller, 2000; Healy \& Perry, 2000; Johnson, 1997; Mathison, 1988; Mishler, 2000). Stenbacka (2001) suggests that if the trustworthiness can be maximized this may lead to generalizabilty, which connects to the quality of research.

\section{Generalizabilty}

Generaliziblity means the degree to which the findings can be generalized from the sample to the entire population. In many situations, a small sample size may be more useful in examining a situation in depth in various perspectives, whereas a larger sample would be inconsequential. The goal of a study may be to focus on a selected contemporary phenomenon such as child abuse or addiction where in-depth descriptions would be an essential component of the process. In such situations, small qualitative studies can gain a more personal understanding of the phenomenon and the results can potentially contribute valuable knowledge to the community (Myers, 2000).

Generalization leads to transferring what one learns, and, according to Eisner (1998b), can be regarded as skills, images, and ideas. Through the application of skills, images, and ideas the learning process is enhanced. In qualitative research it is important to interpret from the results and transfer them into practical application. The results of this study can be generalized and the identified strategies that stabilize the child and nonoffending parent can be used in larger populations. Thus, the learned skills and ideas can transfer to practice (Eisner, 1986). 
Table 1

The Children of the After Care Clinic

\begin{tabular}{|c|c|c|c|c|c|c|c|}
\hline Symptom & Samantha & Lisa & Paige & Kate & Peggy & Brian & Peter \\
\hline Anger & $\mathrm{X}$ & $\mathrm{X}$ & $\mathrm{X}$ & $\mathrm{X}$ & $\mathrm{X}$ & $\mathrm{X}$ & \\
\hline Sadness & $\mathrm{X}$ & & $\mathrm{X}$ & $X$ & $\mathrm{X}$ & $\mathrm{X}$ & \\
\hline Nightmares & $X$ & $X$ & $X$ & $X$ & $\mathrm{X}$ & $X$ & $X$ \\
\hline $\begin{array}{l}\text { Missing } \\
\text { offender }\end{array}$ & $X$ & & $\mathrm{X}$ & $X$ & $X$ & $X$ & \\
\hline $\begin{array}{l}\text { Thoughts } \\
\text { about } \\
\text { abuse }\end{array}$ & $X$ & $X$ & & & $X$ & $X$ & $X$ \\
\hline Anxiety & $X$ & $\mathrm{X}$ & & $\mathrm{X}$ & $\mathrm{X}$ & $\mathrm{X}$ & $\mathrm{X}$ \\
\hline Trouble & $X$ & $\mathrm{X}$ & & $X$ & $X$ & X & X \\
\hline $\begin{array}{l}\text { Poor peer } \\
\text { interaction }\end{array}$ & $X$ & $X$ & & $\mathrm{X}$ & & & $X$ \\
\hline Blame & $X$ & $\mathrm{X}$ & & $X$ & $\mathrm{X}$ & $X$ & $X$ \\
\hline Secrets & $X$ & & & & $\mathrm{X}$ & $\mathrm{X}$ & $X$ \\
\hline Confused & $X$ & $\mathrm{X}$ & & $X$ & $X$ & X & \\
\hline $\begin{array}{l}\text { Urinating } \\
\text { problems }\end{array}$ & & $X$ & $\mathrm{X}$ & & & & \\
\hline $\begin{array}{l}\text { Sad about } \\
\text { ending } \\
\text { therapy }\end{array}$ & $X$ & $X$ & $X$ & $X$ & $X$ & $X$ & $X$ \\
\hline
\end{tabular}


Table 2

The Non-Offending Parent

\begin{tabular}{lcccccc}
\hline Feeling & $\begin{array}{c}\text { Samantha's } \\
\text { Mom }\end{array}$ & $\begin{array}{c}\text { Lisa's } \\
\text { Mom }\end{array}$ & $\begin{array}{c}\text { Paige's } \\
\text { Mom }\end{array}$ & $\begin{array}{c}\text { Kate's } \\
\text { mom }\end{array}$ & $\begin{array}{r}\text { Peggy's } \\
\text { mom }\end{array}$ & $\begin{array}{c}\text { Peter's } \\
\text { mom }\end{array}$ \\
\hline Overwhelmed & $\mathrm{X}$ & $\mathrm{X}$ & $\mathrm{X}$ & $\mathrm{X}$ & $\mathrm{X}$ & $\mathrm{X}$ \\
$\begin{array}{c}\text { Past issues } \\
\text { surface }\end{array}$ & $\mathrm{X}$ & $\mathrm{X}$ & $\mathrm{X}$ & & $\mathrm{X}$ & $\mathrm{X}$ \\
Anger & $\mathrm{X}$ & $\mathrm{X}$ & $\mathrm{X}$ & $\mathrm{X}$ & & $\mathrm{X}$ \\
Blame & $\mathrm{X}$ & $\mathrm{X}$ & $\mathrm{X}$ & $\mathrm{X}$ & $\mathrm{X}$ & $\mathrm{X}$ \\
\hline
\end{tabular}

\section{Ethical Considerations}

The issue of ethics is taken very seriously in the field of counseling. The privacy of the clients is placed first and foremost. Both the MIT and the MIT After Care Clinic have coded all clients that have been forensically interviewed. The same code is used for the client when they begin treatment at the MIT After Care Clinic. Both sets of records are held at the Danbury Regional Child Advocacy Center, which is located at 268 Main Street in Danbury, Connecticut. This is in a different location than where the trauma therapy or the forensic interview is conducted. All children used in the cases in this study have been given pseudonyms to further protect their identities.

The MIT Coordinator is the primary forensic interviewer and the MIT After Care Clinic Clinical Director is the backup interviewer. If the Coordinator conducts the forensic interview, then the MIT After Care Clinic's Clinical Director will provide the 
trauma therapy with the child and the forensic interviewer will meet with the non-

offending parent. This arrangement would change if the backup forensic interviewer (the MIT After Care Clinic's Clinical Director) conducts the forensic interview. In that event, the MIT Coordinator would provide the trauma therapy and the MIT After Care Clinic's Clinical Director would meet with the non-offending parent. Both individuals hold Master's degrees in Counseling Psychology and have attended numerous trainings on trauma and interviewing sexually abused children. The MIT Clinical Director is a Licensed Mental Health Clinician, and the MIT Coordinator is a Certified Forensic Counselor. Both have been entered in the Danbury Superior Court as Expert Witnesses in cases involving child abuse. It is essential that this system be maintained, as the forensic interviewer may not be the primary trauma therapist after conducting the forensic interview. Additionally, it is important to note that both individuals are forensically trained in Connecticut's Finding Words protocol and are able to ascertain information during a clinical session in a court-worthy manner. 


\section{CHAPTER 4}

\section{THE CASES}

\section{Introduction}

The following seven narratives are stories of children who have been sexually abused and their experiences as explained through the therapeutic process. The nonoffending parents share their experience of the aftermath of their children's disclosures of sexual abuse. The experience of being abused and the non-offending parents' experiences of coming to terms with their children's abuse differ. However, the integration of how this impacted their children and their lives is powerful. Understanding these dynamics is important to the families' healing. It is important that the victims feel that they are believed by family and professionals. Oftentimes the validation comes from justice being served in the courtroom; for others it is dealing with the trauma and moving on. The stories of the families have been compiled from the 12 weeks of clinical case notes. The narratives share the details of the challenges from private emotions and feelings to the separate experiences of the child and non-offending parent and their integration as a family. Ultimately, the narratives show how the children experienced the MIT After Care Clinic, how the NOPs experienced the post-disclosure emotions, and what interventions were provided (and worked) to contribute to the families' stabilization. Lastly, the outcomes of the cases assist in understanding whether the MIT After Care Clinic stabilized the children in a way that helped the prosecutions. 


\section{Samantha's Story}

Samantha was referred to the MIT After Care Clinic after being forensically interviewed on two occasions due to separate incidents of sexual assault. The most recent assault was by a family friend. Prior to this rape, her older brother had sexually abused Samantha for many years. It is noteworthy that the primary trauma experience impacting her was from the sexual abuse from her brother. Samantha was a 14-year-old seventh-grader who received special education due to cognitive limitations as well as being diagnosed with Attention Deficit Disorder. Samantha seemed younger than her age and liked cartoons, coloring, and stuffed animals. Her physical appearance was like a young woman. It was not unusual for people to treat Samantha like a young women, even though she did not understand as much due to her cognitive challenges.

During the most recent assault, Samantha had been driving with her Mom's boyfriend Hank and his friend when they pulled into an abandoned area. Hank left Samantha in the car, and his friend raped her. After the first disclosure of abuse, the brother had been removed from the home and was in treatment in a residential facility. Samantha had not dealt with the abuse from her brother. The family had many years of substantiated Department of Children and Families (DCF) involvement due to neglect and abuse. Samantha would dress similar to young girls her age, but her hair and clothing would often be unkempt and dirty.

Mom was 35 years old and worked as a cashier in a local store. She and the biological father had been divorced. The biological father had been in and out of jail for drug-related offenses, and he had sporadic contact with Samantha. Samantha craved to have a relationship with her father. Mom's boyfriend (Hank) resided in the home with 
Samantha and her younger sister. The younger sister also has cognitive limitations. Hank, according to Samantha, was a father figure for her and her sister. Despite the various challenges Mom had faced (limited resources, past drug and alcohol abuse, past sexual abuse) she tried to provide for her children to the best of her capabilities.

The next 12 weeks of trauma therapy included individual sessions with Samantha and Mom with separate clinicians, as well as family therapy. Upon initial meeting, Mom was abrupt and told the trauma therapist she was annoyed at having to be seen at the clinic with her daughter. She was there because DCF had told her she must attend with Samantha or she could be placed in residential care. Mom filled out the intake and Basic Needs Assessment with the assistance of the clinician. Mom denied needing assistance with food or shelter but indicated that having someone to talk to may help; she did not have anyone. She was alone and isolated.

During this session Mom shared with the trauma therapist that she "was having headaches, was overeating, and had no appetite." Mom denied that Samantha had any trauma related to the rape. She did state that Samantha was having "difficulty focusing" but "thought that it was mainly due to the ADHD." Mom stated that Samantha has been in therapy for at least " 3 years, but had not addressed the abuse by her brother in treatment." It is not uncommon when a child begins the intensive trauma therapy that they take a break from their current mental health provider so that the trauma work could be completed, and the child may then resume treatment with the therapist after discharge from the After Care Clinic. Mom briefly touched on the past sexual abuse of Samantha but was non-receptive to talking to the clinician about it, because that was in the past and again she denied it affected her. 
For week 2, Mom had completed the paperwork for the intake. The clinician continued working on taking the history, such as prior DCF involvements, as well as helping Mom identify any new symptoms. Mom reported that the two girls were fighting all the time. She also reported stress in her relationship with her boyfriend Hank and that they were fighting continuously. The man who had raped Samantha was Hank's friend, also a known drug dealer. At this point in the treatment, there was some suspicion that Hank may have agreed to allow his friend have sex with Samantha to pay for Hank's drug debt. This was never confirmed.

During the next therapy session Mom began to talk about Samantha's anger. After the rape Samantha would slam doors, scream, punch, and fight with Mom. Mom "did not know why she was doing this." The trauma therapist continued to engage with Mom, exploring her reactions and feelings as well as helping her identify the types of things that seemed to upset Samantha to the point of rage. The trauma therapist did not push Mom to share more feelings than she was ready to talk about. Mom stated that when "she [Samantha] starts yelling, then Hank starts yelling, and she starts yelling." "Nothing works." Mom was feeling angry and overwhelmed.

At the next week's session, Mom appeared less hostile and angry to be at the MIT After Care Clinic. She greeted both trauma therapists (which she had not done during previous sessions) and, with the help of the trauma therapist, began to identify and share feelings. Mom told the trauma therapist that since Samantha's disclosure, she kept thinking about when she was sexually abused as a little girl. Mom talked about a long history of intra-familial sexual abuse. She questioned why Samantha can't just put it past her and forget. "Why can't she just deal with it; I did?" The trauma therapist talked to 
Mom about Samantha's need to talk about this and for her Mom to provide her with support. Mom had learned as a child that sexual abuse was what happed in her family. There was a code of silence. It was important that Mom not pass that message on to Samantha and instead assist her in talking about the abuse so she could heal. Mom became angry, tearful, and sad, but she wanted to do what was best for her daughter.

The trauma therapist began to prepare Mom for the family session, which often results in the child sharing the details of the abuse with the non-offending parent. This can be extremely painful and emotionally distressing. It is important that the trauma therapist assists Mom in identifying ways that will support her daughter so she does not break down crying or needing to leave the room. "Thank you for telling me." "I believe you." "You are safe." Mom had been made aware by the police that the perpetrator had been arrested. She knew it was going to happen but she still felt alone. Hank was rarely home and when he was they just fought. Mom questioned whether Hank was using drugs again. Mom said she never should have let Samantha go with Hank and his friend that day.

This was a turning point for Mom in a multitude of ways. She was in the beginning stages of believing Samantha had been traumatized. Additionally, Mom was beginning to make connections between her abuse and her daughter's abuse; she was beginning to identify feelings and trust the clinician. The trauma therapist and Mom had not discussed the past sexual abuse by her son Nat, but the clinician was sensing that Mom was getting closer to dealing with that. Later that session, Mom talked about Nat being removed from the home (by Department of Children and Families) and being in treatment due to the abuse. The trauma therapy was court-mandated and Mom expressed 
frustration at having to "deal with DCF, the courts, therapists for years." She was worried about dealing with the courts again and worried that Samantha would be in the same courtroom with the perpetrator. It was during this session that Mom's emotions became explosive for her. She was filled with grief and guilt about her daughter's abuse. Mom allowed the clinician to provide support to her. The connection made at that session with the trauma therapist was lasting.

The next meeting was a Family Session with the two trauma therapists, Mom, Samantha, and Hank. Hank behaved bizarrely and would stare into space, then start talking about his past issues and change topic mid-sentence. He said he wanted to kill the perpetrator because he hurt his "baby girl." This was a challenging family session due to the dynamics of this family and everyone talking at the same time; however, two goals were established: referral for Samantha to have a pharmacological evaluation (to assess for depression and anxiety) and for the family to help Samantha in the middle of the night. Samantha needed help in relaxing and feeling safe. In addition to getting her a nightlight, Mom would call home before her bedtime to say goodnight. Mom agreed to have Samantha evaluated by a psychiatrist. This was demonstrating a great deal of trust by mom to the clinicians, because mom was "totally against any drugs for psychological problems." Samantha brought up the topic of the perpetrator's arrest; she was worried that she got him arrested. Samantha's trauma therapist addressed this privately and the case was not discussed in detail due to Hank's potential involvement.

The next week Mom looked more overwhelmed (messy appearance, dirty clothes) and was "tired of dealing with everything." She and Hank were fighting and she was feeling alone and did not have any friends to talk to. She expressed wanting help but 
feeling uncertain about what she should do. Mom had followed up with the psychiatrist's recommendation to start Samantha on an anti-depressant. The trauma therapist explored whether medication would be beneficial for her during these difficult times as she also seemed depressed, and it was important for her to remain intact to help Samantha. Mom was adamant that she would not take medication. The trauma therapist suggested a child protection team, which is a team that has all the providers in the room (school, the two clinicians, previous therapist, etc.) to discuss what they would do to help this family and to assist mom in feeling less overwhelmed and alone.

The following week a child protection team meeting was held, which included the two trauma therapists, Mom, Hank, the school social worker, a DCF worker, and the previous therapist. A clear plan was made to help Mom and Samantha; Mom agreed to the plan but became emotional because she was so overwhelmed.

For the next session, Mom and Samantha did not show up for trauma therapy, nor did they call. The trauma therapist called their home and spoke to Hank, who did not know. Later that day Mom called and was worried about DCF taking Samantha away because she missed the appointment. The trauma therapist reassured her that Samantha would not be removed from the home and as long she commits to attending treatment regularly DCF would not be notified. The trauma therapist explored why Mom did not come that week; Mom was able to express that she "just has too much to do." The trauma therapist talked to Mom about the importance of her needs being met as well and that she (Mom) needs support too.

The next week Mom proudly reported that she had an appointment with the psychiatrist to meet with Samantha later that day. Mom had taken the younger daughter 
out of school and had brought her to the After Care Clinic and said she wanted the trauma therapists to help her. Mom was overwhelmed with the fighting and was reaching out for support. Although meeting with the siblings was not part of the clinic protocol, that was what Mom needed for support. The trauma therapist provided Mom and the girls with brief strategies to decrease the animosity between the girls.

Mom said she had done everything that was agreed to and that she thought Samantha was sleeping better. Mom reported three new concerning issues: trouble at school that resulted in an in-school suspension, that Samantha was not bathing, and that she thought Hank and Samantha were keeping secrets from her. The secrets were addressed and they were that Hank allowed Samantha to watch television after bedtime. This was discussed and problem-solved. When the trauma therapist probed more about the school-related suspension it was related to Samantha having inappropriate boundaries with the boys and writing boys sexual letters (i.e., "I want to have sex with you," etc.). This is not uncommon in abused children, as they often set themselves up for being revictimized. Samantha's hygiene had progressed to the point that required intervention and a hygiene contract was made.

The following week was a family session with Mom, Samantha, and the two clinicians. Mom reported that Samantha was becoming extremely argumentative and aggressive. Problem solving was done, as well as education for Mom regarding Samantha's limitations. Mom would often give Samantha a list of things to do (i.e., make her bed, fold the laundry, and start dinner); however, Samantha's cognitive ability would only allow her to process the first or the last thing said. She was not always being defiant; she was unable to follow multi-stepped tasks. Visual aid for the chores would be 
posted at home. As the session was ending and the family was walking out the door Samantha stated that her brother (Nat) would be returning home after his treatment had ended. This began to explain why Samantha was having additional behavioral changes; she had just begun to feel safe, and that was being compromised.

The following week the trauma therapist worked with Mom to help her understand Samantha's feelings and to provide support for Mom. Mom required a significant amount of support regarding this issue and in understanding that Nat's potential return home could be traumatic for Samantha. Mom loved both children and was feeling guilty and torn. Mom talked about the court case and was worried that Samantha would have to testify.

Both Mom and Hank met with the trauma therapist because they wanted to talk about the court case. Hank spent a great deal of time talking about himself, as did Mom. The trauma therapist questioned whether Mom had asked Hank to attend the meeting so the focus would be deflected from discussion about the son returning home. The clinician continued to re-focus the session to address that issue until Mom stated that she could not handle discussing it. Strategies to assist in helping support Samantha were reinforced as well as identification of ways they could support each other and that Mom could reach out to community agencies for other areas of support. Mom was beginning to feel empowered and ready to take control.

This was Mom's last session, and the trauma therapist identified the positive work that Mom had done — continuing with the bedtime routine, getting Samantha to therapy, the psychiatrist, communicating with the school, getting Samantha to school on time, and most importantly, that her daughter was beginning to feel her love and support. The 
possibility that when the case came up for trial Samantha would have to testify was explored. Mom agreed to work with prosecution in any way, but could not promise that she would allow Samantha to testify at trial.

The first session with Samantha took approximately 45 minutes. A discussion about mandated reporting took place. It is important that children who are victims of abuse not feel tricked or deceived, as their abuser often lies to them, so their understanding about the rules of therapy is important. Samantha was told why she was referred to the MIT After Care Clinic, and the trauma therapist began the assessment. This first session is always critical because it is the first opportunity to build a rapport and relationship with the child. Samantha was easily engaged and began talking about school and home. She was able to clearly articulate that she did not want to talk about the abuse and just wanted to forget it ever happened. She would hide her face when she did not want to talk about something. She would say, "I don't know," when she was uncomfortable, and she loved to color while talking. Samantha was worried about how she was feeling and wanted to get "outside of her skin." She could not sleep or stop thinking about the rape and her brother abusing her. This was how she felt all day long, especially during the day at school, but also at night. Coping skills such as listening to music, talking to her stuffed animals, and coloring were explored as methods to help her re-focus. The trauma therapist administered the TSCC to Samantha; however, due to her limitations it was unclear how much she understood.

At week 2's session, the trauma therapist went over the results of the Trauma Symptom Childhood Checklist with her. Samantha had scored high in anger, PTSD, and dissociation, which was consistent with what she was reporting to the clinician. 
Samantha said she had slept better that week, but later contradicted herself and talked about being tired because of nightmares. The trauma therapist did not confront this discrepancy, feeling it was too early in the relationship to confront her. At the end of the session Samantha expressed feeling alone; she stated, "I don’t think Mom gets it." When asked what her mother did not get, Samantha stated, "Any of it, how I feel about my brother ..." Samantha told the clinician she had been sick all week.

At week 3's session, Samantha said she was still sleeping better, but before the session Mom had told the trauma therapist that Samantha was often up all night and often crying. Samantha confronted her mother, angrily asking her how she knew this (Mom works the overnight shift at the store). It was pointed out to Samantha that she appeared angry with her mother for working at night. There was no response from Samantha; her body language changed to her head down, arms crossed. Mom continued on to say that Hank told her Samantha was up all night and sad.

During the individual session with Samantha, she reported that Hank was helpful to her. "When I am up at night he [Hank] will tell me to put the TV on to help me sleep." Samantha said she had tried coloring and listening to music but that it made her think, and when she thinks, she just wants to sleep. The trauma therapist explored what the sleep means - that Samantha does not have to think about the abuse. The following week there would be a family session, so Samantha and the trauma therapist had a discussion about the next week's family session and identification of goals.

The following week Samantha had difficulty at school, and the trauma therapist and Samantha discussed the suspension and the notes she was writing to the boys. Initially, Samantha denied that this had happened and said the school was lying about the 
notes. The trauma therapist had a copy of the letter and showed it to Samantha. At this point in the treatment the trust had been established between Samantha and the trauma therapist, thus showing her the letter would elicit a response. Samantha talked about writing the notes and thought these boys were her boyfriends. The trauma therapist talked to Samantha about re-victimization and how offering to give oral sex to someone did not make them her boyfriend. As Samantha was limited in her intellectual processing, but looked older than her age, she was seriously at risk for being victimized again. Additionally, it was clear that Samantha's hygiene was diminishing (this is not uncommon with victims). The link was made between being a victim, writing the letter to set herself up to be re-victimized, and not wanting to have sexual relations (i.e., the poor hygiene). Samantha expressed worry that she was in trouble and that she got the perpetrator arrested. She thought that it was her fault the perpetrator got arrested. She said he used to be nice to her, tell her she was pretty; she was feeling guilty because she thought he was her boyfriend.

This following week Samantha began to share details about the abuse from her brother. She told the clinician that she "feels sick" all the time because she is constantly worried/anxious. Samantha said she had written notes to the boys but knew that it was inappropriate. Relaxation techniques were taught.

This week Samantha became more verbal about the abuse from her brother and feelings associated with it. She hated when Nat called the house because her mother made her speak to him on the phone and it made her sick. She stated that she "did not want to and did not know what to say." She felt guilty that her Mom wanted her to talk, and she thought she should but did not want to. The session was ended early to have a 
family session regarding this issue. Mom shared with Samantha how she was feeling divided between both her children but wanted to do the right thing, although she did not know what that was. Mom agreed not to force Samantha to speak to Nat, or to share information with her about how he was and how much he missed Samantha. Samantha was able to tell her Mom how that made her feel sick. The clinician connected the angry outbursts and aggressiveness to the nights that she spoke to Nat.

This week Samantha continued working on relaxation techniques and began identifying the following feelings: shame, guilt, anger, and secrets. These feelings were connected to the abuse as well as to her feeling "dirty." Samantha talked about the rapist being her boyfriend, because before the rape he would hug her and buy her things and tell her how pretty she was. The clinician processed this with Samantha, along with the idea that he was not her boyfriend and that he had tricked her and deceived her. Even if she liked being hugged by him that did not mean she invited the sexual assault. She was not at fault; she did not get him in trouble. Samantha would not talk about her brother coming home.

This week, before meeting with Samantha, Mom reported that Nat would not be coming home. The treatment facility recommended he transition to independent living. Mom expressed relief and sadness, mostly relief but sadness in recognizing that he had sexually offended Samantha. She told Samantha that she wanted to keep her safe and yet loved her son. The trauma therapist explored that she could continue to do both.

Samantha worked on sharing her secrets with the trauma therapist. Samantha disclosed that one of her secrets was that she performed oral sex on her brother multiple times. (In the letters written to the boys at school, Samantha would offer to give them 
oral sex.) Samantha also expressed feeling guilt about the rape. Although discussed at various sessions, this was the first time Samantha told the clinician that she was beginning to believe that these assaults were not her fault.

During the last session Samantha was very tearful and expressed "deep sadness" about this being her last session. She wanted to come back, but she felt better. The clinician and Samantha worked on letting go of the anger. They released a balloon in the air to symbolize "letting go" of the anger, guilt, shame, and secrets. The TSCC was completed and showed a decrease in anger and dissociation, but Samantha continued to score high (over the normal limit) for Post-Traumatic Stress Disorder.

The Verdict: The perpetrator took a plea and he received 10 years suspended sentence after 2.5 years served and 15 years probation. The prosecutor had contacted the clinician to ask whether Samantha would be stable to testify. It was recommended that it would be emotionally harmful to Samantha if she were to take the stand; consequently the plea was potentially lesser than had Samantha testified. However, her growth and her recovery were far more important than the perpetrator possibly getting a few extra years of jail time. Hank was no longer living at the house as he was incarcerated due to felony drug charges. Samantha continues in therapy with her previous therapist and Mom has engaged in her own therapy.

\section{Lisa's Story}

Lisa is a 6-year-old girl who was forensically interviewed by the Danbury MIT after disclosing that she had been vaginally and anally penetrated multiple times by her 15-year-old cousin who had resided in the home. Lisa's parents had immigrated from Ecuador and, until Lisa's disclosure, had been living with several other family members 
who were also immigrants. Immediately after the disclosure, Lisa, her brother, mother, and father moved out of the home they shared with their family. This move was a tremendous financial burden that put a lot of stress on the marriage, but both parents agreed this was what "they needed to do." Dad did not have a green card and would try to obtain "under the table" work as a day laborer. Mom was a legal citizen and was employed at a local fast-food restaurant for minimum wage. The couple had a son who was 2.

Lisa was a quiet 6-year-old girl who was in the first grade. She did not receive any special education classes, although she did get pulled out for ESL (English as a Second Language) classes. She had never been in counseling before, nor had she displayed any problematic behaviors. The family's primary language was Spanish; however, Lisa was fluent in English. Lisa always arrived at her sessions with clean clothes and hair. She was eager to please and worried about her parents' financial situation, especially about buying food and clothes. She had enjoyed school and had friends until she moved and changed schools. Her new school, as well as the trauma symptoms, was interfering with her daily activities. Learning was becoming a stressor for Lisa. She began to struggle with peer interactions and missed her old friends and consequently began to dislike school.

Lisa felt responsible for getting her cousin in trouble and the upheaval it caused the family. Lisa was sick with constant worry. As a result of Lisa's disclosure, the rest of the family stopped speaking to Lisa and her immediate family; thus, the only support network they knew was gone. 
Mom primarily spoke Spanish, yet could communicate in basic English. Both parents had attended grade school but had no formal education after grade school. The clinician spoke to her in Spanish and would translate for the child's clinician as needed. Similar to Samantha's mom, Lisa's mom was devastated about the disclosure and felt angry and overwhelmed. She was willing to do anything to support her daughter and to help her in any way. She worried about the court case as she feared her daughter would have to testify and re-live her trauma. She was worried that her daughter would be in the court room with her cousin and the rest of the family. She also worried that her husband would be deported and that they would not be able to buy food and would be evicted.

In the beginning of trauma therapy Dad would accompany Mom to the sessions; however, when the family moved he would take any work available. As Lisa's behavior and trauma symptoms began to worsen, his absence at home caused his wife to feel even more isolated and overwhelmed. Dad spoke English quite well and the couple seemed to be a support for each other and for their daughter.

At the first session, both parents sat in the session crying and holding onto each other's hands; they reported feeling "in shock." Dad would vacillate between the sadness and anger. Mom expressed feeling powerless, sad, and overwhelmed. Mom looked exceptionally tired and sick. They both wanted to help their daughter, and the love they had for her filled the room. An intake and basic need assessment was completed. The family did not indicate that they were in need of housing, food, or clothing. They shared their financial problems later once the trust between the family and trauma therapist was established. Mom identified that she was in need of emotional support. The trauma therapist assisted the parents in filling out the intake, as neither parent could read or write 
well, and the intake was in English. Mom verbally reported the following symptoms since the disclosure: headache, recurrent dreams, feeling tense, depression, nightmares, angry, stomach trouble, and unable to relax. Both parents were in agreement about the symptoms that Lisa was having after the abuse: nervous/fearful, afraid to be alone, seems mostly sad, stomach aches, physical complaints, frequent tantrums, very demanding of attention, acts younger than age, urinates in places other than toilet, and urinates in her pants. They just did not know what to do to help, but listened to the strategies that the trauma therapist provided.

At session 2 Mom and Dad said they were employing the strategies on a nightly basis and that they had a better week. They told the trauma therapist that they were financially stressed because of the move and had no other option than to have a tenant move in or fear eviction. They expressed a great deal of fear and apprehension about having someone new in the home. Mom was overwrought with fear. The clinician identified ways they could be proactive in keeping their children safe when the new tenant moved in. They were encouraged to talk to Lisa about how they would continue to keep her safe. However, due to the size of their apartment the parents and both children were now all sleeping in one room-Lisa and the parents in one bed and the toddler in his crib. The parents reported that Lisa was urinating in the closet and on her brother's belongings. She had accidents while watching television, and she also had an accident at school. The clinician prepared Mom for the upcoming forensic medical exam and said that would be a good time for the doctor to reassure Lisa that her body was fine.

For week 3 Mom was alone at the session and she discussed the medical exam. Mom said that Lisa was able to ask the doctor the questions she had identified in therapy. 
Primarily Lisa wanted to know if her body was going to be fine and if she was going to be fine. The medical exam and the doctor were successful in easing Lisa's worry.

Mom shared with the trauma therapist that she felt isolated from her family. She had become aware that the perpetrator had received a summons (because of his juvenile status, and was remanded to detention). Mom was feeling guilty because her nephew was in detention and her sister hated her. She felt guilty about having left Lisa alone with him.

Week 4's session was cancelled due to a snowstorm. It is important to note that the results of the forensic medical exam confirmed that Lisa had been abused. This is rare in cases of child abuse.

Week 5, Mom came to the After Care Clinic alone because Dad was working. Mom was feeling frustration with him being gone and her being alone to deal with everything. She also reported being angry that the family was in need of food and that her husband had been going out to eat during the day, rather than taking his lunch from home. The trauma therapist was able to assist in getting the family food that week.

Mom talked about how the cousin had been arrested and that her family (her sister, the perpetrator's mother) had called the house yelling and blaming Lisa for the arrest. Mom needed a lot of support about her guilt and how brave Lisa was; because of her the cousin would not hurt another child. Mom said Lisa was still hitting her brother without a reason. She did not understand why Lisa got so angry so quickly. The clinician discussed with Mom the criminal proceedings and how typically with juvenile cases it is the court's intention to help with treatment, not punishment. 
The following week Mom was emotional and she thought she might be pregnant. The trauma therapist was the only person she had told. The trauma therapist identified resources in the area where Mom would be able to go for free medical care. The trauma therapist also followed up on how the strategies were working regarding school, toileting, and aggression. Mom said that Lisa still hated school and was now saying inappropriate things and touching the other children. The other children were getting upset with Lisa. Mom said that Lisa no longer had accidents at home or at school. Lisa was beginning to talk to her about the abuse. The trauma therapist assisted Mom with ways that would be most beneficial to Lisa when she shared information about the abuse (i.e., not crying, expressing that she loved and believed her, that the abuse was not her fault). Mom discussed how difficult it was to hear what happened to her daughter and that she felt responsible. Mom could not understand "how come she did not know." She was in denial that her daughter had been abused for so long. Mom shared with the trauma therapist that she was a child victim and no one believed her. All her feelings of anger and grief had surfaced as a result of Lisa's disclosure. She had talked to her husband about it but had never shared this information with anyone else.

The next week Mom confirmed she was pregnant. She had shared the news with her husband, who was supportive. Her husband was also being more mindful of their financial situation. Unfortunately, the stress of the disclosure was impacting her emotionally and physically and she was working fewer hours; she did not want to jeopardize her pregnancy. She was feeling so overwhelmed with worry that she was having trouble focusing. The tenant who was living with the family worked many hours and consequently was not home often. When he was home, she stated he was in his 
room, but she never let her children even watch television alone with him. She reported that she sensed that made Lisa feel safer. She said Lisa no longer had any accidents, was not hitting her brother very much, was spending time with him, and was starting to appear happy again (smiling and laughing at home). Mom "was beginning to think things were getting better."

Mom expressed that things were improving. She said that Lisa seemed happier and did not seem as angry or sad. She was feeling less overwhelmed and happier. She wished that this would just be over, but knew that it could be a long time before it was. She said one of the hardest things for her now was the discord in the family and loving her nephew but wanting him punished, but that she and her husband needed to work with the court to get her nephew help. The trauma therapist worked with Mom on her feelings pertaining to her nephew, sister, and daughter. Lisa's mother, like Samantha's mom, was torn between her love for her family member and feelings of anger and disbelief that he could have done this to Lisa.

Mom did not talk about many major issues that were interfering with her daily interactions. She and her husband were financially able to pay the bills, but were still struggling. The trauma therapist gathered a list of clothing sizes for the children and was able to provide the family with these items. Mom had also been utilizing the food pantry (a local church that provided food), but felt the family's housing was secure. The most pressing issue noted was that Lisa continued to dislike school, although she had not been as somatic; her visits to the nurse had decreased. To date, the school had been responsive to meeting Lisa's needs. 
Lisa was sick and Mom cancelled due to her illness. Similar to Samantha's mom, there was at least one cancellation by Mom.

The following session both Mom and Dad attended. Both were united in their report that Lisa was smiling, laughing, and seeming like her old self. They both looked different from the first session, less tired, and their eyes were not worn from all the tears. They expressed concern about the court proceedings and the repercussions this may have from other family members. Dad still worried that he may be deported and that another family member could turn him in. The trauma therapist worked with the parents on the areas they have control over in their lives, thus empowering them. The trauma therapist provided the family with the name of the Victim's Advocate at the court and what type of support he could provide for them, as well as looking at their current situation and the outcomes of their decisions.

Mom reported that she had contacted the Victim's Advocate and that she was feeling more confidence in the court system. The progress she had made, as well as future goals for the family, was explored. These symptoms that Mom had reported that Lisa had in the beginning had either diminished or dissipated: nervous/fearful, afraid to be alone, seems mostly sad, stomach aches, physical complaints, frequent tantrums, very demanding of attention, acts younger than age, urinates in places other than toilet, and urinates in her pants.

In the first session Lisa easily separated from her mother and father to meet with the trauma therapist and was aware of why she was being seen. She was a verbal and articulate young lady who appeared to process information age appropriately. She expressed that she was sad, "cries," and has nightmares every night. She hated being 
afraid all the time. A strategy to assist her in sleeping through the night was established and discussed with the parents. They agreed to read Finding Nemo to her nightly; this was a book that Lisa seemed to find comfort in and made her have "happy thoughts." Additionally the family agreed to allot more time to establishing a bedtime ritual that would enable her to become settled. Lisa articulated that she got "very mad" at her brother and that she often hit and kicked him. She did not know why she got so mad and that it just happened and she could not control it. This was discussed with the parents along with better methods for them to cope with helping her find alternative techniques to handle her anger. This would help the family in feeling less frustrated by the spontaneous outbursts of anger and aggressiveness. The TSCC was not given as Lisa was too young to take it; however, the symptoms from the parents were representative of what the parents reported on the PEDS.

The following week Lisa said her parents were reading Finding Nemo every night at least one time; they never forgot. She also stated that they were staying in the bedroom with her until she fell asleep. She was very worried about the new tenant. She identified that she did not have nightmares every night that week. The information about the accidents was not addressed, as the clinician was not made aware of it until after the session. Lisa was scheduled for a medical exam with the forensic pediatrician and the clinician explained the process to the family. Lisa was receptive to having the doctor check her from head to toes and was told that she could ask questions about her body.

The primary goal of this session was to identify methods so that Lisa did not have accidents or continue urinating in places other than the toilet. Lisa was open about how distressing this was to her. She was embarrassed that she had an accident at school, it 
was a horrible day for her, and it contributed to her hating her new school. She was so angry about that! She lost her school, her house, her family, and friends all because of her cousin-because she told. Similar to Samantha, Lisa struggled with feelings of anger and loss. She was worried that this was her fault.

It was important to identify what times of days and what activities Lisa was engaging in at the time of the accidents. At home she would urinate in her pants when she was watching television. When she was at school it was during times when she would become distracted with thoughts of the abuse. Lisa said that it was usually math class; since math was difficult for her, her mind would drift. A meeting with the parents and Lisa assisted in clarifying what shows/movies Lisa was watching when she was at home. It appeared that the shows/movies had content that was frightening to her, thus the fear was a precipitant to the urination. Additionally, Lisa said that when she was watching television, similar to at school, her "mind would make her think about the abuse." Her parents identified this as when Lisa would "zone" out; they also reported the school stated she "zoned out" during class. Coping strategies were given to both Lisa and her parents to help them identify when she appeared to zone out so they could refocus her attention. She could talk to her parents about what she was remembering in a safe way, so the family would be aware of what was happening to Lisa. Lisa expressed hating school, especially recess, as she reported, "No one will play with me." "I stand alone the whole time." Mom planned to talk to the school administrators.

During the next session Lisa drew a picture about her feelings associated with the abuse. A great deal of anger and sadness was illustrated in her drawing. She was able to create another picture that she had "happy thoughts." This was the first time Lisa was 
able to separate anger and happiness. The focus of the session was on anger and her expression of anger verbally or on paper, rather than by hitting her brother and yelling. The trauma therapist continued working on concrete strategies to decrease her anger. Lisa said she was happy that she had not had an accident at school since they last met. She reported having one or two accidents at home, but that she had not urinated anywhere other than the bathroom. She stated that talking to her mom about the abuse was helping, and so was her mom checking in with her when she was watching television. She knew her mom would stop whatever she was doing to talk to her.

The next session Lisa said she had a hard week. She said that the kids ran away from her at recess and made fun of her. The trauma therapist identified positive ways to make friends and things that she should avoid talking about (i.e., her personal information or the abuse). Lisa had adults whom she could talk to about the abuse.

Lisa and the trauma therapist worked on finishing the "anger picture" that was illustrative of her abuse. When she was done with the picture, she tore it up into little pieces of paper and threw them everywhere, stomping on them and expressing her rage at the perpetrator. This was a powerful exercise for Lisa; it empowered her and allowed her to have some control and to be in control of her anger. Similar to Samantha's release of the balloon, Lisa was letting go. Lisa did not have accidents at home or school. Lisa had worked hard at not hitting or kicking her brother, and, since she stopped hitting him as much, he wanted to play with her and "sometimes she likes that and he isn't so bad." This was an important session for Lisa, as it provided a "safe" outlet to say what she wanted to the perpetrator as well as expressing her anger in a healthy manner. 
Lisa came to the next session smiling; she had had fun this past weekend because her family went to the park. Additionally, she was sleeping through the night. Mom and Dad were still reading her Finding Nemo and staying with her until she fell asleep. She also said she was happy that she no longer has accidents; she really hated that. The trauma therapist talked to Lisa about her parents staying in the room for 5 minutes after they put her to bed, even though she may still be awake. The parents needed for Lisa to begin to have independence at bedtime; by doing this it would empower both the parents and Lisa. However, they would be in the family room if she needed them. Lisa agreed to try this. Lisa said she was thinking about the abuse only once or twice a day. She agreed to use a journal to draw or write about her feelings. The trauma therapist and Lisa began to work on her feelings of guilt associated with the abuse as well as body safety. Similar to Samantha, Lisa was feeling guilty about her disclosure and having difficulty with peer relationships. Lisa was still struggling at school with her peers, but acknowledged that she no longer was saying "weird" things or touching the other children and that some of the strategies that had been talked about "worked." When Lisa stated this she was smiling and thought she had made a friend.

Lisa had a good week because some children were playing with her; she did not have an accident or nightmares but felt sick during the day. Lisa had visited the nurse on several occasions for stomach aches. This was a new symptom; although Mom had initially reported it, this was first time Lisa was actually seeking out the nurse at school. Possible reasons for the anxiety were explored; Lisa was feeling responsible, and she worried her cousin would go to jail. This was discussed as well as using artwork to demonstrate her feelings. Lisa said she had to write in her journal only a few times 
because she was not thinking about the abuse that much. Ways to identify what was precipitating when she was starting to feel anxious or nervous were discussed (i.e., what she was doing when she had a stomach ache or felt sick). Lisa was encouraged to write this in her journal as well. The journal could be a place to write or draw how she was feeling.

The following week Lisa talked about her school-related issues. She said that the intrusive thoughts had diminished and that she did not feel sick all the time. The clinician and Lisa worked on a picture that was illustrative of Lisa's anxiety. She identified activities that she enjoyed and ways she could take control of her thoughts. The trauma therapist suggested to Mom that she contact a friend from her old school to set up a play date. Mom agreed to do this.

Lisa was not having nightmares, and was able to re-focus her thoughts on things that make her happy. The importance of continuing to discuss these feelings at appropriate times was identified as well as appropriate adults, such as her mother, who are there to help. The trauma therapist began the process of termination of therapy, as the following week would be the last session. Lisa became tearful and expressed wanting to continue; the progress she had made was highlighted.

The next week Lisa was sad about terminating therapy, but felt safe and wellprotected by her family. She was able to articulate that she was feeling less angry and that she now believed that the abuse was not her fault. She told the trauma therapist how much she would miss her. 
The Verdict: The perpetrator was held in detention for several months. After detention, he was transferred to a locked facility for sexual offenders until his $21^{\text {st }}$ birthday.

\section{Paige's Story}

Paige was an extremely articulate 3-year-old girl who was forensically interviewed by the Danbury MIT and referred to the MIT After Care Clinic after disclosing that her father had touched her private areas (both vagina and anus). Her parents were divorced but shared legal and physical custody. The parents' divorce was amicable, and prior to the disclosure the parents worked together regarding schedules and the children's events. The mother expressed to the clinicians that initially she did not believe her daughter's disclosure and was defending her ex-husband; however, throughout the course of trauma therapy she came to believe the allegations. Mother held a Master's degree and was currently staying at home with her two daughters, age 3 (Paige) and age 6. There was no allegation of abuse from the 6-year-old daughter by the father. Mother was financially secure and resided in her own home in an affluent community. The father lived less than a mile away from the mother's residence. The family spoke English as their primary language. Both Mom and Paige were always immaculate and well dressed. Mom had a support network of friends as well as the support from her mother. Her mother resided over 2 hours away; however, she was traveling to her daughter's every weekend to help with the children. The family has no prior history with the Department of Children and Families. This case was investigated by DCF, but was not substantiated. 
The first session Mom met with the trauma therapist and was very tearful. She was feeling overwhelmed by the disclosure and was uncertain about what to do. Mom looked exhausted. She completed the intake form and identified that her symptoms were headaches and nightmares. She also indicated on the intake that she had a history of physical and sexual abuse. Mom did not identify any basic needs that she needed other than support. Like Lisa's and Samantha's mothers, Paige's mom spent the session vacillating between wanting to believe the disclosure and feeling that it "could not be true." She was able to acknowledge that she was beginning to accept that this happened but was in shock. The mother was feeling as though she intellectually could grasp that this was happening, but emotionally could not. She, like the other moms, felt overwhelmed by the disclosure.

Because Paige was 3 years old, Mom completed the PEDS (Saylor et al., 1999) and also identified the following symptoms after the abuse: difficulty sleeping, clingy, soils herself (she previously had not had accidents), and changes in sleep. Mom said Paige seemed mostly happy.

Mom was feeling a significant amount of anxiety that her ex-husband was going to be arrested and how this would impact her children. She talked about what a large part of the children's life he had been and worried about how this would affect the girls. Mom said that immediately after leaving the forensic interview (which had taken place a week prior) Paige had defecated in her pants on the car ride home. She also had accidents when her father's name was mentioned. Mom was feeling like she had no control; the trauma therapist and Mom identified things that she had control over. 
Mom missed the therapy appointment and expressed that she was confused about the time and date. The trauma therapist spoke to mom on the phone to assist in preparing her and Paige for the upcoming forensic medical exam. Paige's mom, along with Samantha's, Kate's, and Lisa's mothers, all missed at least one meeting due to the overall stress and feelings of overwhelming anxiety that interfered with their organizational abilities.

This week Mom said Paige had nightmares and accidents almost daily. She was using the bedtime strategies, including "taking the monsters out of Paige's room," that were provided at the first session. This would entail Mom getting a trash bag and taking the make-believe monsters out of the room. Mom had been feeling overwhelmed and had not taken the trash bag outside; during one session Paige told her Mom that she was forgetting to take the bag "all the way out." Mom agreed to take the trash bag out.

Mom was frustrated with law enforcement and said that she was told her exhusband would be arrested and he had not been arrested yet. She also said the detective assigned to her case had been non-responsive to her calls. The trauma therapist said she would follow up with the detective and find out the status of the case. It is important to note that this was a different police department (i.e., a different town where the crime had been committed) than the previous two cases in which the perpetrator was arrested almost immediately. (Kate's Mom resided in the same town and she was also frustrated.) The clinician identified ways for Mom to take care of herself that had worked in the past: jogging, getting a manicure, and going out with friends. Mom was encouraged to do at least one of these things a week.

Mom canceled the therapy session because her older daughter was sick. 
The following week Mom looked very tired and she was concerned for Paige's aggression toward her sister. She was feeling so tired and overwhelmed that she did not always use the strategies that had been discussed. Her ex-husband was arrested but made bond, and since that time she had not been able to focus; her anxiety was high. Bond means he paid the amount the judge set and was out of jail. He also lawyered up; this is a common term for when someone retains a lawyer. Paige's father had financial resources and retained a lawyer with a good reputation.

Mom had been proactive and had already gone to court for an immediate hearing for physical and legal custody of the girls. This was granted, and the judge issued a protective order that would not allow the father to be in physical contact with the children. Mom talked about the shift in having her daughters all the time; prior to the abuse her ex-husband and she shared the physical custody. She was angry about the situation.

Mom said there had been a decrease in the nightmares and accidents. She had asked a friend to watch the girls so she could go jogging. One of her stressors was how to respond when the girls asked when they would see their father. Mom was given concrete suggestions about what to say. Mom requested that both trauma therapists be present when she would tell Paige that she will not see her dad. When Mom told Paige, she did not have a response, but gave Mom a hug. Mom was emotional and told Paige how much she loved her and that she would keep her safe. Before she left, Mom gave the clinician a picture illustrative of male genitalia. When Paige was asked what the picture was about, she stated "Daddy." 
Mom and Paige's older sister came to the session. Mom reported that the nightmares have remained the same, have not improved, or have worsened since the last session. She felt relief in telling Paige about visitation, and Paige had stopped asking questions. Mom asked for the clinicians to help her tell Paige's sister. The trauma therapists agreed and they helped Mom tell Paige's sister. Similar to Samantha's mom, Paige's mom had asked for support with her daughter. It was important that the trauma therapist be responsive to Paige's Mom's needs.

Mom was now monitoring phone calls from the father; the girls had told Mom that he told them he would be seeing them soon. Paige became aggressive, often wetting herself after phone calls. Mom purchased a phone with a speaker so she could hear the conversations. She was feeling anxious, and was able to identify this as situational anxiety that was specific to the abuse. She just wished this was over and questioned whether the father should ever be allowed to see the girls.

During the week, Mom had redone Paige's room; she had purchased a "big girl" bed and painted it pink (Paige's favorite color). Mom said that Paige had not had any accidents since the last session. She noticed a decrease in the nightmares and was excited that the new room was helping. She was feeling less anxious and was looking forward to her mom coming to stay for the week. She said "that it was such a relief not to be responsible for everything." Mom was considering going to therapy after she was done at the MIT After Care Clinic. She said she was ready to start dealing with her past abuse; she had never talked about it with anyone. She began to share information about her abuse. Just like Samantha's and Lisa's moms, the past had resurfaced and was forcing 
these mothers to address their issues of abuse. For each of these non-offending parents, the MIT ACC was the first place they had shared the details of their abuse with anyone.

Mom reported that the accidents had almost completely stopped and that every evening Paige reminded her to "do the bedtime routine." She was worried about the length of the criminal proceedings, as it could be at least a year, and she did not think she could handle waiting. She was frustrated that her ex-husband could be out on bail that entire time and could hurt another child. Paige's Mom was on an on-line dating service and came across her ex-husband's profile. It literarily made her sick—she said she vomited after reading it—as he listed that he enjoys doing "special things" with his 3year-old daughter. Mom was encouraged to speak to the victim's advocate at the court to help her understand the court process. The trauma therapist explained what a victim's impact statement was and explored whether Mom would be interested in writing one. This is when the family member of a victim has the opportunity to share with the court how the perpetrator's actions have altered many lives. Although the case was many months away, it could be useful for the secondary victim to write their statement when they are in the middle of the situation, rather than when things have settled down. Mom said that Paige seemed to be acting silly and happy and more like a 3-year-old again. She said there were no bad dreams or accidents that week.

Mom said that Dad had been consistent with calling the girls. During one of the conversations he told the girls that they would be going on an overnight to his house. Mom was angry but calmly took the phone off of speaker and told him that was inappropriate. He became enraged and started yelling at her and blaming her for everything. Mom said this was difficult to hear. She had been blaming herself for not 
recognizing that her daughter was being abused. She felt guilty enough and his statements were reinforcing this feeling. Paige's mom, Lisa's mom, and Samantha's mom all experienced this feeling. The trauma therapist talked to Mom about this not being her fault and how everything she was doing now was helping and supporting her daughter.

Paige had a "hard week," but Mom was encouraged that it felt different from than the other weeks. She attributed it more to developmental/age-appropriate behavior. Mom said Paige was having temper tantrums and had been taking toys away from the other children during play dates. Mom had decided that the girls would no longer have contact with their father as it was becoming detrimental to their emotional well-being. Mom was starting to take control of the things she could control.

Mom was very tearful about ending the After Care Clinic. She asked the trauma therapist if she could still call and keep in touch. She was feeling more positive about the court system but was still worried that because her ex-husband had financial resources he would "buy his way out of this." Mom said the detective who was assigned to the case had been more responsive after the clinician had called. He had called her last night and told her that they had issued a search warrant and had seized his computer to look for child pornography. They found a blow-up doll. The blow-up doll became a piece of evidence as Paige identified it in the forensic interview. Paige's mom said she felt sick about it but that she was able to "breathe" again and felt optimistic about their future.

Paige separated easily from her Mom, although asked for her mother on two occasions. The trauma therapist and Paige would go to the waiting room where Mom was so Paige could see her. She talked about her "Mom's house" and her "Dad's house." 
When talking about her father she spontaneously stated, "My dad kisses my butt." She talked about having a lot of "bad dreams" about monsters. Mom, Paige, and the two clinicians talked about some bedtime routines and strategies that would assist in relieving the stress at bedtime and help Paige to diminish her fear of monsters. Mom was encouraged to speak with her attorney about custody and visitation, as her ex-husband was "demanding" to see the daughters. He was also calling the house and although both daughters expressed eagerness to speak to him, Paige's behavior often became aggressive after the conversations, and she also would have accidents.

The following week Paige talked to the trauma therapist about missing her father and wondering when she would see him again. Paige wrote him a card and drew him a picture. She talked about the scary dreams and feeling scared at night. Paige also talked about getting in trouble when she hit her sister. The trauma therapist identified two alternatives to hitting and discussed safe places.

The next week Paige was very excited to have her sister at therapy and wanted her to go with the clinician and her. Both girls went to the therapy room and began to draw and talk. The trauma therapist was able to explore if the "hitting" had improved. The older sister said that Paige was trying hard not to hurt her, but sometimes she made a mistake. Paige talked about a scary dream and reported that she was not afraid of monsters anymore; she was now afraid of witches.

Paige was very excited about her new room and was "sure that there will not be any witches in the room." Paige talked about a happy dream she had and how she was excited to go to the beach after she was done talking with the clinician. Paige proudly reported that she was not "peeing in pants too much." Paige talked about not seeing her 
father anymore and drew a sad face. She said she misses him. He had been leaving her notes in the mailbox. The trauma therapist began to talk to Paige about body safety, which was done through a coloring book entitled It's My Body. The clinician talked to Paige about not hitting her sister or her friends. Paige and the two trauma therapists met with Mom, who explained that she would not be seeing her dad but would be able to talk to him and write him letters.

Paige came into the session and immediately told the clinician that her father calls her a lot. She said that her father said she would be going to his house for an overnight visit. Paige did not want to go there. This conversation was interrupted as Paige defecated in her pants during the session. Once she returned to the session, she refused to speak. The trauma therapist assured her that she had not done anything wrong, she was not in trouble, and that her Mom and other people would help keep her safe. Paige colored silently.

During this session Paige was very silly and laughed throughout. She drew a picture and told the trauma therapist that the "monsters are all gone." Paige stated, "She doesn't miss her dad anymore," and was "sad about it but not anymore." She told the trauma therapist that her "mommy always does the bedtime routine." The trauma therapist talked to Paige about her only having one more week to come to the After Care Clinic. Like Samantha and Lisa, Paige wanted to stay in the place that was safe for her to express her feelings. Paige drew a sad face and stated, "I want to come back." The trauma therapist explained that she was not having bad dreams anymore, had not had many accidents (only the one in the previous session in weeks), and that she was not 
hitting her sister anymore. The trauma therapist and Paige finished the book on body safety and she was told she could take it home.

The last session Paige was mad and would not speak to the trauma therapist. They discussed safety and what a good job she had done. Before she left, Paige ran back and hugged the trauma therapist.

The Verdict: Mom kept in contact with the child's trauma therapist periodically. Each call was positive about how she and the girls were doing. The case had been continued and the prosecution was offering a plea. At that time the perpetrator wanted to go to trial. Most recently the case went to trial and the perpetrator was sentenced to 7 years suspended after 5 years served. He will have to register as a Sexual Offender.

\section{Kate's Story}

Kate was a very bright 5-year-old girl who was referred to the MIT After Care Clinic after being molested on more than one occasion by a neighbor. Kate and Paige resided in the same town, thus the same police department investigated the crimes. Kate's primary language is English. Kate was in half-day kindergarten and an extended school day that was offered by the school.

The male babysitter, who was a neighbor, had digitally penetrated her on more than one occasion. Her mother felt that Kate had become fearful of males and was exhibiting signs of aggression with her younger brother. She resided in an affluent community with both her parents and brother, who was 4 years old. Her parents were educated (Master's degrees) and very involved in supporting their daughter. The mother was so distraught by the disclosure that she immediately quit her job because she feared leaving her daughter in the care of anyone other than herself. Prior to the disclosure, 
Mom and Dad were both full-time working parents. The family did not have prior DCF involvement, and no one in the family had been in therapy prior to the After Care Clinic. DCF did not substantiate neglect against the parents.

For the first session, Mom arrived very early to the appointment and was anxious. The two trauma therapists met with Mom and Kate and explained the process of the treatment. Mom was very tearful and angry about her daughter's abuse. She provided the trauma therapist with a list of questions and concerns about Kate starting in trauma therapy. Primarily she was worried that if Kate kept talking about the abuse then she would become more traumatized. It is important to note that Mom was continuously asking her daughter questions pertaining to what happened. Kate had asked her Mom to stop asking her about the abuse, and Mom assumed she did not want to talk about it. The clinician helped Mom understand that Kate would talk about it when she was ready, when she has control over her feelings of readiness. Mom wished that everything were back to normal. The trauma therapist explained the process could take over a year and the main concern was to assess and treat her daughter for symptoms related to the abuse. The only symptom Mom reported was that she had headaches. Although she reported only having headaches she appeared to the trauma therapist as overwhelmed and angry; she would cry during sessions and raise her voice when talking about the abuse. She identified that her daughter had become somatic at home and school and seemed more aggressive, but that the other children were provoking her daughter and that was why she was aggressive.

During this session Mom reported being frustrated with the police. She wanted to know why the perpetrator was still "walking around" and "not in jail." She also 
expressed concern for the safety of the other neighborhood children and questioned whether she should tell them. The clinician encouraged Mom to call the detective to find out the status of the case. The clinician would also follow up with the detective. The clinician provided Mom with strategies for how to handle seeing the perpetrator when she was with her daughter, because Mom said she "panicked" when they saw him. Kate's mom felt like she was to blame for her daughter's victimization and that she should have known. This was the same way Samantha's, Lisa's, and Paige's moms felt. Mom said the school had sent a note home that Kate was being more aggressive with the other children as well as becoming defiant. Mom was mad at the school and thought they were unfair because her daughter was never defiant.

Both Mom and son were at the session. Both trauma therapists observed Kate kick her brother; Mom did not respond to Kate's kicking. The trauma therapist tried to identify this as the behavior that the school had reported the week prior and talk about it. It is unclear whether this was an old behavior that Mom did not identify or a new behavior resulting from the abuse. Mom was feeling very tired and frustrated and was having difficulty sleeping. Since she was awake during the night she had noticed that her daughter also did not seem to be sleeping well. The trauma therapist provided strategies and discussed the upcoming medical exam.

Mom reported to the trauma therapist that she was surprised that Kate would want to talk about the abuse; the less Mom talked about it the more Kate talked about it. The trauma therapist provided education to Mom about disclosure and the need for the victim to process the abuse. Mom said that the past week Kate had been somatic, but Mom was able to help Kate identify her feelings when she had a stomach ache: worry, anger, 
sadness, etc. Mom was concerned that her daughter was "blinking too much." She feared that was a symptom related to the abuse and asked the trauma therapist to observe during the session. Mom talked about feeling a great deal of anger that "she had allowed this boy into her home, she had treated him like her own, and he abused Kate." She felt as though it "were my fault." Kate's mom felt she was to blame, just as Samantha's, Paige's, and Lisa's moms felt they were also at fault.

Kate was sick, and Mom cancelled the therapy appointment. This had been a consistent behavior by every client.

This week Mom was very angry with the perpetrator. She had driven down her street and he was riding his bike. She had slowed because the children were playing outside and he stopped in front of her car and waved and smiled at her. She was furious! Mom was aware that the perpetrator had received a summons and had not gone to detention. As the perpetrator was a juvenile, it is often the intention of the court to try and help the child receive treatment, which is also mandated through probation. However, in many of these cases the court has placed certain restrictions on the child such as no contact with younger children. If the probation is violated, the juvenile is then at risk for going to detention. Mom was encouraged to call the juvenile prosecutor to report this behavior as the perpetrator may have been violating the restrictions from the court. This encouraged and empowered Mom to have some control over the situation. During this week's session, Mom said that Kate was sleeping much better and had rarely called her during the night. She had seen the detective who was handling the case and felt that she had a positive response. She was referred to the victim's advocate at the 
court for his assistance with the pending case. She was feeling stressed and worried that the neighbors wondered why she was driving Kate to school. She was feeling isolated.

During this session Mom was feeling less overwhelmed and said that she was interested in returning to work. She thought she might have a job; consequently, she began to visit day cares. Mom met the teachers but worried because one day care had a male teacher. She thought that Kate would refuse to be in that room. The trauma therapist explored whether Kate had demonstrated fear of men, as indicated on the intake. Mom said she had not seen her become afraid, but knew she must be. The trauma therapist explored whose fear this was-Mom's or Kate's.

Mom cancelled the following week's therapy session.

Kate's visit to the day care went well and she did not appear nervous about the male teacher. Mom started work the following week. Mom noticed Kate's symptoms of kicking, bad dreams, somatic complaints had diminished and she expressed that she was feeling confident that going back to work was best. The trauma therapist provided support and empowerment to Mom regarding her decision. It was decided that, due to Mom's new work schedule, they would have one more session for closure. Mom was still feeling guilty but she was able to recognize that she was doing a good job supporting Kate.

During the last session Mom reported that Kate's day care provider has been "wonderful." There had been no issues at home, school, or day care. Mom had continued to keep in touch with the victim's advocate and had been made aware that this was the perpetrator's first offense and that the goal for the Juvenile Court would be to help him get sex offender treatment for an extended period of time. Mom said that she 
was comfortable with that decision. She was feeling less overwhelmed and better able to focus on moving forward.

Kate easily separated from her mother and talked to the trauma therapist about school and her brother. She was unaware of the reason for being seen; she did not remember being in that room (the therapy room is the same room used for forensic interviews) or talking to the forensic interviewer. The forensic interview had taken place approximately 1 week prior. The clinician told Kate she did not have to talk about what happened but that was a reason children came to the After Care Clinic. Kate stated she "did not want to talk about it." The trauma therapist reassured Kate that she did not have to talk about it. The rest of the session was spent building rapport and talking about school, friends, etc. Later in the session she asked the trauma therapist why she had to stay with her Mom when they see the neighbor (the perpetrator). She missed seeing him, and he used to do fun things with her, such as tag and coloring. She was confused about everything. The trauma therapist talked to Kate about her feelings, which were confusing. All the children seen had expressed feeling confused, too.

Kate did not want to be there and did not feel like talking. She wanted to color. The trauma therapist and Kate began to work on a workbook for body safety that included coloring and education. Kate did not engage in conversation with the clinician regardless of the topic.

This week Kate was more talkative to the clinician during the session. She talked about being confused about everything and thought she was in trouble. The trauma therapist explored why she thought she was in trouble. She said at home her Mom was always asking her if she was all right and when she saw the babysitter (the perpetrator) 
Mom seemed angry. The trauma therapist explained to Kate that she was not in trouble and that she had not done anything wrong. (This had also been stated previously but Kate had not participated in the discussion and was non-responsive.) The trauma therapist was able to talk to Kate about her concerns and connect them to how she was feeling. For example, the stomach aches and frequent trips to the nurse seemed to be a manifestation of her anxiety. The trauma therapist and Kate were able to identify other worries; Kate was worrying about her Mom, as her Mom, she reported, cried a lot and was always on the phone. She also stated that she was confused about how she felt about the babysitter and was worried that she got him in trouble. Like the previous children, Kate was worried about being in trouble and that her disclosure got the perpetrator in trouble.

This was a turning point in the therapeutic relationship as it was the first time that Kate felt safe enough to begin to explore her feelings and ask clarifying questions. The clinician and Kate talked about how his touching her body was wrong; Kate was able to articulate to the clinician how confusing the abuse was for her. The clinician talked to Kate about the upcoming medical exam. The trauma therapist and Kate identified things she liked to do that helped her feel safe: reading, hugs, and coloring. The trauma therapist and Kate talked to Mom about how Kate was worried about being in trouble and that she got the babysitter (perpetrator) in trouble. Kate told her that Mom was on the phone all the time and she was worried when Mom cried. The trauma therapist had already provided Mom with ways to respond when Kate brought up the abuse. Mom was able to tell her daughter how much she loved her and that it was not her fault. She told her daughter that what the babysitter did was wrong and that his actions got him in 
trouble. Kate was not in trouble and Mom would be more present at home to help support Kate.

During the session the trauma therapist had observed Kate's blinking; Kate was rubbing her eyes a great deal and sneezing. She reported having a stuffy nose. Kate was feeling better since the last session and had not had stomach aches every day. She could not sleep because there were monsters in her room and she was moving to a new house. The clinician talked to Kate about that and discussed it with Mom. Mom said she and her husband had been discussing moving and that Kate must have overheard. Without Kate present, Mom's trauma therapist reiterated the importance of keeping the adult information private as it was impacting Kate. Somatic complaints are often a manifestation of anxiety; they were seen with all the children.

This week Kate reported to the trauma therapist that she was happy that her Mom told her that she was not going to move. She was not as scared at bedtime and had better dreams. Mom had employed all the strategies suggested to help get rid of the monsters. She told the clinician she got in trouble at school for kicking. The trauma therapist problem-solved alternative methods for handling her frustration rather than hitting. The clinician spoke to Mom about the school incident, and Mom did not think it was Kate's fault. Both trauma therapists, Mom, and Kate had a conversation about responsibility and Kate's role in the kicking; however, Mom appeared to be unwilling to help Kate identify her role in the kicking.

Kate was sleeping through the night. She also went to a friend's house to play. She had a good time and wanted to go back. She told the trauma therapist about starting to believe that she was not in trouble. She said that many changes happened since she 
first told her Mom what the babysitter did and that it made her Mom very sad. She still worried about Mom. The trauma therapist and Kate identified some of the positive changes, such as her feeling safe and that the babysitter would never touch her again. Additionally, because she had told someone what happened she might have helped other children who may have been touched by the babysitter as well. Kate expressed, "I was brave." The clinician agreed that Kate was brave.

Kate did not report any worries this week at therapy. She talked about her Mom going back to work and did not report concern about it. She questioned who would take care of her when Mom was working. The trauma therapist and Kate talked to Mom about Kate's question and Mom told her about day care. Kate expressed that may be fun, as many of her friends went to that day care. The trauma therapist suggested bringing Kate to visit.

Kate talked about visiting the day care (making no mention of the male teacher) and reported that she was excited to start day care. Kate had a one bad dream during the week, but Dad came in and she fell back asleep. Kate had not been spoken to by the teacher for hurting the other children. The trauma therapists explained that Kate would only come back to meet once more.

During the last session Kate talked about day care with the trauma therapist. The trauma therapist worked with Kate to make sure she understood body safety. The trauma therapist felt that Kate was comfortable with understanding the information on body safety. Additionally, Kate seemed to understand that she was not at fault; she stated she was "feeling happy again." She thanked the trauma therapist for helping her. 
The Verdict: Kate's perpetrator was remanded to a locked facility as well as sexual offender treatment until the age of 21 . The perpetrator was 15 at the time of arrest.

\section{Brian's Story}

Brian was 10 years old and resided with his grandparents, biological brother (Matt), and sister (Barbara). He was referred to the MIT After Care Clinic after being forensically interviewed due to a disclosure of sexual abuse. It is important to note that during the forensic interview in October, Brian had a minimum disclosure; however, during the course of therapy Brian was able to report details of the abuse. Brian had been abused by both siblings_-digital stimulation, performing and receiving oral sex, and being sodomized by his older brother, Matt. Many times the three children would engage in these acts together. The brother was 16 years old and the sister was 13 . His sister had severe medical problems and appeared younger than her stated age. The biological parents were allowed visits with the children; the mother had court-ordered supervised visits and the father and his current wife were allowed overnight visits with the three children. The reason for the children's removal from the parents involved pornographic pictures taken of the two oldest children (not Brian) as well as exposure to sexual acts. It was unclear whether the parents had sexually abused the children. The father had been ordered by the court to undergo an evaluation to assess for sexual offending predilection. To date, the father had failed to follow through with the recommendation. The family had a long history with DCF with several substantiations for abuse and neglect. Brian was a good student and did not have any disciplinary problems at school. The grandparents had been raising the grandchildren for at least 3 years. 
During the first session the grandmother met with the trauma therapist to complete the intake. Grandmother did not feel her grandson needed treatment; she was abrupt and annoyed to be at the After Care Clinic. Grandmother had "better things to do." The trauma therapist explained that Brian had been sexually abused on multiple occasions and that he was being assessed for trauma due to his recent disclosure of sexual abuse. Grandmother told the trauma therapist that she would do whatever she needed to do to help her grandson. She did not have any symptoms she was experiencing as a result of the disclosure, and Brian was fine.

Grandmother reported that DCF had removed her older grandson, Matt, for abusing Brian and his sister Barbara. Barbara had also been removed from her and her husband's care due to the possibility that Barbara had also been abusing Brian; Barbara had been placed with her biological father and his wife. Grandmother was angry and did not understand why the children had been removed from her home. The trauma therapist talked to Grandmother about the concern regarding the sexual abuse and the need to keep all the children safe.

Matt had been issued a summons and was currently in juvenile detention.

Grandmother believed it was all a "mistake." This week there was a family session with both trauma therapists, Barbara, Brian, and Grandmother. Brian and Barbara shared their feelings about the changes that had occurred in their family as a result of the disclosure. It is important to identify that Barbara had also been forensically interviewed on the same day as Brian. She disclosed that Matt had anally and vaginally penetrated her, as well as performing and receiving oral sex. She denied any sexual contact with Brian during the interview. 
During this session, Brian and Barbara talked about how their separation was affecting them and how much they missed each other. (At this point in the therapy Brian had not disclosed that Barbara had also abused him on multiple occasions, thus the only known perpetrator was Matt.) Both were both worried that Matt was in trouble for the abuse. As all the details of the abuse were not known, Matt had been released from detention and returned to the grandparents' home. However, there were certain courtrelated stipulations that the children must be supervised and never left alone. It became unclear to both trauma therapists during the session whether the grandmother understood the importance or was ambivalent. After the session, the trauma therapist called the grandmother to reiterate that the recommendations of the court must be followed and that it was her responsibility to keep her grandson safe. A call was also placed to Department of Children and Families (DCF) by the clinician to make the DCF investigator aware of this information.

The following session Grandmother arrived late. She was quite angry with the clinician for the call to DCF (the clinician had told her during the phone conversation that she would be placing that call). Grandmother felt this was the biological mother's fault and that she was the problem. Grandmother talked about the history of DCF involvement with the mother and her "crazy sexual behaviors." The trauma therapist asked the grandmother whether Brian's father had followed through with his court-ordered sexual offender evaluation, especially since DCF had temporarily placed Barbara there. Grandmother became enraged and was non-responsive to the trauma therapist during the rest of the session. 
This week Grandmother talked about how hard it was to keep the children's therapy sessions as Barbara, Brian, and Matt all were required to go to therapy. She asked if she could bring Matt to the After Care Clinic. The trauma therapist explained that he was a sexual offender and the After Care Clinic provides trauma therapy for victims of abuse, not the abuser, and he needed specialized sexual offender treatment. The trauma therapist attempted to identify trauma-related symptoms that she was seeing in Brian; however, Grandmother said he did not have any trauma.

This week Grandmother was not at the session. Brian was removed from her and her husband's care. Due to her alleged knowledge of the sexual abuse that was occurring while in her care, DCF took immediate custody of the children.

Grandmother called the trauma therapist and was furious. She stated, "I fulfilled every requirement from DCF." "I brought Brian to therapy and did everything I was supposed to." The trauma therapist confronted the grandmother about her knowledge of the incidents of abuse. She responded to the trauma therapist by saying, "You know how kids are, they think their grandmother knows everything." She told the trauma therapist she would retain an attorney; the trauma therapist explained that that was within her rights; however, DCF currently had custody of the grandchildren and that any future information about Brian's trauma therapy needed to be ascertained through them.

The first session with Brian was spent building rapport and used to begin the trauma assessment. Brian said he was "happy and nothing bothers him." Brian told the clinician that he had "short-term memory loss" and "cannot remember things." He was unable to identify any one feeling that he has. This would be one of Brian's therapeutic goals. 
This week Brian continued to report that he "had no problems and everything was fine." He expressed the inability to recall anything that was negative or upsetting that had happened to him. He was missing his sister, as she had been removed from the grandparents' care and was now in the care of the father. Brian stated, "She was my playmate." The trauma therapist met with the other trauma therapist, Brian, and Grandmother to speak to her to arrange a time for Brian and his sister to visit in a safe way (i.e., supervised). Grandmother agreed to speak to DCF and work with the children's schedules so they could visit. The clinician had a discussion with Grandmother and the trauma therapist regarding the next week's family session (i.e., appropriate responses and the importance of listening to the grandchildren).

Brian thought family session was helpful, and he now understood why his sister was removed and why he could not be alone with his brother. He said his grandmother also told him. He would not share with the trauma therapist what his grandmother told him. At this point Brian's demeanor changed and he began staring into the mirror and refused to talk. When the trauma therapist tried to explore how he was feeling, he pointed to the feelings picture on the wall. (The feelings picture is a group of pictures of children with different facial expressions, i.e., mad, sad, etc.).

Too often, sibling sexual abuse victims are blamed for what happened to them, not only by their perpetrator but also by their parents. When the victim is a child, it is difficult to hold on to the reality of her own experience in the face of denial and blame by other important people in her life (parents and siblings). (Wieche, 1996, p. 57)

Brian pointed to the sad and guilty emotion picture. The trauma therapist explained that this was a safe place to share emotions and feelings and that he was not in trouble. Brian did not speak to the trauma therapist but began to draw a picture and 
wrote, "Grandpa and mad." He would not respond any more during the session. Prior to his unresponsiveness, Brian completed the TSCC.

This week the results of the TSCC were reviewed with the trauma therapist and Brian. The results were not considered valid scores as Brian had underreported his symptoms. For example, Brian scored himself 0-1 in the subscale of anger; however, that was a $\mathrm{T}$ score of less than 35 , which indicated his responses were not accurate. Brian did receive high scores in the area of disassociation, which could not be determined as reliable due to the underreporting. It would not be uncommon for a child with such a traumatic history to disassociate.

The trauma therapist talked to Brian about the importance of sharing the areas in which he was having trouble (i.e., sleeping and nightmares, etc.) if he was going to begin to feel better. The trauma therapist began to work with Brian on body safety. It was during this time that Brian disclosed that his sister Barbara had abused him at Grandmother's and Dad's house on more than one occasion. Brian told the trauma therapist that the grandparents were aware that this had occurred and had walked in on it. The trauma therapist explained to Brian that she needed to let his DCF worker be aware of this information.

The night prior to this session Brian was placed at a Safe Home. His sister was removed from the biological father's home and placed in a Safe Home in another location. This session was focused on stabilizing Brian from the removal from home. He told the clinician that he did not want to visit with his grandparents, but was upset that he missed his visits with his father and his mother. Brian began crying. He reported to the trauma therapist that he "felt good that he told" but was worried that he got his sister in 
trouble and that he was in trouble. The trauma therapist explained that is a common feeling among abused children, but that he did nothing wrong,

During therapy Brian said things were going well; he had not seen or spoken to anyone in his family. The trauma therapist began talking about the abuse and Brian began speaking like a baby and was not using words that made sense. He then began talking about the abuse from both siblings, that it occurred at night. He stated that the oral sex was "yuck" and made a face. Brian talked about letters that his sister would write to him that included sexual content. He said his grandmother found many letters and that he disclosed the abuse to her; his grandmother told Brian she would talk to his sister so she could stop abusing him. Brian reported to the clinician that he had shared $50 \%$ of his secrets.

This session Brian said that he had a visit with his father and stepmother as well as his grandparents (he made a face when he said grandparents). The trauma therapist talked to Brian about the secrets he had; he refused to acknowledge that statement. Later he stated he "would not talk about it today." However, he was able to demonstrate on a chart that his secrets also included embarrassment, anger, and guilt. The trauma therapist identified positive methods of coping, such as coloring and reading.

Brian told the trauma therapist, "It was a good week." When the trauma therapist brought up the secrets, he responded by saying that he "did not want to talk about them for fear of getting someone in trouble." Brian found it the easiest to talk about the abuse from his brother Matt. Brian provided details about the acts that he was forced to perform and that were performed on him. He stated the secrets had not decreased, as he had not told anything "new." 
Brian brought a book to therapy and "thought I would read while you talk." The trauma therapist explained this was not the purpose of therapy and that he had been doing a great job expressing his feelings. Brian was very worried that he would get his sister in trouble. However, he provided details of the abuse to the clinician, but stated he forgot the rest of the secrets (due to his short-term memory loss). His secrets were almost all out of his mind. He was beginning to get angry that his brother and sister abused him; he was also confused. He stated, "Sometimes I am angry and sometimes disappointed in myself." The clinician explained to Brian that he was not at fault and he did not do anything wrong.

Brian was initially resistant to the trauma therapist's attempts to discuss the last secrets. Brian was able to write it down - that the DCF people ruined his life. The clinician and Brian talked about how things had changed and how he had not had adequate time to prepare. Brian talked about the ways things had improved. He told the trauma therapist that the last secrets involved adults. He was afraid he would get them in trouble. The trauma therapist also prepared Brian for his medical exam that was scheduled for the following week. Brian agreed it would "feel good to be checked from head to toe." That way, he reported, he would know he was all right. The clinician began preparing for termination the following week.

Brian told the trauma therapist that he was sad about ending therapy. The trauma therapist identified the good work that he had done in the past 3 months. Brian reported that he was really beginning to feel better. The trauma therapist asked in what ways he felt better. Brian said he was less anxious, sleeping better, and feeling as though he was 
not to blame. The trauma therapist asked Brian why he never reported those symptoms. Brian stated that he did not know that he had them until they were gone.

The Verdict: Brian's perpetrator was a juvenile at the time of his sexual offense. He was transferred from the juvenile court to adult status. He received 20 years suspended sentence, 20 years probation. He will be a lifetime registered sexual offender and was mandated to sexual offender treatment.

\section{Peggy's Story}

Peggy was an 8-year-old female who was referred to the MIT After Care Clinic after a disclosure that her father had sexual abused her by digitally penetrating her. Peggy, her two brothers, and Mom resided in a very affluent community and Peggy would visit her father every other weekend. Although the parents were divorced, the father would often come to the house and have dinner with his ex-wife and children; thus it appeared to be an amicable divorce. Peggy was intelligent and well-mannered; English was the primary language spoken. She loved animals, was a good student, and was age appropriate. Her mother said that Peggy had a lot of friends. Mom was unemotional and detached. She talked about being devastated but did not display any facial expression that would indicate she was upset. She was verbal about her feelings that the treatment might be helpful, but she felt it would be best to just forget it. She thought it would be best not to talk about it. However, DCF had strongly recommended that she bring Peggy to the After Care and that was her reason for attending. DCF did not substantiate the case against Mom.

During the first session, Mom began to complete the intake packet with the

clinician. She was fairly abrupt and somewhat non-responsive to the clinician. Mom did 
not have any symptoms that she was experiencing as a result of the disclosure. It is important to note that the mother was the first person Peggy disclosed the abuse to; Mom responded appropriately and reinforced to her daughter that she did not do anything wrong and was very brave to tell. Mom immediately stopped visitation with the father and contacted the authorities. Mom said her daughter did not have any symptoms that would indicate trauma. The trauma therapist conducted a Basic Needs Assessment, and the family did not need food, shelter, or clothing. Mom was an independent contractor who had always altered her work schedule around the needs of the children. She owned her own home and appeared to be quite successful.

This week Mom said that Peggy was getting to sleep without problem and the "time before bed" was working. Mom, like the other mothers, was feeling confused about the situation, but she was reluctant to talk about it. Mom does not have many friends and family and had not confided in the people she was close with. The trauma therapist shared with Mom that her ex-husband was arrested that morning. The police notify the family once the arrest is made; Mom had received a call from the detective but had not returned it. Mom could not express how this made her feel; she was worried that her daughter would be very upset. Mom was encouraged to tell her daughter, but Mom was adamant that she not be told of her father's arrest.

The trauma therapist began to do history-taking with the mother. Mom was able to identify that one of the reasons for the divorce was that her ex-husband drank a lot. She expressed feeling responsible for the abuse; however, was unable to process her feelings associated to that. She said Peggy had been sleeping through the night. She also told her 
two sons that they would not be seeing their dad for a while. She had a difficult time doing this, but she told them he did some "bad" things to Peggy.

Mom was surprised that Peggy would bring up the abuse. The trauma therapist talked to Mom about appropriate responses and ways to handle additional information. Mom, it appeared, was saying helpful things to Peggy, such as, "It's not your fault," "I am glad you told me," "You are safe," etc.; however, the trauma therapist expressed the importance of letting her know it is okay to talk about it. Mom thought that would be difficult for her, but she would try. She just wanted to forget about it. Mom said that Peggy was asking questions about her dad and she was considering telling her about the arrest. The trauma therapist explained that oftentimes the trauma therapist could assist with telling the child if that would be helpful. Mom was clear that she did not think that would be helpful. The trauma therapist began to prepare her for the family session next week. The trauma therapist also shared with Mom that Peggy struggles with identification of feelings and that she could be a good role model by sharing her feelings during that session.

This was a family session with Mom, Peggy, and the two trauma therapists. Mom had told Peggy about her father's arrest and that Peggy told her she was "glad she was told." The trauma therapist explored the importance of sharing information and communicating with each other, as well as identifying feelings. The mother's trauma therapist explored how the arrest made Mom feel. Mom reported that although she wanted him to be arrested, she was saddened by it; Peggy told her that she felt the same way. The trauma therapist helped Mom explore what about the arrest was making her sad. She told her daughter that she felt guilty that she had not protected her and was sad 
this happened to her. Peggy told her she felt like this was "all her fault." The mother was able to tell her daughter that it was not her fault and that what her dad did was wrong. For Peggy and her mom having this opportunity to process their feelings of guilt and blame was necessary to their recovery. This was a turning point for both Mom and Peggy in their recovery. Being able to express feelings was difficult for both of them, but, once they were able to identify the feelings, the trauma therapists were able to help them begin to heal.

This week Peggy was sick and Mom cancelled, similar to the other families. Mom told the trauma therapist that Peggy had been worrying that her dad was "mad" at her. Mom was struggling with her feelings about the abuse. Mom disclosed to the trauma therapist that her sister had been abused by their older brother and was wondering whether her sister would be helpful to Peggy. The trauma therapist explored the relationship with mom and her sister and questioned whether Peggy was aware that her sister had been sexually abused. Mom said her sister had called and she had shared with her sister Peggy's abuse. Her sister had offered to talk to Peggy and she shared her story; Peggy asked that she come for a visit. Although her aunt lived in the Midwest, she agreed to come and would be there the following weekend. The trauma therapist expressed to Mom what a great job she did reaching out for support and that this visit seemed to be something she was looking forward to. Mom was so glad she told her sister; the trauma therapist was able to connect that to the relief Peggy must have experienced when she told her about the abuse. This was the first time Mom told anyone about the family secret. The trauma therapist role modeled appropriate responses and provided support for Mom. 
Mom thought the visit with her sister went well, and her sister was helpful to Peggy. Mom noticed that Peggy seemed to be happier and was asking to have friends over and wanting to go out more. Peggy had not had any difficulty sleeping. Mom and Peggy did not write the letter because Peggy decided she wanted to write it in therapy. Mom was provided with information about the upcoming medical exam for Peggy as well as the Office of Victim's Services to answer any questions pertaining to her exhusband's arrest. He had not bonded out and was still incarcerated.

This week Mom was feeling upset that Peggy told her friend about the abuse. Mom expressed worry that Peggy would share this information and it "would change how people thought of her." The trauma therapist explored how this impacted Mom and her feelings about the abuse.

Mom talked about her ex-husband's release from jail; she was worried that her daughter would want to see him. Mom talked about the possibility of supervised visits for the boys and Peggy. Mom was beginning to worry that Peggy would have to testify against her father. The trauma therapist talked to Mom about the court system; Mom stated she was not sure she would let Peggy testify. She would "rather he go free" than that. The trauma therapist talked to Mom about the possibility of other children being abused if he went free. Mom wanted him to get "help" but did not want Peggy testifying. This was similar to the feelings expressed by the other mothers.

In the family session with Mom, the two trauma therapists, and Peggy, both Peggy and Mom reported that things were going well—no difficulty sleeping or nightmares. Peggy told her mom that she had been thinking about the abuse during the 
day and now was beginning not to think about it much. Peggy wanted to call her aunt; Mom told her she could later that day.

The following week Mom had been busy as the boys were involved in sports. Things were beginning to get back to normal. Mom stated that she was the only parent to take the kids to activities, so that had not changed for her. She said the boys had asked for more information about what their dad did. Mom told the boys about his touching Peggy. Peggy became very upset about her telling them. The trauma therapist worked with Mom on understanding that was Peggy's information and that she may need to give her permission before Mom told anyone. Mom said she would talk to Peggy and felt badly that she had upset her. No sleep issues were reported. Body safety was addressed along with ways Mom could continue to protect and teach her daughter to protect herself. Mom talked to the clinician about how much better she was feeling. She said that originally she just wanted Peggy to forget this happened so that she could forget too. She confessed that she first thought this (the MIT After Care Clinic) would be a "waste of time" but that it had "saved their lives."

The first session Peggy was unaware of why she was being seen. She had been told that her Mom just said she had to talk to a "lady." Peggy said she got nervous when she realized it was the "same place that she talked to someone else about her dad." The trauma therapist talked to Peggy about why she was there and that her (the clinician's) job was to help kids understand and feel better about the abuse. Peggy said she had no feelings about it. Peggy was able to express that she could not sleep and frequently woke up scared throughout the night. Peggy was having bad dreams nightly; she had not told her mother. The trauma therapists, Peggy, and her mom met to discuss the bedtime 
difficulties that Peggy was having (i.e., unable to sleep, fearful). Strategies were formulated that would help encourage her to seek her mother's support during the night, as well as Mom checking in on her at night. A more definitive bedtime routine was established. Mom was receptive to the strategies.

Peggy was getting to sleep better and "likes" having her mom tuck her in. Peggy really missed her dad and wished that things would be like they were before the abuse. The trauma therapist was able to clarify that the abuse started after the divorce and began to help Peggy recognize she was not at fault. The Trauma Symptom Childhood Checklist (TSCC) (Briere, 1996b) was completed.

This week Peggy talked to the trauma therapist about how much she missed her father and wanted to know how he was doing. Peggy contradicted herself and said that she did not care that she had not seen him. The trauma therapist talked to Peggy about why she thought she did not see him anymore. Peggy said it was because of what he did to her, but wondered if that was her fault. The trauma therapist worked with Peggy about the abuse not being her fault and that it was her dad's fault. The trauma therapist also tried to work with Peggy on identification of feelings associated with the abuse, but Peggy was unable to identify a feeling. The trauma therapist identified that when her TSCC was scored it was not valid as it showed that she was not ready to talk about her feelings. Peggy agreed with the trauma therapist that she was not ready to talk about feelings yet; a plan of slowly implementing "feeling talks" into therapy was developed.

This week Peggy was unable to identify feelings associated with the abuse, so the trauma therapist and she worked on identification of body reactions to the abuse. For example, did she get stomach aches or headaches? Peggy asked, "How did you know 
that?" The trauma therapist was able to help Peggy try to connect the physical/somatic complaints with how she was feeling. Peggy agreed to write in a journal if she was not feeling well and would try to identify what she was doing or thinking before she felt sick. Peggy told the trauma therapist she had thoughts about the abuse while she was at school. Peggy relayed to the trauma therapist the conversation with her aunt. She and the clinician came up with a list of questions she wanted to explore, some of which included how she felt. Peggy spent time talking about missing her father. The trauma therapist identified that as a common feeling by kids; Peggy, like all the children seen at the After Care Clinic, identified feeling confused. This was processed in the session. Peggy identified that she thought it would be helpful to write her dad a letter. The trauma therapist and Peggy met with Mom to discuss this; Mom agreed to help her write the letter.

Peggy talked about her aunt's visit and what she found helpful from talking to her. Peggy stated that everyone told her it was not her fault, but after talking to her aunt she was beginning to believe it. Peggy wanted to write her dad the letter; she was able to identify feelings of anger and sadness as well as missing him. She did not wish to send it but decided to "hold on to it." The trauma therapist continued working on coping skills to help Peggy during the day when she thought about the abuse.

Peggy talked about telling her friend what happened and that her Mom was upset that she told. Peggy was confused by whom she could tell and whom she could not. The clinician worked on having Peggy identify adults whom she could talk to about the abuse. Peggy was sleeping and feeling better. She was also able to ask Mom questions and talk about her feelings more. She said that has been "great." She asked the clinician if they 
could meet with Mom so she could ask when she would see her dad. Peggy said that her mother told her she would have supervised visits and she wondered when they would start. The two trauma therapists, Mom, and Peggy met, and Peggy was able to ask her questions. Mom seemed surprised that Peggy remembered her saying that she could see her dad again, but would look into it. The trauma therapist explained to Peggy that it might be a long time before a decision was made and that was to continue to keep her safe. Peggy said that was "fine."

This week Peggy was unhappy Mom told her brothers. She stated she was very embarrassed by this and was "angry with mom." The trauma therapist helped Peggy to appropriately tell her mom how she felt. Peggy said she had written that in her journal; she felt fine and thought she would have a stomach ache, but did not. The two trauma therapists, Mom, and Peggy met, and Peggy was able to share how she felt. Mom apologized and had tears in her eyes.

At the last session Peggy was sad about ending therapy but said that she was ready to end. She no longer thought she was to blame. She also reported she was uncertain whether she would want to see her dad again, but would think about it. Body safety was discussed.

The Verdict: Mom reports that she and Peggy are doing well. The perpetrator (Dad) had taken a plea rather than going to trial. On the day of the sentencing Mom had written a long statement, which she read to the judge. What was unusual was that, in most cases, the secondary victim (NOP) often asks for additional jail time and punishment. Mom told the judge that she wanted her children to have some type of relationship with their dad and if he were taken away for many years that would impact 
them. The judge, in his Memorandum of Decision, took that into account, but identified he did not agree that the perpetrator should get a lighter sentence. The judge, however, did grant a lighter sentence. Peggy's father was sentenced to 10 years suspended after 30 months served and 5 years probation. Peggy did not testify, as the father took a plea.

\section{Peter's Story}

Peter was an 8-year-old boy who was in regular education and was referred to the MIT After Care Clinic by DCF after a disclosure of sexual abuse by his father. Peter was in third grade and to date had not had any major school-related issues. It is important to note that both of his cousins had been forensically interviewed, as Peter's father had vaginally and digitally penetrated both female cousins. Peter was ordered to watch the abuse as well as having acts, such as oral sex, performed on him by his father. Peter was a shy young boy who did not speak much. English was his and his mother's second language. His mother was very angry about the abuse and wanted her ex-husband to go to jail. Mom had a high-school diploma and worked in a local factory, often midnights until morning. At home resided Peter, his mother, and his 19-year-old sister, who was attending college to become a teacher. He had another brother who lived in New York and who rarely visited home; he was also in college. The family had prior DCF involvement due to the father's abuse of the cousins; the girls first disclosed the abuse and later Peter disclosed after the girls talked about Peter being present. Peter's disclosure was reluctant, and it was the hope that additional information would be shared during therapy. Peter appeared to have internalized the feelings and worked hard at being "perfect." 
Mom met with a Spanish-speaking trauma therapist to conduct the intake. Similar to the other non-offending parents, Mom shared that she was angry and overwhelmed. She did not have much food or clothing and was worried about losing her housing; the trauma therapist assisted Mom in identifying resources to help. Mom told the trauma therapist that she did not think the abuse had affected her son much; this is difficult to articulate for any parent, as it was the first sign of acceptance that her son was abused. She stated that he was the same now as he was before. This was a commonly expressed feeling by the non-offending parents when asked about symptoms.

Mom met with the trauma therapist, who completed the intake and history-taking. Mom reported serious domestic violence in the home by the father. She had never really dealt with it, and that this was bringing up a lot of her past issues. The trauma therapist provided Mom with names of free clinics in the area to provide assistance for victims of domestic violence. Mom stated she had seen a change in Peter and that he seemed to withdraw from others. She said that the school had identified this as an issue, but she thought he was just shy.

This was a family session with the two trauma therapists, Mom, and Peter. Peter was able to share with his mother how fearful he was of his father and the threats his father had made to him. Mom was able to assure Peter that she would keep him safe. Mom told Peter that before his dad was arrested she had a protective order that ordered the father to keep away from Peter, his sister, and Mom. The trauma therapist asked for Peter to see a copy of this, which Mom agreed to do later that day. Peter shared with his mother how poorly he slept and that he felt safe only when she was there. Mom agreed to ask whether she could change her work schedule; however, that might not be possible. 
In the interim, a plan was devised to assist Peter in a bedtime routine that his Mom would work with his sister to implement. Results of the TSCC (Briere, 1996b) were reviewed: Peter scored highest in the areas of depression, anxiety, and PTSD, which appeared consistent with the behavior and emotion that were observed by the clinician.

In the next session Mom shared with the trauma therapist how scared she was of the father. She said that Peter has witnessed the father trying to strangle her on various occasions. She was concerned about having her son or the cousins testify against him; she feared he would kill them all. She understood why her son was so fearful and wished that she had left the father earlier; maybe he would not have sexually abused any of the children.

Like each of the other non-offending parents, Mom did not show up to the After Care Clinic nor did she call to cancel her appointment.

Mom was overwhelmed with too many things and forgot about last week's session. This is a recurring theme for each of the non-offending parents that must be addressed by the clinician in order to assist the non-offending parent in taking control of the situation. The importance of trauma therapy was reiterated by the trauma therapist. Mom said that Peter is "sleeping fine" and that he does not think about the abuse or being afraid anymore. She reported this in front of her son, who looked at the floor. The trauma therapist met with Mom, who expressed that she just wanted this behind them: "Peter needs to forget it happened and she wished the cousins would do the same." The trauma therapist talked to Mom about the need for trauma treatment and that her son had been a victim and that it was important to encourage him to share those feelings in therapy so he could heal. 
This week Mom had switched to a day shift one day, and when she was home that night Peter was up the whole night. Mom said she stayed with him until he fell asleep. Mom was concerned about his lack of sleep. Mom felt guilty that she had not left the perpetrator sooner, but stayed because he told her he would kill her if she left.

Mom reported that initially she was very angry with the trauma therapist but did want to help her son. She agreed to keep the appointment and think about the recommendations. The trauma therapist talked to Mom about what to expect at the forensic medical exam and provided Mom with the information for the Office for Victim's Advocate.

The next session was a family session with the two trauma therapists, Mom, and Peter, in which Mom expressed concern about Peter. She told the trauma therapists that he had wet the bed last night. Strategies were identified to assist Peter at home and at school due to Peter's intrusive thoughts (per Peter's report). Peter was able to identify that he has a lot of secrets but was not going to share them. The trauma therapist working with Peter identified that Peter continued to appear depressed. The trauma therapist asked Peter what he thought about last week's evaluation at the hospital and that medication might help him. The trauma therapist explained that the medication would not make the pain of the sexual abuse go away; however, it could be helpful in relieving some of the depression and sadness. Once those feelings began to improve he may be better able and willing to address his sexual abuse, thus start feeling better overall. Mom reiterated that she was not comfortable with medication; Peter asked that she think about it so he could "get better." Both trauma therapists worked with the family to assist in providing realistic methods for the mother to engage with and enable her son to feel safe. 
Peter expressed feeling "unsafe" at home, worrying that he and his family would be killed. There had been an ongoing dialogue with the trauma therapist and DCF regarding the need for Peter to be evaluated, as this was an "open case" with DCF, due to the pending investigation. The DCF worker would meet with the mother regarding this issue.

Mom told the trauma therapist that she was going to continue working on the night shift. The clinician suggested that her daughter come to the next session so she could hear some of the strategies that Peter needed at bedtime. Mom reported that she (the daughter) would not be able to attend, as she works. The trauma therapist asked for the daughter to call her to discuss. Mom had not followed through with the recommendation from the psychiatrist for medication; however, she was considering the other recommendation from the psychiatrist (and Peter's trauma therapist) that Peter engage in intense outpatient therapy upon completion at the clinic. Mom had not spoken to anyone from the court and expressed that she continued to worry and be afraid. She reported that she had been feeling sick lately. She also reported that DCF was coming for a visit later that day.

Mom cancelled another session.

This week Mom told the trauma therapist that things had dramatically improved at home; she reported that her daughter stated Peter is sleeping through the night and that she felt this was behind her. She told the trauma therapist that if Peter needed to testify she did not think she would allow him to, but was aware that the cousins had agreed to testify if needed. Mom expressed that it would be too much for Peter. As the criminal proceedings were at least a year away, Mom was encouraged to have Peter go to the 
Outpatient Clinic and to begin a medication trial. Mom agreed, although it was unclear whether she followed through with the recommendation.

Peter was not aware of the reason for starting therapy. He stated he remembered being in the room before but that he did not remember what he talked about. The clinician explained why his Mom brought him to therapy and that she was concerned about how the abuse had affected him. Peter stated he did not want to talk about the abuse because it scared him. The trauma therapist asked what was scaring him; Peter stated he did not want to say. The trauma therapist assured him that he was not there because he was in trouble and that he had done nothing wrong. Peter reported that he could not sleep and was "really" worried about his mom. Peter would not elaborate to the clinician why he was worried. He just wished he could fall asleep. The trauma therapist and Peter came up with strategies to assist Peter in sleeping and discussed them with Mom. Peter said it would help him to have lights on during the night and for his sister to stay with him until he fell asleep. He also needed to see that the doors were locked and wanted to have another lock put onto the outside door to help him feel safe.

This week Peter still could not sleep and said that his mother working midnights was difficult for him. He said his sister was "nice," but he did not think she could protect him. The trauma therapist asked Peter what he needed protecting from. Peter told the trauma therapist that he was afraid of his father, because his father had threatened to kill him (Peter), his mom, his sister, and his brother. The trauma therapist discussed safety with Peter and that his dad was in jail. (Peter was aware that his father had been arrested and was in jail, shortly after his cousins disclosed abuse.) Peter expressed feeling as if it were up to him to protect the family. This was discussed with Peter as well as preparing 
him for the next week's family session. Peter completed the TSCC (Briere, 1996b), and the clinician and Peter talked to Mom about her being responsible for his safety and that Peter was not responsible for keeping his mom and sister safe.

Peter reported that his uncle had flown in from Costa Rica to provide support to his mom and aunt (cousins' mom). He was disappointed that his mother had not been able to follow through on any of the suggestions (i.e., she had not shown him the Protective Order, nor had she implemented the bedtime strategies or door lock). He said she was just too busy to do these things. He reported that the nightmares had increased and he was afraid to go to bed. He thought that having his uncle there may help him feel safer. The trauma therapist met with Mom to impress on her the importance of her following through. Mom promised her son she would do everything that day.

This week Peter told the trauma therapist that "everything was fine." He also reported that he did not have nightmares anymore. "He just wants to forget it." Peter refused to speak to the clinician; he drew a picture, then ripped it up.

Peter was non-responsive during most of the session. The trauma therapists, Mom, and Peter had a meeting in which the trauma therapist suggested to Mom that Peter receive a psychopharmological evaluation as he seemed very depressed. Mom stated that she was against medication and would not take him anywhere to be evaluated. The trauma therapist talked to mom about the importance of this and while Mom was there the trauma therapist called and made the appointment. Mom agreed to take Peter, although she was clearly dissatisfied with having the evaluation appointment made.

Peter talked about the abuse a lot but told the trauma therapist that he was beginning to feel as though the abuse was not his fault. At first, he thought it was his fault 
for not protecting his cousins, or his Mom when his dad would hurt her, but now he thinks that it "was his dad's fault." He wondered what was wrong with his dad and why his dad hurt everyone. "Why couldn't his dad be like the other dads?" The clinician told Peter that he was not responsible for protecting his cousins or his Mom; he was an 8year-old boy who was protecting so many other children by disclosing the abuse. He could not have protected his Mom; she was there to protect him. The trauma therapist identified ways that she was starting to protect him.

The trauma therapist and Peter processed the family session as well as continued to work on identification of feelings and body safety. Peter was unable to share the "secrets" he had, but did report that they were not interfering with his thoughts as much as they "used to." Peter was using some of the coping strategies that had been talked about it therapy. Peter was unable to provide the trauma therapist with any more details about what strategies he was using. The trauma therapist began termination with Peter.

Like the other children, Peter was feeling sad about ending trauma therapy, but was also happy that it was over. He was feeling better than when he first came to trauma therapy, but was still fearful and worried. The trauma therapist encouraged him to talk to his mother about his feelings and to share them with the therapist that he would have after the After Care Clinic.

The Verdict: As there were multiple victims, there were several charges that were filed. The perpetrator went to trial because he would not accept a plea; he pled not guilty to all accounts. The following are the charges:

1. Sex 1

2. Illegal Sexual Contact with a minor 
3. ROI Risk of Injury to child

4. Illegal Sexual Contact with a minor

5. ROI Risk of Injury to child

6. Illegal Sexual Contact with a minor

7. ROI Risk of Injury to child

8. Illegal Sexual Contact with a minor

9. ROI Risk of Injury to child

10. Illegal Sexual Contact with a minor

11. ROI Risk of Injury to child

12. Sex 1

13. Illegal Sexual Contact with a minor

14. ROI Risk of Injury to child

15. Illegal Sexual Contact with a minor

16. ROI Risk of Injury to child.

Each charge held various maximum sentences. Peter's father was found guilty on all accounts and sentenced to 32 years. 


\section{CHAPTER 5}

\section{CROSS-CASE ANALYSIS}

\section{Introduction}

Chapter 5 answers the research questions through the data obtained from nonoffending parent sessions, child sessions, and family sessions. These families' stories provide insight into their experience at the MIT After Care Clinic. They have shared how the disclosure of sexual abuse has affected their lives, as well as the components of care and strategies provided by the MIT After Care Clinic that assisted in family stabilization overall.

Child sexual abuse is a significant problem that requires attention. The disclosure of sexual abuse from a child can be a life-altering experience that requires prompt response and skill to provide the child the opportunity to share their story. The forensic interview is essential for law enforcement and prosecutors to seek justice on behalf of the victim. Follow-up care for the victim and families is essential to the overall prognosis of the family. Additionally, for many victims, having the perpetrator convicted is significant in their healing.

Prior to 2006, in the state of Connecticut, children who were forensically interviewed by their Regional MIT were referred to community providers for trauma therapy. The MIT did not have the ability to follow up on the cases or to know whether trauma therapy was successful. The families of the victims were provided with names of 
areas support services for their own support, but the trauma therapy for the child and the non-offending parent were not connected. The Danbury Connecticut MIT After Care Clinic opened September 1, 2006; it remains the only such facility in the state.

From September 1, 2006, to December 31, 2006, 22 children were forensically interviewed by the Danbury MIT. Of those 22 children who were interviewed, two victims attended the After Care Clinic. Both offenders were found guilty and sentenced to prison. It is important to note that both of the two cases did not meet criteria for this study. The child had been a witness to a murder, not a victim of sexual assault. The second case was a sexual abuse case, but did not meet criteria for this study, because the forensic interview was not conducted by the Danbury MIT.

From January 1, 2007, to December 31, 2007, the Danbury MIT forensically interviewed 33 children. Fourteen of the 33 children received treatment at the After Care Clinic. The outcome of the 14 cases is as follows: three separate cases (all siblings) had the same perpetrator, who was a juvenile. The case was transferred to the adult court and he (the perpetrator) was convicted; he is currently imprisoned. Two cases (both siblings) had the same perpetrator, who was also a juvenile. His case was also transferred to adult court and he was convicted. The perpetrator was sentenced until his $21^{\text {st }}$ birthday at a locked treatment facility for sexual offenders. In two cases there was no arrest, because the disclosure of abuse lacked sufficient evidence for the police to pursue an arrest. Four cases involved separate juvenile perpetrators who each received a summons to juvenile court where they were either remanded to detention or for sexual offending treatment. Three adult offenders were convicted. In sum, 11 cases that received treatment at the MIT After Care Clinic had prosecutions on either the juvenile or adult level. 
During the time period of January 1, 2008, to December 31, 2008, 49 children were forensically interviewed by the Danbury MIT. Twenty-two children were seen at the After Care Clinic. The prosecution of those cases is still pending at the time of this writing.

At the time of inception of the After Care Clinic, the treatment modality identified was Trauma-Focused Cognitive Behavioral (TF-CBT). Since that time, the treatment model has been manipulated to better serve the victims and their families. Although Trauma-Focused Cognitive Behavioral continues to be used as the primary trauma therapy model, the MIT After Care Clinic has found that the children and families serviced have varying needs that need to be addressed, therefore modifications have been made to the trauma therapy, depending on the child or non-offending parent being seen.

The families are serviced immediately post-disclosure; therefore, most have a pending criminal case against the perpetrator. That is a major stressor for each of these families that must be explored. The uniqueness of having two clinicians who are forensically trained and providing treatment simultaneously is a variant from the traditional TF-CBT. However, the success of the TF-CBT must be highlighted and the strategies are often utilized with the children at the After Care Clinic.

The After Care Clinic has been successful in engaging the children with strategies that have minimized trauma symptoms. Additionally, the relationship that is formulated between the child and clinician provides a safe and empathetic environment that promotes growth and healing. Similarly, the relationship between the clinician and the non-offending parent assists in overall stabilization with skills learned that continue posttreatment. These skills are later seen in the non-offending parent's ability to seek justice 
through the courts on behalf of their child. Each of the children in this study learned that their sexual abuse was a terrible thing that happened to them, but it does not define them.

This is a single-subject qualitative research study and includes narrative descriptions of data that were collected through intakes, therapy sessions, and observations that were recorded at the MIT After Care Clinic's clinical cases notes after each session. All data used are secondary. The children attended approximately 12 trauma therapy sessions with their non-offending parent. Only cases where the child had been sexually abused were used and the sampling was purposeful. This study consists of a total of 7 children who met the following criteria: (a) the child disclosed sexual abuse, (b) the child was forensically interviewed by the Danbury Connecticut, MIT, (c) the child attended the MIT After Care Clinic, (d) law enforcement applied for an arrest warrant of the perpetrator, (e) the court accepted the warrant application, (f) the perpetrator was arrested, and (g) the case was heard by the Danbury Superior Court. Cases that did not meet these specific criteria were not used. Data were organized by the case notes to identify connecting themes, patterns, and categories. Coding occurs at two levels: identifying information about the data and interpretive constructs related to the analysis (Merriam, 1998). The data were examined and re-examined to ensure that the themes identified were most prevalent. The themes contribute to the existing literature on the Traumagenic Dynamics of Sexual Abuse (Finkelhor \& Browne, 1985), the Child Sexual Abuse Accommodation Syndrome (Summit, 1983), and the effectiveness of the TF-CBT (Cohen et al., 2000) in trauma treatment; adding to the importance of understanding these dynamics and practices to provide treatment to trauma survivors. The findings of this study add to the existing literature on the need for immediate engagement in trauma 
therapy (Everson et al., 1989; Hunter et al., 1990, Pellegrin \& Wagner, 1990), the importance of maternal support and the child's stability (Keeble, 1993), and therapy strategies that are useful in working with victims of sexual abuse (Gil, 2006).

\section{Research Question 1: How Did the Children Experience the MIT After Care Clinic?}

The stories shared by the victims have been filled with pain, grief, and loss. Trauma treatment can be an intense experience for the child that elicits various feelings and emotions.

\section{A Place to Let Go}

An analysis of the children's stories provided several themes that were woven throughout. These themes were illustrative of feelings that needed to be identified and addressed. Separately, each of these emotions may mean something different to each child, as their experiences vary. Yet each child is a survivor, trying to let go of their pain and to heal so they can move forward in their lives.

\section{Anger}

The rage that the children felt from being betrayed by a trusted individual can be devastating. Family members victimized Brian, Peter, Paige, Peggy, Lisa, and Samantha. A sibling abused Samantha, and Brian was abused by his two siblings simultaneously. Paige, Peggy, and Peter were all sexually abused by their fathers. A trusted babysitter violated Kate, and Lisa was abused by her cousin. Paige, Lisa, Samantha, and Kate all demonstrated their anger through hitting or kicking. Paige, Lisa, and Kate were between the ages of 3 and 6 years old; although Samantha was 13, she was developmentally 
delayed and demonstrated behaviors similar to the younger victims. Paige would "hit" her sister, Lisa and Kate would "hit" their brothers, and Samantha would engage in physical altercations with her sister. Peter and Peggy were 8 years old, Brian was 10 years old, and each of them verbally expressed feeling "angry" or mad. Lisa drew a picture symbolizing the anger and then ripped it up, and Peggy wrote her father a letter expressing her feelings of anger. When the offender is a trusted person, feelings of anger must be identified and addressed or they will be expressed in unhealthy ways. Each of the children dealt with their anger in individual ways at the After Care Clinic, but each felt a release in the anger at the end of treatment.

It is not uncommon for young victims of sexual abuse to exhibit acting out behaviors. These behaviors are demonstrated in the form of aggression (i.e., hitting, punching, etc.), while the older victims manifest in other ways (promiscuity, defiance, substance abuse). During the course of treatment the clinician is often able to help the non-offending parent identify when the behavioral changes occurred. It often coincided with the onset of the abuse. "From the child's point of view the essence of trauma is the loss of control. Following the trauma, many children's own controls fail them. They may cry more over little things, make angry demands, show more aggression, test limits and rules" (Monahon, 1993, p. 111). Essentially, the child victim has been conditioned that when two people are together, one will be hurt. Oftentimes child victims may "bully" other children and become aggressive in other ways. It is important for child victims to have a safe outlet to feel and experience their anger so they do not carry it with them. "An ability to acknowledge or express anger can result in profound depression" (Camino, 2000, p. 55). The therapeutic intervention of connecting thoughts with actions 
was useful in reducing the negative acting-out behaviors. It was essential that the clinician working with the victim understood the Traumagenic Dynamics of Sexual Abuse (Finkelhor \& Browne, 1985) in order to assist the child in understanding the betrayal they had endured, which is important in the healing process.

\section{Grief and Loss}

Each child was faced with grief and loss in various capacities. Each of the children's offenders was sentenced to prison or treatment, and the children were faced with losing either a loved family member or friend. The children were subjected to sexual experiences that were age inappropriate, and their knowledge and experience of sex became distorted as a result. The victims needed to grieve what was taken from them. Lastly, trust was gone and the children needed to find a way to have an experience in which they could trust an adult. For Peter, Samantha, and Brian, this meant sharing their secrets with the clinician. For Peggy, Paige, Kate, and Brian, it was missing their relationship with the offender, despite the abuse, and being able to process how that would affect them. Additionally, the feelings associated with the non-offending parent not protecting them needed to be re-established. A sense of trust needed to be built again so the child and non-offending parent could heal; this was done during the family sessions.

Unresolved grief and anger can lead to depression. Grieving is a normal response to a loss. A child who has been abused experiences various types of loss. The loss of their innocence, as well as the loss of a loved one (i.e., the perpetrator or changes in the intact family), loss of trust, loss of joy, and loss of healthy sexual knowledge and selfesteem can all result from the abuse. "In some cases, as in sexual abuse, the loss of a 
secure relationship with the parent can be quite sudden and expected....Victim's grief is delayed because most abused children learn how to adapt to even astonishingly difficult circumstances in order to survive but they do pay a price" (Bloom, 2000, p. 1).

\section{Worry}

The experience of feeling guilt and blame for being victimized or getting the offender in trouble was evident in the children. Many of the children were told it would be their (the child's) fault if they told and then the offender went to jail. This leads to even more confusion, which, like the other feelings of guilt and blame, often manifests itself as anxiety. Samantha, Lisa, Brian, Peggy, Kate, and Peter all expressed worry and concern during the course of treatment. Brian, Kate, and Peggy wondered if they were "in trouble or did something to get someone in trouble." Peter worried that "his family would be killed." Samantha, Kate, and Brian were confused by everything that was happening, and Peter, Kate, and Brian blamed themselves for being victimized.

Children sometimes believe (or were taught) that they were responsible for attracting the abuser and causing the abuse. Children may feel responsible for attracting the abuser and causing the abuse. Children may feel overly responsible, believing that they should have stopped it or disclosed it. (Otis, 2002, p. 146)

The worry that each child shared was for different reasons, but the children did not have the skills to cope with the stress. Lisa, Peter, Samantha, Kate, and Brian all had stomach aches and were somatic after the abuse. At the end of treatment, each of those symptoms had subsided, as had their anxiety. The MIT After Care Clinic provided a place to let go of unhealthy feelings. 


\section{Feeling Better}

The children all came to the MIT After Care Clinic with trauma-related symptoms. Lisa, Peggy, Paige, Kate, Peter, Samantha, and Brian all had nightmares and experienced difficulty sleeping. "Many PTSD clients report sleep disturbances particularly with nightmares related to the trauma and the heightened arousal symptoms which prohibits the client from falling asleep and staying asleep" (Schupp, 2004, p. 63). Peggy, Lisa, Paige, Peter, and Samantha would think about the abuse during the day and night. Lisa and Paige would urinate on themselves. At the last session at the MIT After Care Clinic, each child expressed "feeling better," and Peggy, Paige, Peter, Samantha, and Brian all expressed feeling "sad about ending therapy," but each expressed feelings of "hope" about their future (Munson \& Riskin, 1995, p. 17).

\section{Research Question 2: In What Ways Did the Non-Offending Parent Describe Their Experience After the Sexual Abuse Disclosure?}

The stories shared by the families were illustrative of the hardships and challenges faced during times of emotional devastation resulting from a child's disclosure of sexual abuse. Seven families were used in this analysis; however, it is important to identify that Brian's grandmother was involved minimally in the trauma therapy at the MIT After Care Clinic as she emerged as a co-conspirator in allowing her grandson to be perpetrated by his siblings.

The analysis of the seven non-offending parents provided themes that emerged from the parents: initial disbelief/denying the significance about the abuse, feelings of guilt, feelings of isolation, worry about the legal system, feeling overwhelmed, and reliving past issues. The importance of the joint sessions was essential in helping the 
child heal (Cohen et al., 2000). The MIT After Care Clinic varied from that model slightly by having two trauma therapists, one meeting with the child and one meeting with the non-offending parent at the same time. "The most striking finding with regard to the impact of familial mediating factors was the importance of parental emotional support given to the mother and to the child by the mother in predicting a more positive outcome" (Cohen \& Mannarino, 1998, p. 47).

Initial Feelings of Disbelief or Denying the Significance of the Abuse

Of the non-offending parents, Kate's mother was the only one to fully accept her daughter's disclosure, while the remaining families had difficulty acknowledging the significance of being sexual abused. However, Kate was the only victim to have been sexually abused by a non-family member as the neighborhood babysitter victimized her. Although a non-family member also raped Samantha, she had also been sexually abused by her brother, which during the course of treatment emerged as her primary traumatic event.

Only Paige's mother stated that she initially did not believe her child's disclosure of sexual abuse. During treatment Paige's mother expressed that "initially I did not believe Paige and defended my ex-husband, but over the course of trauma therapy I came to believe the allegations." Paige's mom spent the session vacillating between wanting to believe the disclosure and feeling that it "could not be true." Ultimately, she came to believe her daughter and protected her and her sister.

During the first treatment sessions, the rest of the non-offending parents reported that their children did not have trauma-related symptoms resulting from the sexual abuse. Samantha's mother said she "does not think she [Samantha] had any trauma related to the 
abuse." She did state that Samantha was having "difficulty focusing" but "thought that it was mainly due to the Attention Deficit Hyperactivity Disorder (ADHD)." Lisa's parents were "in shock." Brian's grandmother said that "her grandson [Brian] did not need treatment." Peggy's mom told the trauma therapist that "her daughter [Peggy] did not have symptoms that would indicate trauma." Peter's mother "does not think the abuse has affected her son much.”

These themes were all reported at the first meeting, when the trauma therapist asked about symptoms. As the trauma therapy became more intensified and the families began to engage and trust the clinicians, the non-offending parents began to identify behaviors or emotional changes they were observing.

Review of the literature has suggested that the initial non-offending parent's response is similar to the grieving process. And the non-offending parent will go through the stages from denial to anger and depression before accepting reality.

The initial reaction is often shock and denial. This may be momentarily for some, while others refuse to believe the abuse could have taken place. Non-offending parents who continue to deny the abuse could have taken place may need considerable therapeutic intervention before they accept their child's allegations. Some mothers are never able to acknowledge the sexual abuse and resist all efforts to be engaged in treatment. (Keeble, 1993, p. 12)

\section{Isolation}

Several of the non-offending parents who attended the MIT After Care Clinic expressed feeling isolated and alone after their child's disclosure of abuse. The need for support was evident. The personal nature of their child's disclosure often prohibited the NOPs from seeking support. However, some of these parents expressed that when they did try to tell a friend that the friend "did not want to hear it." Paige's mother appeared to 
have the most support and assistance from her mother. Paige's mother had preestablished coping strategies that she utilized after her daughter's disclosure. Mom was able to identify strategies that she found useful in taking care of herself (i.e., jogging, getting a manicure, etc.). The other moms had trouble identifying ways to take care of themselves.

Lisa's mother's support system prior to the disclosure was her sister (the perpetrator's mother). When Lisa disclosed her cousin had sexually offended her, Lisa's aunt as well as other family members would not speak to Lisa or her family. This resulted in Lisa's mom feeling very alone and isolated. During the times the extended family would speak to Lisa's mom, it was to try to coerce her to "drop the charges."

Samantha's mother expressed feeling like she was "alone" and did not have anyone to talk to. Hank was rarely home, and when he was home they just fought. Kate's mother expressed that her husband was a support to her, but she reported feeling stressed that the other neighbors wondered why she was driving Kate to school and why Kate did not play in the neighborhood anymore. She expressed feeling isolated. Kate's mom had enjoyed the morning conversations with the other moms at the bus stop as well as the social atmosphere of the neighborhood. After the disclosure, Mom did not attend any more social events in the neighborhood.

Peggy's mom was unemotional and detached. She did not have any friends nor did she have any family in the area. When Peggy told her friend that she had been sexually abused, Mom expressed worry that Peggy would share this information and it "would change how people thought of her." For Mom, sharing the information about the sexual abuse could also alter how people thought of her as well. Eventually, after several 
weeks working with the trauma therapist, Mom spontaneously reached out for support by telling her sister. It is interesting that the person with whom Mom shared that Peggy was sexually abused was also a victim. After the visit by her sister, who immediately came to Connecticut, Mom reported she was so glad she told her sister. It was evident that isolation is a common theme that the non-offending parents experience as a result of their child's disclosure. Either the non-offending parents lost their familial support network, because the perpetrator was a family member, or their friends and family did not want to "hear it" (Kim et al., 2007).

\section{Feelings of Guilt}

Every non-offending parent expressed feelings of guilt. This was a very intense feeling that needed to be addressed during the course of treatment with the non-offending parents. For the parents of the older children, their sharing their feelings of guilt with their children was often helpful to both the child and parent. This was done during family sessions that enabled both the child and the parent to process and for Mom to begin to forgive herself so she could be more available to support her child.

The mother who seemed to feel and express the most guilt was Peter's mother; not only did she feel guilty for the sexual abuse of her son, she felt guilty for the years she exposed him to the violence in the home. Samantha's mom talked a great deal about wanting to do what was best for both her children but not knowing how to provide support for them both. Samantha's mom was experiencing feelings of guilt for her daughter being sexually offended in their home by her brother and then from a family friend. Mom was clearly torn between loving both children and feeling guilty that the decision that Nat remain in residential housing was out of her control. 
Lisa's mom discussed how difficult it was to hear what happened to her daughter and that she felt responsible. Paige's mom reported she was blaming herself for not recognizing that her daughter was being abused. Kate's mom stated that it was "my fault." Peggy's mom expressed "feeling responsible for the abuse." In each of these cases, the children had been left alone with a "trusted" individual. The intense feelings of guilt each mother was feeling appeared to revolve around leaving their children with someone else and not being present to protect them.

\section{Overwhelmed}

Each of the non-offending parents expressed feeling overwhelmed. Six of the six non-offending parents either canceled or missed an appointment due to "illness." Samantha's mother expressed feeling "angry and overwhelmed." For Samantha's mother, the yelling, fighting, and aggressivity was when she was especially prone to feeling overwhelmed and not knowing how to deal with the behaviors. During a subsequent session, Mom's physical appearance was untidier than usual, and she reported feeling overwhelmed and "tired of dealing with everything." Mom missed one appointment and told the clinician that it was because she "just has too much to do." When Mom would become overwhelmed, she would often state that "she could not handle discussing it" or she would become abrupt with the trauma therapists.

Lisa's mom was devastated about the disclosure, angry, and overwhelmed. The disclosure of sexual abuse by Lisa's cousin had multiple layers of stressors that compounded each other. Out of all the families, Lisa's family was most affected financially by the disclosure. Additionally, the father was not a legal U.S. citizen and finding employment was difficult; he feared deportation. Many times Mom said she felt 
powerless, sad, and overwhelmed. As Lisa's behaviors increased in aggressivity (i.e., hitting) and she urinated in places other than the bathroom, Mom would feel less in control and more overwhelmed. As treatment continued and Lisa's symptoms dissipated, Mom began to express feeling less overwhelmed and more in control.

During the first session, Paige's mom met with the trauma therapist and was very tearful and expressed feeling overwhelmed by the disclosure and being uncertain about what to do. The following week Mom missed the appointment and expressed that she was confused about the time and date; she canceled again a few weeks later because her older daughter was sick. During later sessions, Mom reported feeling so tired and overwhelmed that she did not always use the strategies that had been discussed to help Paige sleep. As Paige's mom began to accept help from her mother, she expressed "that it was such a relief not to be responsible for everything." At the end of the trauma therapy, Mom was not only looking less tired but was able to manage things quite well. For Paige's mom, she was faced not only with the disclosure of sexual abuse from her daughter but with no longer having a co-parent; thus she was responsible for every aspect of the children's lives.

Kate's mother was also able to express feeling overwhelmed. Kate's mom seemed more in control than the other non-offending parents. For example, at the first session Mom had a detailed list of questions about trauma therapy, she had quit her job, and was linking every behavior to the abuse (i.e., Kate's blinking). Peggy's mother appeared in control of her life as well as the lives of her children. She was independent and struggled with identifying her emotions. It was during the last session that she stated how much better she was feeling. Mom had also canceled one session due to illness. 
The feeling of being overwhelmed is often filled with a sense of powerlessness. Each of the non-offending parents wanted to help their children to move forward from the abuse, but remained stagnated due to their own feelings of devastation. Once the families became stabilized, then the non-offending parents seemed to begin to take control of the situation.

\section{Bringing up Past Issues}

The disclosure of sexual abuse can bring up many feelings for the caregiver. It is not uncommon for a non-offending parent who has a history of past abuse to remember their own abuse. Of the families, Samantha's mom, Lisa's mom, Paige's mom, and Peter's mom all stated the disclosure was bringing up "past issues." Peggy's mom, although she did not speak about her past abuse, talked to the clinician about how when her brother sexually abused her sister the family was devastated. Having a child disclose abuse could bring up unresolved issues from the past. Unless the non-offending parent has a strong support network, they may become consumed in their own issues and not be present to provide the necessary support for their child.

\section{Legal System}

The legal system was an issue for all of the non-offending parents as each of them worried about the outcome of their case (Stone \& Hubbard, 2000, pp. 73-95). For some, such as Peter and his mother, the fear of retaliation from the father was evident, should he get out of jail. Peggy’s mom worried about having Peggy's father imprisoned and thought that may be worse than him sexually abusing their daughter. Lisa, Kate, Paige, and Samantha's parents all wanted justice; however, each feared how their child would 
be impacted by the court proceedings. However, when the court cases were heard, each of the mothers cooperated with prosecution.

\section{Research Question III: How Did the MIT After Care Clinic's Interventions Help Stabilize the Families?}

The emotionality and distress that the families expressed after their child's

disclosure were significant. Having concrete strategies was necessary to help the families regain normalcy in their lives. When behavioral issues arose, it was important for the families to address them so they did not continue to disrupt the availability for their child to learn at school and thrive at home.

\section{Establishing Positive Relationships}

The child and the non-offending parent each had separate relationships with the trauma therapist. Each child was able to build a rapport with their trauma therapist that was safe and supportive. The non-offending parent was also able to establish a safe and supportive relationship with her clinician. During the family sessions, both the child and the non-offending parent had their own support and guidance. Samantha's, Paige's, Lisa's, and Peter's mothers had confided in their clinicians their history of abuse. Peggy's mom shared that her family had also been affected by the sexual abuse of her sister. Samantha, Paige, Lisa, Peter, Kate, Peggy, and Brian all shared details and feelings about their abuse with their trauma therapists. The non-offending parents were provided with support that assisted in emotionally stabilizing them so they could be available for their child. This was done by the trauma therapists' ability to role model and respond appropriately to their individual stories. 
The families and their children were provided support where they were at emotionally; for example, Kate's mother required support around her understanding her daughter. Peggy's mom needed to learn to share her feelings so she could role model to her daughter. Samantha's mom needed to find a way to put her past aside and deal with the reality of her daughter's multiple victimizations. Peter's mom needed to teach her son about how she would keep him safe. Paige's mom needed to take control back in her life. Lisa's mom needed to find strength to help her daughter heal. In each case, the relationship formed with the trauma therapist encouraged the non-offending parent to be open to feedback.

The strategies that were found most useful to the child and non-offending parent in establishing a positive relationship with the child include: creating an environment that the child felt a sense of safety. One way this was done was to remind on many occasions that the child is in a safe place to share their feelings. Prior to family sessions, have a clear and set understanding with the child regarding what was acceptable to share with the non-offending parent, and what was not to be shared (unless the child disclosed homicidal, suicidal, or injurious acts). Allow the child to express missing the perpetrator and encourage the child to process these feelings. Many times when the children express that to family members the family does not respond kindly. Have activities and rituals to allow the child the opportunity to say goodbye to that person (if they are incarcerated) or if they will be seeing them again to help them do so in a safe way. Allow the child to set the goals they want to accomplish during the 12 weeks. Evaluate and re-evaluate those goals, identifying progress with each goal. For younger children, have concrete activities to attach to each goal. It was useful to many children to hear the clinician say that 
nothing they will hear will shock them or make them think any differently about them. Timelines are especially helpful with children to help them sequence the abuse. Different types of charts depending on the child are helpful in sharing secrets and then connecting the feelings with the abuse. Lastly, in working with trauma victims the child wants to be heard. It is their session and although difficult work is done in each session, it does not mean that you cannot laugh and have fun too!

The strategy found most helpful when working with the non-offending parent is to allow them the freedom to express themselves. The clinician must work with the nonoffending parent where they are at emotionally. For example, if mom is in the denial stage, then talking about court procedures is irrelevant. It is important to help the nonoffending parent move from that stage into acceptance by identifying factors that indicate abuse. For example, although the non-offending parent does not view the forensic interview, they are made aware of the disclosure. Bringing it up during the therapy session could be a manner in which the non-offending parent can be gently confronted with the reality of the disclosure. However, this can be done kindly and through the understanding that just as the disclosure is a process for the child, it is also a process for the non-offending parent (Keeble, 1993). It is also important to establish boundaries and limits during the session, and, similar to working with the child, create a safe environment.

\section{Role Modeling}

Part of the process for many children is to share the details of abuse with the nonoffending parent; many of the non-offending parents had not heard the details of their child's abuse. It is important to have the non-offending parent prepared for hearing the 
information in a way that would not inhibit their child from sharing future details or limit their child's already fragile emotional state. Up to that point, many of the non-offending parents had not talked about it with anyone (Paige's, Peggy's, Peter's, Lisa's, and Samantha's mothers). The response from their trauma therapist was critical, just like the non-offending parents' response to the details of their children's abuse would be critical during the trauma narrative. "I am glad you told me." "It was not your fault." "You are safe." These are statements that are told to the non-offending parent by their clinician. They are told to the child by his/her trauma therapist and then by the non-offending parent.

The clinician can be a positive role model by using the following strategies: be as honest as possible. Children who are victims often have a lot of unanswered questions. It is not uncommon for the non-offending parent to believe they are benefiting their child by shielding them from information such as the arrest of the perpetrator. If the child is interested in knowing the information, it is useful to have the other clinician work with the non-offending parent to understand the ideology of why the child would like to know and how it will benefit the victim. However, it is important to relate the information in a child-friendly manner, with the utterance that the child is not at fault for the arrest. During any of the family sessions, both trauma therapists are demonstrating appropriate responses, especially during a trauma narrative. Do not cry even if a child discloses heinous acts of abuse. When the child is disclosing the abuse to the non-offending parent, it is essential that the non-offending parent be emotionally present and not become distraught. How well the non-offending parent does is often reflected on the prognosis of the child. If the non-offending parent is not emotionally stable enough to hear the details, 
it is recommended that the narrative not occur. The trauma therapists working with the non-offending parent role models appropriate responses and behaviors during the 12 weeks of trauma therapy as does the trauma therapist with the child. It is critical during family sessions, so the interventions can be discussed with the non-offending parent, including the response from the child. For many of the non-offending parents the behavior changes can be frustrating and because of the multiple stressors from the disclosure, the non-offending parent may respond by yelling or in a manner that the child does not respond well to. Teaching to respond in a healthy manner is essential to help both the child and non-offending parent.

\section{Empowerment}

The lack of control in both the lives of the children and their parents is evident. During the course of trauma therapy, the children learned strategies to take back control of their lives. When nightmares interfere with sleep, the abuser remains in control of their sleep and their thoughts. Teaching the child strategies (bedtime routines, coping skills, anger management) enables them to be in charge of their thoughts, feelings, and emotions. Peter, Peggy, Paige, Kate, Samantha, Peter, and Brian utilized the suggestions that assisted with improved sleep, thoughts, somatic complaints, urination issues, and feelings regulation.

The non-offending parent was also given the tools in a supportive manner that did not enable them. Ultimately, the non-offending parent would be at home with their child without supports or in the courtroom alone during criminal proceedings. The choice whether or not they cooperated with the prosecution was theirs. Peter's, Peggy's, Paige's, Samantha's, Kate's, and Peggy's mothers all cooperated and were significant in 
maintaining the safety of their children, as well as other possible victims, by participating in the court proceedings.

One of the strategies that is helpful to the children of the After Care Clinic has been the use of rituals throughout the course of trauma therapy. It is useful to have the same routine each session, as many of these children have had non-predictability at home and in their lives. They need routines. It is useful to help the non-offending parent establish routines at home, especially during bedtime. It is helpful that as each of the goals the child has identified is met, to highlight the accomplishment with a ceremony or ritual. For example, after a child finishes disclosing all their secrets, let a balloon go as an example of letting the past go and moving toward the future. This ties into the idea that sexual abuse does not define the child. It is also helpful to start the sessions with both the child and the non-offending parent to see if any issues need to be addressed during the session as well as ending the session with a family session to share what the child would like shared with the non-offending parent. As a closing ritual at the end of therapy a certificate is given to the child as well as a small gift. Usually a small stone with a word, such as hope is written on it. This serves two purposes: the first is to share in the celebration that the child has successfully completed the After Care Clinic, and second, due to the tactile feeling of the stone it can be kept in the child's pocket and the smooth sensation could have a calming effect if the child becomes anxious. Always encourage the family to seek additional support in the future should they need it.

\section{Discussion}

Providing trauma therapy is a privilege, as the trauma therapist is privy to intimate details of events that have caused the victims pain and sorrow. It is the responsibility of 
the trauma therapist to understand the Traumagenic Dynamics of Sexual Abuse (Finkelhor \& Browne, 1985) and to provide best clinical practice. Each child is unique, so there should be variations in trauma therapy. It is important to note that the above strategies come from a multitude of sources and clinical practices that have been formulated from clinical experience.

Very little research has been conducted regarding the experiences of the children when receiving trauma therapy. However, a significant amount of literature exists on the dynamics of sexual abuse. Finkelhor and Browne (1985) assert that these traumagenic dynamics are generalized dynamics, not necessarily unique to sexual abuse; they occur in other kinds of trauma. But the conjunction of these four dynamics in one set of circumstances is what makes the trauma of sexual abuse unique, different from such childhood traumas as the divorce of a child's parents or even being the victim of physical child abuse. There has been much controversy in Roland Summit's article on child sexual abuse accommodation (Summit, 1983) where Summit describes sexually abused children's secrecy, helplessness, entrapment, delayed disclosure, and retraction. Although this has been both admired and maligned, it has been identified as one of the most influential papers ever written on child abuse (Oates \& Donnelly, 1997).

In the state of Connecticut the expert testimony on Summit (1983) as well as Finkelhor and Browne (1985) is accepted in Superior Court. The Traumagenic Dynamics of Sexual Abuse identifies four dynamics: traumatic sexualization, betrayal, powerlessness, and stigmatization. Summit's CSAAS identifies secrecy, helplessness, entrapment, delayed, conflicted, and unconvincing disclosure and retraction. Secrecy and helplessness have often led to children feeling as though they were to blame and they did something "bad." Entrapment also alters the child's perspective and the child will often view themselves to 
blame and not the perpetrator. Table 1 lists the symptoms of anger, sadness, blame, secrecy, confusion, and anxiety, which are important components of understanding the Child Sexual Abuse Accommodation Syndrome. Additionally, Table 1 represents the traumagenic dynamics of sexual abuse: traumatic sexualization, betrayal, powerlessness, and stigmatization. Traumatic sexualization was demonstrated through poor social interaction, which at times were inappropriate sexualized behavior, betrayal was demonstrated through the children missing their abuser, feeling as though they were in trouble for telling, and increased amounts of anger and hostility (Freeman \& Morris, 2001). Powerlessness was shown through the feelings of confusion and anxiety (Freeman \& Morris, 2001), and lastly stigmatization was shown through feeling as though the abuse was their fault (blame), and that they had done something to cause the victimization, thus they are damaged. During the court proceedings, the understanding of both Finkelhor and Browne (1985) and Summit's CSAAS (1983) can be pertinent testimony for the jury to understand why a child not only behaves the way they do but also how they have experienced the abuse; secrecy, delayed disclosure, entrapment and accommodation, helplessness, and retraction. Examples of all of these, with the exception to retraction, are illustrated in each of the case studies, thus linking the existing literature to this study.

\section{Recommendations for Practice}

The results of this study have implications for use for Multi-disciplinary Investigation Teams. The research is applicable to professionals who deal with trauma victims as well as the secondary victims, to individuals who prosecute criminal-level crimes against children, the Department of Children and Families, as well as law enforcement. Lastly, this research is applicable to current Multi-disciplinary Investigation Teams who do not provide follow-up trauma therapy after a forensic 
interview. After a forensic interview, children may be referred to community-based clinicians who do not specialize in trauma. These clinicians are often not affiliated with a MIT; therefore, there is little follow-up if the child attends treatment or with the prosecution. Additionally the community-based clinicians are not forensic interviewers and cannot gather details of the abuse in a court-worthy manner. Each of these disciplines would benefit from having a better understanding of experiences shared by these families and the strategies that were identified as useful to the child and nonoffending parent.

\section{Recommendations for Further Study}

Further study is needed. Many victims and their families are devastated by disclosure and are in need of support. There have been multiple studies conducted on trauma therapy, child abuse disclosure, and the necessity for support by the nonoffending parent. The following is a list of recommendations that would continue to support this area of study: (a) compare the conviction rates of sexual offenders with conviction rates when families were not engaged in treatment connected to the Multidisciplinary Investigation Team, (b) perform a study with a larger number of families, (c) perform a study with group therapy for the children and families and look at the success rates of trauma-symptom reduction and court cooperation, and (d) perform a study in which there is only one clinician providing service to the victim. 
REFERENCE LIST 


\section{REFERENCE LIST}

Ackard, M. D., Kearney-Cook, A., Peterson, B.C. (2000). Effect of body image and selfimage on women's sexual behaviors. International Journal of Eating Disorders, 28(4), 422-429.

Alexander, P. C. (1992). Application of attachment theory to the study of sexual abuse. Journal of Consulting and Clinical Psychology, 60, 185-195.

Amecher, E. (2001). The extended assessment of the child victim. Child sexual abuse investigations multidisciplinary collaborations: An internet resource for forensic investigation of child sexual abuse cases. University of Georgia Center for Continuing Education. Retrieved March 13, 2009, from http://childabuse.georgiacenter.uga.edu/both/amacher3/amacher3_print.phtml

Beck, J. S. (1995). Cognitive therapy: Basics and beyond. New York: Guilford.

Bloom, S. (2000). The grief that dare not speak its name, Part II: Dealing with the ravages of childhood abuse. Psychotherapy Review, 2(10), 469-472.

Bolen, R., \& Lamb, J. L. (2002). Guardian support of sexually abused children: A study of its predictors. Child Maltreatment, 7(3), 265-276.

Bottoms, B. L., \& Goodman, G. S. (1994). Perceptions of children's credibility in child sexual assault cases. Journal of Applied Social Psychology, 24, 702-232.

Briere, J. (1988). The long term clinical correlates of childhood sexual victimization. Annuals of the New York Academy of Sciences, 528, 327-334.

Briere, J. (1992). Child abuse trauma: Theory and treatment of the lasting effects. Newbury Park, CA: Sage.

Briere, J. (1996a). Therapy with adults molested as children ( $2^{\text {nd }}$ ed.). New York: Springer.

Briere, J. (1996b). Trauma Symptom Checklist for Children (TSCC) professional manual. Odessa, FL: Psychological Assessment Resources. 
Briere, J. (1996c). A self trauma model for treating adult survivors of severe child abuse. In J. Briere, L. Berliner, J. A. Bulkley, C. Jenny, \& T. Reid (Eds.), The APSAC handbook on child maltreatment (pp. 140-157). Thousand Oaks, CA: Sage.

Briere, J., \& Elliott, D. M. (1994). Immediate and long term impacts of child sexual abuse. The Nature of Children, 4, 54-69.

Briere, J., \& Scott, C. (2006). Principles of trauma therapy: A guide to symptoms, evaluation, and treatment. Thousand Oaks, CA: Sage.

Burgess, A. W., Hartman, C.R., Wolbert, W. A., \& Grant, C. A. (1987). Child molestation: Assessing the impact of multiple victims (part 1). Achieves of Psychiatric Nursing, 1, 33-30.

Camino, L. (2000). Treating sexually abused boys: A practical guide for therapists and counselors. San Francisco, CA: Jossey-Bass.

Ceci, S. J., \& Bruck, M. (1995). Jeopardy in the courtroom: A scientific analysis of children's testimony. Washington, DC: American Psychological Association.

Cederborg, A., Lamb, M. E., \& Orbach, Y. (2007). Child sexual abuse disclosure, delay, and denial: Delay of disclosure, minimization, and denial of abuse when the evidence is unambiguous: A multi-victim case. New York, NY: Taylor \& Francis Group.

Chantler, L., Pelco, I., \& Mertin, P. (1993). The psychological evaluation of child sexual abuse using the Louisville checklist and human figure drawings. Child Abuse and Neglect, 17, 271-279.

Child Welfare League of America's 2009 fact sheet. (2009). Retrieved May 4, 2009, from http://www.cla.org/advocacy/nationalfactsheet09/htm

Child Sexual Abuse Task Force and Research \& Practice Core, National Child Traumatic Stress Network. (2004). How to implement trauma-focused cognitive behavioral therapy. Durham, NC, and Los Angeles, CA: National Center for Child Traumatic Stress.

Clandinin, D. J., \& Connelly, F. M. (2002). Narrative inquiry: Experience and story in qualitative research. San Francisco, CA: Jossey-Bass.

Cohen, J. A., Berlinger, L., \& Mannarino, A. P. (2000). Treatment of traumatized children: A review and synthesis. Journal of Trauma, Violence, and Abuse, 1(19), 29-46. 
Cohen, J. A., Deblinger, E., Mannarino, A. P., \& Steer, R. A. (2004). A multi-site, randomized controlled trial for children with sexual abuse-related PTSD symptoms. Journal of the American Academy of Child and Adolescent Psychiatry, 43(4), 393-402.

Cohen, J. A., \& Mannarino, A. P. (1997). A treatment study for sexually abused preschool children: Outcome during a one-year follow-up. Journal of the American Academy of Child and Adolescent Psychiatry, 36(9), 1228-1235.

Cohen, J. A., \& Mannarino, A. P. (1998). Factors that mediate treatment outcome of sexually abused preschool children: Six- and 12-month follow-up. Journal of the American Academy of Child and Adolescent Psychiatry, 37, 44-51.

Cohen, J. A., Mannarino, A. P., \& Knudsen, K. (2005). Treating sexually abused children: One year follow-up of a randomized controlled trial. Child Abuse and Neglect, 29(2), 135-145.

Cole, P. M., \& Putnam, F. W. (1992). Effects of incest on self and social functioning: A developmental psychopathology perspective. Journal of Consulting and Clinical Psychology, 60, 174-184.

Conte, J. R., \& Schuerman, J. R. (1987). Factors associated with an increased impact of child sexual abuse. Child Abuse and Neglect, 11, 201-211.

Conine, C., Daniel, L., Curtis Holmes, C., Lumsden, K., McAfee, T., McDaniel, J., et al. (2001). Using a multi-disciplinary team approach; Child sexual abuse investigations multidisciplinary collaborations: An internet resource for forensic investigation of child sexual abuse cases. University of Georgia Center for Continuing Education. Retrieved on line March 13, 2009, from http://childabuse.georgiacenter.uga.edu/chronological/conine_etal/conine_etal3.p html

Conn. Gen. Stat. § 53a-70a (2009).

Conn. Gen. Stat. § 53a-71 (2009).

Conn. Gen. Stat. § 53a-72a (2009).

Conn. Gen. Stat. § 53a-73a (2009).

Cooney, J. (1987). Coping with sexual abuse. New York: Rosen.

Creswell, J. W., \& Miller, D. L., (2000). Determining validity in qualitative inquiry. Theory into Practice, 39(3), 124-131. 
Deblinger, E., \& Heflin, A. H. (1996). Treating sexually abused children and their nonoffending parents: A cognitive-behavioral approach. Thousand Oaks, CA: Sage.

Deblinger, E., Lippmann, J., \& Steer, R. (1996). Sexually abused children suffering posttraumatic stress symptoms: Initial treatment outcome findings. Child Maltreatment, 1(4), 310-321.

Deblinger, E., Lippmann, J., \& Steer, R. (1999). Two-year follow-up study of cognitive behavioral therapy for sexually abused children suffering post traumatic stress disorder syndrome. Child Abuse and Neglect, 23(12), 1271-1378.

DeNavas-Walt, C., Proctor, B., \& Smith, J. (2007). Income, poverty and health insurance coverage in the U.S.: 2007 (U.S. Census Bureau Current Population Report, P60-235). Washington, DC: U.S. Government Printing Office.

Dominquez, R. Z., Nelke, C. F., \& Perry, B. D. (2002). Child sexual abuse encyclopedia of crime and punishment (D. Levinson, Ed.). Thousand Oaks, CA: Sage.

Eisner, E. W. (1986). A secretary in the classroom. Teaching and Teacher Education, 2(4), 325-328.

Eisner, E. W. (1998). The enlightened eye: Qualitative inquiry and the enhancement of educational practice. Upper Saddle River, NJ: Prentice Hall.

Everson, M. D., \& Boat, B. (1989). False allegations of sexual abuse by children and adolescents. Journal of American Academy of Child Adolescent Psychiatry, 28(2), 230-235.

Everson, M. D., Hunter, W. M., Runyon, D. K., Edelsohn, G. A., \& Coulter, M. L. (1989). Maternal support following disclosure of incest. American Journal of Orthopsychiatry, 59, 197-207.

Fiering, C., Taska, L., \& Lewis, M. (1996). A process model for understanding adaptation to sexual abuse: The role of shame in defining stigmatization. Child Abuse and Neglect, 20, 767-782.

Finkelhor, D. (1984). Child sexual abuse. New York: Free Press.

Finkelhor, D., \& Browne, A. (1985). The traumatic impact of child sexual abuse: A conceptualization. American Journal of Orthopsychiatry, 55(4), 530-541.

Finkelhor, D., \& Jones, L. (2004). Explanation for the decline in child sexual abuse (Juvenile Justice Bulletin No. NC 199298). Washington, DC: U.S. Department of Justice, Office of Justice Programs, Office of Juvenile Justice and Delinquency Prevention. 
Freeman, K.A., \& Morris, T. M. (2001). A review of conceptual models explaining the effects of child sexual abuse. Aggression and Violent Behavior, 6, 357-373.

Freeman, K.A., \& Morris, T. M. (1999). Explaining the effects of child sexual abuse: A behavior analytic conceptualization. Journal of Child Sexual Abuse, 7, 3-21.

Freedman-Longo, R.E., \& Blancard, G.T. (1998). Sexual abuse in America: Epidemic of the $21^{\text {st }}$ century. Brandon, VT: Safer Society Press.

Gil, E. (2006). Helping abused and traumatized children: Integrating directive and nondirective approaches. New York: Guilford.

Golafshani, N. (2003). Understanding reliability and validity in qualitative research. The Qualitative Report, 8(4), 597-607.

Goldstein, S. L., \& Tyler, R. P. (1998). Sexual abuse allegations in custody cases: Difficult decisions in diverse divorces. APSAC Advisor, 11(3), 15-18.

Goodman, G. S., Bottoms, B. L., Herscovici, B. B., \& Shivor, P. (1989). Determinants of the child victim's perceived credibility: Perceptions on children's testimony. New York: Springer-Verlay.

Goodman, G. S., Golding, J. M., \& Haith, M. M. (1984). Jurors' reactions to child witnesses. Journal of Social Issues, 40, 139-156.

Goodman, G. S., Golding, J. M., Helgeson, V., Haith, M., \& Mitchelli, J. (1987). When a child takes the stand: Jurors' perceptions of children's eyewitness testimony. Law and Human Behavior, 11, 27-40.

Hancock, D., \& Algozzine, B. (2006). Doing case study research: A practical guide for researchers. New York: Teachers College Press.

Hazzarel, A., Celeno, M., Could, J., Lawry, S., \& Webb, C. (1995). Predicting symptomologies and self-blame among child abuse victims. Child Abuse and Neglect, 19, 707-714.

Healy, M., \& Perry, C. (2000). Comprehensive criteria to judge validity and reliability of qualitative research within the realism paradigm. Qualitative Market Research, 3(3), 118-126.

Heriot, J. (1996). Maternal protectiveness following the disclosure of intrafamilial child sexual abuse. Journal of Interpersonal Violence, 11, 181-194. 
Hobfol, S. E., Freedy, J. R., Green, B. L., \& Solomon, S. D. (1996). Coping in reaction to extreme stress: The roles of resource loss and resource availability. In M. Aeidner \& N. S. Endler (Eds.), Handbook of coping: Theory, research, applications (pp. 322-349). New York: John Wiley.

Hobfoll, S., Watson, P., Bell, C., Bryant, R., Byrmer, M., Friedman, M., et al. (2007). Five essential elements of immediate and mid-term mass trauma intervention. Empirical Evidence Psychiatry, 70(4), 283-315.

Hoier, T. S., Shawchuck, C. R., Pallotta, G. M., Freeman, T., Interbitzen-Pisaruk, H., MacMillan, V. M. et al., (1992). The impact of sexual abuse: A cognitivebehavioral model. In W. O'Donahue \& J. H. Geer (Eds.), The sexual abuse of children: Theory and research (Vol. 2, pp. 100-142). Hillsdale, NJ: Lawrence Erlbaum.

Horowitz, M. J. (1997). Stress response syndromes ( $3^{\text {rd }}$ ed.). Northvale, NJ: Jason Aronson.

Horowitz, M. J., Marmae, C., Krupnick, J., Wilner, N., Kaltreider, N., \& Wallerstein, R. (1997). Personality styles and brief psychotherapy ( $2^{\text {nd }}$ ed.). New York: Basic Books.

Hunter, W., Coulter M., Runyan, D., \& Everson, M. (1990). Determinants of placement for sexually abused children. Child Abuse and Neglect, 14, 407-417.

Jaycox, L. H., Zoellner, L., \& Foa, E. B. (2002). Cognitive behavioral therapy for PTSD and rape survivors. Psychotherapy and Practice, 58(8), 891-906.

Johnson, B. R. (1997). Examining the validity structure of qualitative research. Education, 118(3), 282-292.

Keeble, P. (1993, February). Non-offending parents. Child Sexual Abuse, pp. 1-32.

Kendall-Tacket, K. A., Williams, L. M., \& Finkelhor, D. (1993). Impact of sexual abuse on children: A review and synthesis of recent empirical studies. Psychological Bulletin, 113, 163-180.

Kiser, L. J., Ackerman, B. J., Brown, E., Edwards, N. B., McColgan, E., Pugh, R., et al. (1988). Posttraumatic stress disorder in young children: A reaction to purported sexual abuse. American Academy of Child and Adolescent Psychiatry, 27, 645649.

Kim, K., Noll, J., Putnam, F., \& Trickett, P. (2007). Psychosocial characteristics of non-offending mothers of sexually abused girls: Findings from a prospective, multigenerational study. Child Maltreatment, 12, 338-351. 
Krupnick, J. L. (2002). Brief psychodynamic therapy and PTSD. Journal of Clinical Psychology, 58(8), 919-932.

Kvale, S. (1996). Interviews: An introduction to qualitative research interviewing. Thousand Oaks, CA: Sage.

Levenson, J., \& Cotter, L. P. (2005). The effects of Megan's Law on sexual offender reintegration. Journal of Contemporary Criminal Justice, 21(1), 49-66.

Lieppe, M. R., \& Romanczyk, A. (1989). Reactions to child (versus adult) eyewitnesses: The influence of jurors' preconceptions and witness behavior. Law and Human Behavior, 13, 103-132.

Lindberg, F. H., \& Distad, L. J. (1985). Post-traumatic stress disorders in women who experienced childhood incest. Child Abuse and Neglect, 9, 329-334.

London, K., Bruck, M., Ceci, S. J., \& Shuman, D. W. (2005). Disclosure of child sexual abuse: What does the research tell us about the ways that children tell? Psychology, Public Policy, and Law, 11(1), 194-226.

Lovett, B. B. (1995). Child sexual abuse: The female victim's relationship with her non offending mother. Child Abuse and Neglect, 19, 729-738.

Maione, P. V. (1997). Choice points: Creating clinical qualitative research studies. The Qualitative Report, 3(2). Retrieved February 3, 2009, from http://www.nova.edu/ssss/QR/QR3-2/maione.html

Mathison, S. (1988). Why triangulate? Educational Researcher, 17(2), 13-17.

Mannarino, A. P., \& Cohen, J. A. (1996). Family related variables and psychological symptoms formulation in sexually abused girls. Journal of Child Sexual Abuse, 5, $105-120$.

Mannarino, A. P., Cohen, J. A., \& Berman, S. (1994). The children's attributions and perceptions scale: A new measure of sexual abuse related factors. Journal of Clinical Child Psychology, 23, 204-211.

Mishler, E. G. (2000). Validation in inquiry-guided research: The role of exemplars in narrative studies. In B. M. Brizuela, J. P. Stewart, R. G. Carillo, \& J. G. Berger (Eds.), Acts of inquiry in qualitative research (pp. 119-145). Cambridge, MA: Harvard Educational Review.

Merriam, S. B. (1998). Qualitative research and case study applications in education. San Francisco: Jossey-Bass. 
Monahon, C. (1993). Children and trauma: A guide for parents and professionals. San Francisco, CA: Jossey-Bass.

Morrison, N. C., \& Clavenna-Valleroy, J. (1998). Perceptions of maternal support as related to self-concept and self-report of depression in sexually abused female adolescents. Journal of Child Sexual Abuse, 7, 23-40.

Morrow, K. B., \& Sorrell, G. T. (1984). Factors affecting self-esteem, depression and negative behaviors for sexually abused female adolescents. Journal of Marriage and Family, 51, 677-686.

Munson, L., \& Riskin, K. (1995). In their own words: A sexual abuse workbook for teenage girls. Washington, DC: Child Welfare League of America.

Myers, M. (2000). Qualitative research and the generalizability question: Standing firm with Proteus. The Qualitative Report, 4(3/4). Retrieved April 1, 2009, from http://www.nova.edu/ssss/QR/QR4-3/myers.html

National Clearinghouse on Child Abuse and Neglect Information. (2001). What is child maltreatment? Washington, DC: Children's Bureau.

Nightingale, N. N. (1993). Jurors' reactions to child victim witnesses: Factors affecting trial outcome. Law and Human Behavior, 17, 678-694.

Oates, R. K., \& Donnelly, A. C. (1997). Influential papers in child abuse. Child Abuse and Neglect, 21, 319-326.

Olafson, E., \& Lederman, C. S. (2006, Winter). The state of the debate about children's disclosure patterns in child sexual abuse cases. Juvenile and Family Court Journal, 27-40.

Otis, C. M. (2002). What's happening in our family? Understanding sexual abuse through metaphors. Brandon, VT: Safer Society.

Padgett, D. K. (1998). Qualitative methods in social work research: Challenges and rewards. Thousand Oaks, CA: Sage.

Patton, M. L. (2002). Understanding research methods ( $3^{\text {rd }}$ ed). Los Angeles, CA: Pyrczak.

Patton, M. Q. (2002). Qualitative evaluation and research methods (3rd ed.). Thousand Oaks, CA: Sage.

Pellegrin, A., \& Wagner, W. (1990). Child sexual abuse-factors affecting victims' removal from home. Child Abuse and Neglect, 14, 53-60. 
Polunsky, M. A., \& Follette, V. M. (1995). Long-term correlates of child sexual abuse: Theory and review of the empirical literature. Applied and Preventative Psychology, 4, 143-166.

Putnam, F. W. (1990). Disturbances of "self" in victims of childhood sexual abuse. In R. P. Kluft (Ed.), Incest-related syndromes of adult psychopathology (pp. 113-131). Washington, DC: American Psychiatric Press.

Redlich, A. D., Myers, J. E., \& Goodman, G. S. (2002). Juvenile sexual re-offense risk. Journal of the American Professional Society on the Abuse of Children, 7(4), 291316.

Rix, R, (Ed.). (2002). Sexual abuse litigation: A practical resource for attorneys, clinicians, and advocates. New York: Hawthorne Maltreatment \& Trauma Press.

Sawicki, M. (2007). Key ethical and practical issues in child abuse case screening. Update: American Prosecutors Research Interview, 20(1), 1-2.

Saylor, C. F., Swenson, C. C., Reynolds, S. S., \& Taylor, M. (1999). The pediatric emotional distress test: A brief screening measure for young children exposed to traumatic events. Journal of Clinical Child Psychology, 28(1), 70-81.

Scott, M. (2000). The "normality" of repeat victimization from adolescence through early adulthood. Justice Quarterly, 17(3), 543-574.

Schupp, L. J. (2004). Assessing and treating trauma and PTSD. Eau Claire, WI: PESI.

Scholle, A. (2000). Sex offender registration (The FBI Law Enforcement Bulletin). Washington DC: Federal Bureau of Investigation.

Schonberg, I. J. (1992). The distortion of the role of mother in child sexual abuse. Journal of Child Sexual Abuse, 1, 47-61.

Sedlak, A. J., \& Broadhurst, D. D. (1996). Executive summary of the third national incidence study of child abuse and neglect. Retrieved February 2, 2009, from http://www.childwelfare.gov/pubs/statsinfo/nis3.cfm

Seidman, I. (2006). Interviewing as qualitative research: A guide for researchers in education and the social sciences $\left(3^{\text {rd }}\right.$ ed.). New York: Teacher's College Press.

Sgroi, S. (1982). Handbook of clinical intervention in child sexual abuse. Lexington, MA: Lexington Books.

Shapiro, F. (1995). Eye movement desensitization and reprocessing: Basic principles, protocols, and procedures. New York: Guilford Press. 
Snyder, H. N. (2000). Sexual assault of young children as reported to law enforcement: Victim, incident, and offender characteristics. Washington, DC: National Center for Juvenile Justice, U.S. Department of Justice.

Sorenson, T., \& Snow, B. (1991). How children tell: The process of disclosure in child sexual abuse. Child Welfare, 70(1), 3-15.

Spaccarelli, S. (1994). Stress, appraisal, and coping in child sexual abuse: A theoretical and empirical review. Psychological Bulletin, 116, 340-362.

Stake, R. E. (1995). The art of case study research. Thousand Oaks, CA: Sage.

State of Connecticut Department of Children and Families. (2008). Town pages number of accepted reports and allegations to department of children and families state fiscal year 2008. Retrieved May 1, 2009, from http://www.ct.gov/dcf/lib/dcf/agency/pdf/tp_2008.pdf

Stenbacka, C. (2001). Qualitative research requires quality concepts of its own. Management Decision, 39(7), 551-555.

Stone, J. L., \& Hubbard, J. (2000). Sexual abuse litigation: A difficult journey through unfamiliar territory. New York: Hawthorne Maltreatment \& Trauma Press.

Summit, R. C. (1983). The child sexual abuse accommodation syndrome. Child Abuse and Neglect, 7, 177-193.

Summit, R. C. (1992). Abuse of the child sexual abuse accommodation syndrome. Journal of Child Sexual Abuse, 1, 153-163.

Tang, S.S., Freyd, J., \& Wang, M. (2007). What do we know about gender and disclosing sexual abuse? Journal of Psychological Trauma, 6(4), 1-26.

Tjaden, P., \& Thoennes, S. (2000, November). Full report of the prevalence, incidence and consequences of violence against women: Findings from the national violence against women survey. Washington, DC: U.S. Department of Justice.

United States Department of Health and Human Service Administration on Children, Youth, and Families. (2005). Child maltreatment $\left(16^{\text {th }}\right.$ ed.). Washington, DC: U.S. Government Printing Office.

Walsh, W. A., Lippert, T., Cross, T.P., Maurice, D.M., \& Davidson, K.S. (2008). How long to prosecute child sexual abuse cases for a community using children's advocacy center and two comparison communities? Child Maltreatment, 13(1), $3-13$. 
Webb, E. J., Campbell, D. T., Schwartz, R. D., \& Sechrest, L. (1966). Unobtrusive measures: Nonreactive measures in the social sciences. Chicago: Rand McNally.

Wieche, V. R., (1996). The brother-sister hurt: Recognizing the effects of sibling abuse. Brandon, VT: Safer Society Press.

Windom, C. S., Czaja, S. J., \& Dutton, M. (2008). Childhood victimization and lifetime revictimization. Child Abuse and Neglect: The International Journal, 32(8), 785796.

Wolfe, V. V., Gentile, C., \& Wolfe, D. (1989). The impact of sexual abuse on children: A PTSD formulation. Behavior Therapy, 20, 215-228.

Yin, R. K. (2009). Case study research: Design and methods ( $4^{\text {th }}$ ed.). Thousand Oaks, CA: Sage.

Yozwiak, J. A., Golding, J. M., \& Marsil, D. F. (2004). The impact of type of out-ofcourt disclosure in a child sexual abuse trial. Journal of the American Professional Society on the Abuse of Children, 9(3), 325-334. 
VITA 


\title{
Danielle J. Williams, MA LMHC \\ 30 Columbia Drive \\ New Fairfield CT 06812 \\ 203 746-3484 \\ djdimauro@yahoo.com
}

\author{
Danbury Regional Child Advocacy Center Danbury, CT \\ May 2006-current \\ Clinical Director of the MIT After Care Clinic and Forensic Interviewer
}

Education Connection Danbury, CT

The Access School / Gertrude Fielding Learning Center

Assistant Director of Education/Clinical Services and School Counselor

Curtis School currently named the Grace Webb School Cheshire, CT School Social Worker

1999-2000

Learning Prep School

West Newton, MA

High School Counselor and Health Teacher

1996-1999

Middlesex Human Service Agency- Meadowhouse Waltham, MA

Clinical Director

1994-1996

Middlesex Human Service Agency-Middlesex Regional Addictions Treatment

Center

Waltham, MA

Substance Abuse Clinician P/T

1994-1996

Middlesex Human Service Agency-Project Outreach

Co-Director

Waltham, MA

1994-1995

Education

Andrews University, Berrien MI 2003-present

$\mathrm{Ph} . \mathrm{D}$. candidate in Leadership

Lesley University, Cambridge MA 1994

Masters of Arts in Counseling Psychology

Merrimack College, North Andover Ma 1991

Bachelor of Arts Degree in Sociology 
